\title{
Characterization of neurotensin's bipolar effects on nociceptive modulation using SR 142948A and SR 48692, two non-peptide neurotensin receptor antagonists
}

\author{
Jeffrey P. Smith \\ West Virginia University
}

Follow this and additional works at: https://researchrepository.wvu.edu/etd

\section{Recommended Citation}

Smith, Jeffrey P., "Characterization of neurotensin's bipolar effects on nociceptive modulation using SR 142948A and SR 48692, two non-peptide neurotensin receptor antagonists" (1999). Graduate Theses, Dissertations, and Problem Reports. 1049.

https://researchrepository.wvu.edu/etd/1049

This Dissertation is protected by copyright and/or related rights. It has been brought to you by the The Research Repository @ WVU with permission from the rights-holder(s). You are free to use this Dissertation in any way that is permitted by the copyright and related rights legislation that applies to your use. For other uses you must obtain permission from the rights-holder(s) directly, unless additional rights are indicated by a Creative Commons license in the record and/ or on the work itself. This Dissertation has been accepted for inclusion in WVU Graduate Theses, Dissertations, and Problem Reports collection by an authorized administrator of The Research Repository @ WVU.

For more information, please contact researchrepository@mail.wvu.edu. 
Characterization of Neurotensin's Bipolar Effects on Nociceptive Modulation Using SR 142948A and SR 48692, Two Non-peptide Neurotensin Receptor Antagonists

\author{
Jeffrey P. Smith \\ Dissertation submitted to the \\ School of Medicine \\ at West Virginia University \\ in partial fulfillment of the requirements \\ for the degree of \\ Doctor of Philosophy \\ in \\ Pharmacology and Toxicology \\ David J. Smith, Ph.D., Chair \\ David A. Taylor, Ph.D. \\ Charles R. Craig, Ph.D. \\ James L. Culberson, Ph.D. \\ Mieczyslaw Michalkiewicz, Ph.D., D.V.M. \\ Department of Pharmacology and Toxicology
}

Morgantown, West Virginia

1999

Keywords: Neurotensin, Analgesia, Antinociception, Pain Facilitation, Narcotic, Morphine, SR 142948A, SR 48692

Copyright 1999 Jeffrey P. Smith 


\begin{abstract}
Characterization of Neurotensin's Bipolar Effects on Nociceptive Modulation Using SR 142948A and SR 48692, Two Non-peptide Neurotensin Receptor Antagonists
\end{abstract}

\title{
Jeffrey P. Smith
}

\begin{abstract}
Results from the current study confirmed that neurotensin has a dose-dependent bipolar effects on nociception within the RVM. Microinjection of low (picomolar) doses of neurotensin into the RVM resulted in a facilitation of nociception and resolved the anti-analgesic properties (tail flick test) of the peptide in models where basal analgesia is established by stressing rats or following PAG administration of opioids (morphine). Whereas microinjection of higher (nanomolar) doses of neurotensin into the RVM produced antinociception. Furthermore, these same pain facilitatory and inhibitory effects of neurotensin were observed following i.c.v. administration.

Direct evaluation and comparisions of the two non-peptide neurotensin receptor antagonists, SR 48692 and SR 142948A, revealed that they differ in their ability to modulate these actions of neurotensin. In contrast to SR 48692, SR 142948A resulted in a complete inhibition of neurotensin-mediated antinociception in a dose-dependent bellshaped manner. Further discrimination between the two antagonists was demonstrated in their ability to inhibit neurotensin-mediated pain facilitation within the RVM. In contrast to SR 48692, SR 142948A administration into the RVM (1) did not produce a significant antinociceptive effect when administered alone (2) failed to promote antinociception from microinjection of a low $(30 \mathrm{pmol})$ dose of neurotensin microinjected into the RVM (3) did not inhibit the anti-analgesic effect of a low (3 pmol) dose of neurotensin administered into the RVM of a stressed rat (4) microinjection of SR 142948A dose selectively (only a $30 \mathrm{pmol}$ dose) resulted in a potentiation of the antinociceptive response to morphine $(6 \mathrm{nmol})$ administered into the PAG.

Moreover, these direct comparisons demonstrated that the ability of neurotensin to produce its bipolar effects relies on the ability of the peptide to interact with multiple receptors within the RVM. Furthermore, studies performed using levocabastine, a selective antagonist of the NTR2 receptor, demonstrated that the action of neurotensin within the RVM is mediated via receptors or receptor subtypes that do not share the characteristic properties of the NTR2 receptor. Therefore, these studies indicate the existence and involvement of multiple NTR1 receptor subtypes or splice variants in mediating these actions of neurotensin within the RVM.
\end{abstract}




\section{ACKNOWLEDGMENTS}

The author wishes to express gratitude to his advisor, Dr. David J. Smith, for his assistance and guidance throughout this project. Appreciation is also extended to members of the examining committee and to Dr. Dale Birkle for their advice and assistance during various stages of this study. The author would like to thank the staff and faculty of the Department of Pharmacology and Toxicology for their helpfulness and support of this work. Additionally, the contributions of additional members of the laboratory, Dr. Philip Monroe, Dr. Alyssa Hawranko, Deborah Smith, and Jude Kotsko are acknowledged for their friendships and assistance in this study.

Lastly, the author wishes to acknowledge and extend thanks to his family, and particularly his wife, Heather, whose unconditional love and constant support made this goal a reality. 
TABLE OF CONTENTS

Page

I. TITLE PAGE...................................................... i

II. ABSTRACT ................................................... ii

III. ACKNOWLEDGMENTS............................................. iii

IV. LIST OF FIGURES ......................................... vi

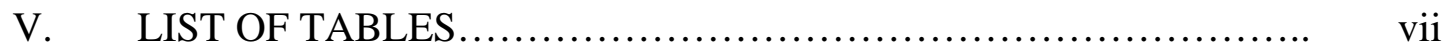

VI. LIST OF ABBREVIATIONS ................................... vii

VII. BACKGROUND

Anatomy and physiology of endogenous descending

nociceptive modulatory pathways......................... 1

Modulation of nociception within the rostral ventromedial medulla............................................. 23

VIII. INTRODUCTION AND RATIONALE FOR PROJECT

Neurotensin's role in pain modulation............................ 34

Role of neurotensin in opioid-mediated pain modulation....... 45

IX. SUMMARY AND HYPOTHESIS ................................ 47

X. MATERIALS AND METHODS.......................................................... 49

XI. RESULTS

1. The influence of the microinjection of SR 142948A into RVM on the antinociceptive response to neurotensin within the RVM......... 56

2. The influence of the microinjection of SR 142948A into the RVM on the pain facilitatory response to neurotensin within the RVM....... 64

A. The influence of the microinjection of SR 142948A into RVM on the response to low dose of neurotensin within the RVM................................................... 65 
B. The influence of the microinjection of SR 142948A on the anti-analgesic response to neurotensin within the RVM of the stressed rat.

1. The dose-response relationship of neurotensin administration into the RVM in the stressed rat.........

2. Comparison of SR 48692 and SR 142948A within the RVM for their ability to block neurotensinmediated anti-analgesia in the stressed rat.

C. Comparison of SR 48692 and SR 142948A microinjected into the RVM to alter the antinociceptive response to systemically administered morphine.

3. The influence of levocabastine (RVM) on the anti-analgesic (pain facilitatory) response to neurotensin (RVM).

4. Evaluation of intracerebroventricular administration of neurotensin on nociception, body temperature and tail temperature

5. The dose-response relationship of intracerebroventricularly administered neurotensin in the stressed rat........................ 101

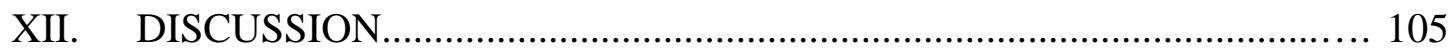

XIII. REFERENCE LIST .............................................................. 122






\section{LIST OF FIGURES}

Page

Figure 1. Illustration representing the anatomy of the rostral ventromedial medulla (RVM).

Figure 2. Illustration representing hypothesized connections and descending pain modulation within the RVM

Figure 3. Chemical structure of the two non-peptide neurotensin receptor antagonists SR 48692 and SR 142948A.

Figure 4. Dose-response relationship for SR 142948A injected into the RVM.

Figure 5. The influence of SR 142948A microinjected into the RVM on the response to an antinociceptive dose $(10 \mathrm{nmol})$ of neurotensin injected into the RVM

Figure 6. The dose-response relationship for the influence of administration of SR 142948A into the RVM on the response to an antinociceptive dose $(10 \mathrm{nmol})$ of neurotensin injected into the RVM.

Figure 7. Time effect curves for various doses of SR 142948A microinjected into the RVM prior to a low dose (30 pmol) of neurotensin.

Figure 8. Lack of influence of various doses of SR 142948A microinjected into the RVM on a low dose (30 pmol) of neurotensin.

Figure 9. The dose-response relationship for anti-analgesic and antinociceptive responses to neurotensin in the RVM of the stressed rat.

Figure 10. The influence of SR 142948A and SR 48692 microinjected into the RVM on the development of stress-induced analgesia.

Figure 11. Comparison of SR 142948A and SR 48692 for their ability to block neurotensin-induced anti-analgesia in the stressed rat. 
Figure 12. Influence of SR 48692 and SR 142948A administered into the RVM on the response to an antinociceptive dose of morphine $(2 \mathrm{mg} / \mathrm{kg})$ injected intraperitoneally.

Figure 13. The ability of neurotensin injected into the RVM to reduce and increase the antinociceptive response produced by PAG administration of morphine.

Figure 14. The inability of various doses of levocabastine to alter morphine-induced antinociception.

Figure 15. The inability of various doses of levocabastine to alter neurotensin-mediated anti-analgesia within the RVM.

Figure 16. The ability of SR 48692 to alter neurotensin-mediated antianalgesia within the RVM.

Figure 17. The dose-response relationship of neurotensin following intracerebroventricular administration.

Figure 18. The effects of i.c.v. administration of neurotensin on rectal and tail temperature.

Figure 19. The dose-response relationship for the anti-analgesic and antinociceptive responses to neurotensin following i.c.v. administration in the stressed rat.

\section{LIST OF TABLES}

Table 1. Listing of the hypothesized neurotensin receptors found within the RVM that are involved in pain modulation.

\section{LIST OF ABBREVIATIONS}

Calcitonin gene related peptide (CGRP)

Central nervous system (CNS) 
Cholecystokinin (CCK)

Dorsal lateral funiculus (DLF)

Foot shock-induced analgesia (FSIA)

Intravenous (i.v.)

Intracerebroventricular (i.c.v.)

Intracisternal (i.c.)

Intrathecal (i.t.)

Neuropeptide FF (NPFF)

Neuropeptide Y (NPY)

Nucleus raphe magnus (NRM or RMg)

Nucleus reticularis gigantocellularis (Gi)

Nucleus reticularis gigantocellularis pars alpha $(\operatorname{Rgc} \alpha)$

Nucleus reticularis paragigantocellularis (Rpg)

Nucleus reticularis paragigantocellularis lateralis (Rpgl or LPGi)

Opioid analgesia (OA)

Periaqueductal gray (PAG)

Rostral ventromedial medulla (RVM)

Serotonin (5HT)

Stimulation produced analgesia (SPA)

Stress-induced analgesia (SIA)

Thyrotropin-releasing hormone (TRH)

Vasoactive intestinal polypeptide (VIP) 


\section{BACKGROUND}

\section{Anatomy and physiology of endogenous descending nociceptive modulatory pathways}

Our knowledge and understanding of pain and nociception has vastly improved from the days when the Aristotelian belief that pain was an affective quality was widely accepted by philosophers and scientists. Advancements in anatomical, physiological and behavioral techniques have provided information that has enabled us to take a mechanistic view of the mammalian central nervous system, allowing us to better discern the body's responses to noxious stimulation. Since Schiff's work in 1858, we have understood that nociceptive information in animals is transmitted in an ascending system from the spinal cord dorsal horn to the brain via pathways in the anterolateral quadrant. A number of years passed before evidence that descending projections originating in supraspinal sites that could modulate nociceptive transmission at the level of the spinal cord was established. However, we now know that there are many different neuronal projections that originate within the brain and terminate within the spinal cord dorsal horn. These projections which include the rubro-, vestibulo-, recticulo-, cortico- and bulbo-spinal tracts, to name a few, can affect not only the transmission of information from the periphery into ascending tracts, but can also affect transmission to the motor neurons over reflex pathways (Kuypers, 1967; Wall, 1967). The fact that spinal cord dorsal horn neurons are under tonic inhibitory control via supraspinal sites was first realized in 1915 by Sherrington and Sowton (Sherrington and Sowton, 1915). They observed that when the spinal cord of a decerebrate cat is transected, not only is the 
stretch reflex reduced, but also the flexion reflex is enhanced. Further support for this contention was demonstrated by Wall (Wall, 1967). In this study, he showed that blockade of the thoracic spinal cord (T13-L1) with Ringers ice solution (cold block), in decerebrate cats, enhanced the spontaneous activity of dorsal horn neurons and increased their responsiveness to peripheral mechanical and electrical stimulation. Further characterization of the neurons that respond in this manner has revealed that they are nociceptor specific (Besson et al., 1975; Duggan et al., 1977; Handwerker et al., 1975; Soja and Sinclair, 1983). That is they will respond to noxious stimulation such as heat or pinch, but not to non-noxious stimuli such as touch or brush. Taken together, these studies provided the first lines of evidence that spinal cord dorsal horn neurons were under the control of supraspinal sites and therefore provided evidence for the existence of endogenous descending pain modulatory pathways.

Further evidence of endogenous analgesia systems comes from observations that electrical stimulation of discrete supraspinal sites could elicit profound analgesia (absence of pain in response to a noxious stimulus) without any impairment of general behavior. This stimulation-produced analgesia (SPA) was originally reported to follow stimulation of the midbrain periaqueductal gray (PAG) (Mayer et al., 1971; Reynolds, 1969). Therefore, this region was the first to be implicated in pain modulation. However, SPA can be observed upon stimulating a number of other sites within the CNS. Within the diencephalon electrical stimulation of the periventricular gray, medial and lateral hypothalamus, and the thalamus attenuates the responses of dorsal horn neurons responding to noxious heating of the skin and produces antinociception (increase in latency for response) in the tail-flick, hot plate and pinch tests (Carstens et al., 1981; 
Carstens, 1982; Carstens et al., 1982; Gerhart et al., 1981; Rhodes and Liebeskind, 1978; Yunger et al., 1973). At the level of the mesencephalon, electrical stimulation of sites such as the aforementioned PAG, the mesencephalic reticular formation, and the dorsal raphe nucleus decreased responses of dorsal horn neurons responding to noxious heat or paw pinch and increased latencies in the tail flick test (Carstens et al., 1981; Dostrovsky et al., 1983; Goodman and Holcombe, 1976; Liebeskind et al., 1973; Mayer and Liebeskind, 1974; Soper and Melzack, 1982). At the level of the medulla, SPA has been observed after stimulation of the nucleus raphe magnus, nucleus paragigantocellularis, nucleus paragigantocellularis pars alpha and the nucleus paragigantocellularis lateralis (Beall et al., 1976; Fields et al., 1977; McCreery et al., 1975; McCreery et al., 1979; Zhuo and Gebhart, 1992). Other sites where SPA can be produced include the caudate nucleus (Rodriguez and Sacristan, 1989), the septum (Gol, 1967), and the internal capsule (Adams, 1976). While stimulation of all of these sites within the CNS is capable of producing analgesia, stimulation of the ventrolateral part of the PAG is the most consistent and effective in producing SPA (Lewis and Gebhart, 1977; Mayer and Liebeskind, 1974). In addition, there is evidence that analgesia elicited from electrical stimulation of sites rostral to the PAG is mediated through a PAG connection (Rhodes and Liebeskind, 1978). Furthermore, SPA does not appear to result from some temporary disruption of afferent nociceptive transmission within the site being stimulated (i.e. disruption of spinomesencephalic neurons as a result of stimulation of the PAG). In support of this contention, injection of a local anesthetic into the PAG does not result in the production of analgesia (Helmstetter et al., 1998). Therefore, the contention can be made that SPA after PAG stimulation is the result of a cascade of events, which originate 
within the PAG and results in the inhibition of afferent input at another site within the CNS. This is supported by the fact that SPA in the PAG develops gradually over a period of time (possibly due to the build up of neurotransmitters or diffusion of neurotransmitters to another site) and lasts much longer than the period of stimulation (Adams, 1976; Hosobuchi et al., 1977). These observations concerning the PAG and SPA further implicated this region as an important modulatory site of endogenous analgesia.

The relative importance of the PAG as a part of an endogenous descending analgesia pathway gained further support from the study of opioid analgesia (OA). One major advancement was the identification of opioid receptors (Pert and Snyder, 1973) and the endogenous peptides that bind to these receptors (Hughes, 1975; Hughes et al., 1975), both of which are found in a high concentration within the PAG (Goldstein, 1976; Pasternak et al., 1975; Pert et al., 1976). Moreover, other studies demonstrated a link between SPA and OA. It was demonstrated that in addition to electrical stimulation, exogenous opioid administration into the PAG could also produce antinociception in the tail-flick test as a result of inhibiting spinal cord dorsal horn neurons (Bennett and Mayer, 1979; Carstens et al., 1981; Hayes et al., 1979; Lewis and Gebhart, 1977; Liebeskind et al., 1973; Mayer and Liebeskind, 1974; Mayer and Price, 1976; Pert and Yaksh, 1974; Yaksh et al., 1976). In addition, it was demonstrated that cross-tolerance exists between SPA and morphine analgesia (OA)(Mayer and Hayes, 1975). In this regard, it was demonstrated that opioid receptor antagonists could antagonize SPA (Adams, 1976; Akil and Mayer, 1976; Hosobuchi et al., 1977), and that lesions of the dorsal lateral funiculus (DLF) could antagonize the effects of both SPA and OA within the PAG (Basbaum et al., 
1976; Basbaum et al., 1977; Murfin et al., 1976). Therefore, in addition to showing that SPA and OA have a common neural mechanism, these studies suggested an anatomical connection between the PAG and the spinal cord (Basbaum et al., 1977).

The PAG has been anatomically defined as the portion of the ventricular gray matter which surrounds the midbrain aqueduct. Rostrally it is continuous with the periventricular gray matter surrounding the third ventricle in the hypothalamus and thalamus, and caudally it is continuous with periventricular gray matter which in the dorsal pons forms the ventral and ventrolateral border of the fourth ventricle (Bandler et al., 1991). The boundaries of the PAG are formed by two fiber streams, the tectobulbospinal fibers originating in the superior colliculus and the fibers of the mesencephalic trigeminal tract (see reviews by Cowie and Holstege, 1992; Holstege, 1991a). While all of the functions of PAG are not clearly understood, it is apparent that the PAG is an integrative nucleus that is important in the control of nociception, vocalization, cardiovascular and respiratory responses, reproductive behavior, as well as behavioral responses to threatening or stressful stimuli (Lovick, 1992; 1993; Ogawa et al., 1991). As with many integrative nuclei, the PAG has a very diverse afferent input. Anterograde and retrograde studies have demonstrated that the PAG receives input from the frontal and insular cortices, the limbic system, locus coeruleus, pontine reticular formation, nucleus cuneiformis, amygdala, superior colliculus and hypothalamus as well as input directly from the spinal cord (Beitz, 1982b; Gebhart, 1986; Hammond, 1986; Mantyh and Peschanski, 1982; Mantyh, 1983; Mehler, 1962; Redgrave et al., 1986; Rhoades et al., 1989; Semenenko and Lumb, 1992). The PAG contains a number of enkephalin and dynorphin cells and terminals, terminals of $\beta$-endorphin axons, as well as 
non-opioid peptides and amino-acid containing cells and terminals such as those for neurotensin (Beitz, 1982a; Moss et al., 1981; Moss et al., 1983; Moss and Basbaum, 1983b; Uhl et al., 1979; Williams and Beitz, 1989), serotonin (5HT) (Clements et al., 1985), substance P and vasoactive intestinal polypeptide (VIP) (Moss and Basbaum, 1983a), acetylcholine (Mash and Potter, 1986; Spencer et al., 1986), dopamine (Bouthenet et al., 1987; 1988), norepinephrine (Moore and Bloom, 1979), histamine (Airaksinen et al., 1989; Inagaki et al., 1988), glutamate (Barbaresi and Manfrini, 1988; Beart et al., 1990; Clements et al., 1987; Greenamyre et al., 1984; McLennan, 1983; Sherman and Gebhart, 1975), aspartate (Clements et al., 1987; Monaghan and Cotman, 1985), $\gamma$-aminobutyric acid (GABA) (Reichling, 1991) and glycine (Araki et al., 1988) exist. While the circuitry within the PAG is quite complex, it is apparent that most of the aforementioned neurotransmitters are in some way involved in PAG-mediated antinociception. However, the relative contribution of each is still not fully understood. One possibility may be that these transmitters work in conjunction with each other to either antagonize or to potentiate one another's effect within the PAG in a manner that serves to regulate PAG mediated antinociception. For example, studies have revealed that similar to the opioid peptides, microinjection of neurotensin, substance P, VIP, glutamate, histamine, and GABA into the PAG all produced analgesia (Behbehani and Fields, 1979; Behbehani and Pert, 1984; Behbehani et al., 1990; Frederickson et al., 1978; Glick and Crane, 1978; Jensen and Yaksh, 1984; Mohrland and Gebhart, 1979; Naranjo et al., 1982a; 1982b; Sullivan and Pert, 1981; VanPraag and Frenk, 1990). However, analgesia produced by these neurotransmitters in the PAG appears to be due to activation of different neuronal substrates. For example, analgesia induced by substance 
$\mathrm{P}$ administration into the PAG can be reversed by naloxone, showing that the effect is opioid receptor mediated (Frederickson et al., 1978; Malick and Goldstein, 1978; Mohrland and Gebhart, 1979; Naranjo et al., 1982a; 1982b). In contrast, VIP-induced analgesia is naloxone insensitive, and thus a non-opioid receptor mediated response (Sullivan and Pert, 1981).

Analgesia due to opioid administration within the PAG appears to involve many different neurotransmitters. Systemic morphine administration $(10 \mathrm{mg} / \mathrm{kg}$, i.p.) results in a decrease in the release of GABA within the PAG, while having no effect on extracellular glutamate, aspartate and glycine levels (Renno et al., 1992). Moreover, microinjection of muscimol, a $\mathrm{GABA}_{\mathrm{A}}$-receptor agonist, into the PAG antagonizes morphine's antinociceptive effect in rats, an effect that can be partially reversed by bicuculline, a $\mathrm{GABA}_{\mathrm{A}}$-receptor antagonist (Zambotti et al., 1982). Interestingly, morphine microinjection into PAG induces the release of neurotensin (increases the extracellular concentration of neurotensin within the PAG) through a process that is nonGABAergic but is both calcium-dependent and naloxone-reversible (Stiller et al., 1997). Furthermore, systemic morphine administration dose-dependently increases extracellular histamine levels in the PAG, an effect that can be reduced by repetitive exposure to a noxious stressor (Barke and Hough, 1992), and $\mathrm{H} 2$ receptor antagonists have been demonstrated to antagonize morphine analgesia as well as opioid-mediated footshockinduced analgesia (Gogas et al., 1989). In addition, morphine microinjection into the PAG has been associated with an increase in the metabolism of brain norepinephrine (Reigle, 1985).

While the circuitry and neurochemistry of the PAG is quite complex, the fact 
remains that excitation of PAG output neurons is required to initiate descending inhibitory controls. In their review of endogenous pain control systems, Basbaum and Fields (1984) proposed that since the actions of opioids on target neurons is generally inhibition, that morphine or endogenous opioids do not act directly on the PAG output neurons, but activate the output neurons via disinhibition. That is opioids act by inhibiting an inhibitory interneuron (i.e. a GABAergic neuron). This contention has subsequently received direct scientific support. It has been demonstrated that cells double labeled for MOR1 (cloned $\mu$-opioid receptor) and GABA are common in the PAG (Kalyuzhny and Wessendorf, 1998). Furthermore, whole-cell patch-clamp recordings from PAG output neurons, retrogradely labeled from injections in the rostral ventromedial medulla (RVM), demonstrate that the opioid agonists methionine enkephalin and DAMGO can inhibit GABAergic inhibitory postsynaptic currents (IPSCs) (Osborne et al., 1996; Vaughan and Christie, 1997).

Retrograde and anterograde tracer studies have demonstrated that the majority of labeled neurons within the PAG project to the RVM, specifically the nucleus raphe magnus (RMg), nucleus reticularis paragigantocellularis (Rpg), nucleus reticularis gigantocellularis pars alpha $(\operatorname{Rgc} \alpha)$ and nucleus reticularis paragigantocellularis lateralis (Rpgl), as well as the ventral part of the caudal pontine and medullary medial tegmentum (Abols and Basbaum, 1981; Beitz et al., 1983; 1988; Holstege, 1988; Mantyh, 1983; Marchand and Hagino, 1983). On their way to the medulla, these axonal projection neurons distribute fibers ipsilaterally to the locus coeruleus, the nucleus subcoeruleus and the paralemniscal cell group, all of which have projections to laminae I and V of the spinal cord (Holstege, 1988; 1991b). In addition, the PAG also has a small but 
significant portion of cells that project directly to the spinal cord (Kneisley et al., 1978; Kuypers and Maisky, 1975). However, these direct projections to the spinal cord do not appear to play a major role in OA or SPA (Akil and Liebeskind, 1975). Further classification of the projection neurons from the PAG to the RVM came from studies which combined retrograde transport and immunohistochemistry analysis, and showed that serotonergic and neurotensinergic neurons project to the RVM, while substance P and enkephalin containing neurons do not (Beitz, 1982a; 1982c).

A number of observations demonstrate the relative importance of this PAG-RVM connection in the modulation of nociception, as well as implicating the RVM as a relay site of endogenous analgesia. First, the RVM is the major source of axons projecting in the DLF to the spinal cord (Basbaum et al., 1978; Basbaum and Fields, 1979; Leichnetz et al., 1978; Martin et al., 1978), and as mentioned previously the DLF is essential for OA and SPA. Accordingly, antinociception induced by systemic morphine can be antagonized by electrolytic lesion of the RMg (Proudfit and Anderson, 1975; Yaksh et al., 1977). However, more recent experiments have demonstrated that antinociception mediated by the PAG does not rely solely on this nucleus (Gebhart et al., 1983; Sandkuhler et al., 1982). These studies showed that large lesions or simultaneous disruption (with a local anesthetic) of the $\mathrm{RMg}, \mathrm{Rgc} \alpha$ and $\mathrm{Rpgl}$ together are required to completely block the antinociceptive response from the PAG (Chung et al., 1987; Gebhart et al., 1983; Morton et al., 1984; Prieto et al., 1983; Sandkuhler and Gebhart, 1984). Furthermore, activation of the PAG either by electrical stimulation (Fields and Anderson, 1978) or by morphine microinjection (Behbehani and Pomeroy, 1978) results in an excitation of RVM neurons within these nuclei. 
The rostral ventromedial medulla (RVM) is anatomically described in the rat as containing the nucleus raphe magnus ( $\mathrm{RMg}$ ), nucleus reticularis gigantocellularis pars alpha $(\operatorname{Rgc} \alpha)$, nucleus reticularis paragigantocellularis lateralis $(\operatorname{Rpgl})$ and the adjacent reticular formation ventral to the nucleus reticularis gigantocellularis $(\mathrm{Rgc})$ from the caudal pole of the facial nucleus to the level of the trapezoid body (Basbaum and Fields, 1984) (see Figure 1 for illustration). The major afferent input to the RVM comes from the aforementioned PAG and adjacent cuneiform nucleus (nucleus cuneiformis) (Abols and Basbaum, 1981; Beitz, 1982c; Beitz et al., 1983; 1988; Mantyh and Peschanski, 1982; Marchand and Hagino, 1983). However, the RVM receives significant afferent input from other sites as well, such as the adjacent medullary reticular formation (Abols and Basbaum, 1981; Mason et al., 1986), the dorsolateral pontine tegmentum (Holstege, 1988), hypothalamus, frontal cortex, amygdala, the bed nucleus of the stria terminalis (Fields et al., 1991; Holstege, 1987), noradrenergic input from locus coeruleus, nucleus subcoeruleus, and noradrenergic neurons in A1, A5, A7 regions, as well as adrenergic input from neurons in the $\mathrm{C} 1$ region (see Tanaka et al., 1996 for references).

Like the PAG, the RVM contains cell bodies, terminals and receptors for numerous neuropeptides, amino acids, and catecholamines such as those for endogenous opioids (enkephalins and dynorphins), serotonin, neurotensin, epinephrine, norepinephrine, GABA, glutamate and aspartate (see review by Fields et al., 1991). Accordingly, these neurotransmitters may play a role in nociceptive processing. Microinjection of morphine (or endogenous opioid peptides) (Azami et al., 1982; Dickenson et al., 1979; Jensen and Yaksh, 1986; Levy and Proudfit, 1979), serotonin (Inase et al., 1987; Llewelyn et al., 1983), glutamate (Satoh et al., 1983; Zhuo and 


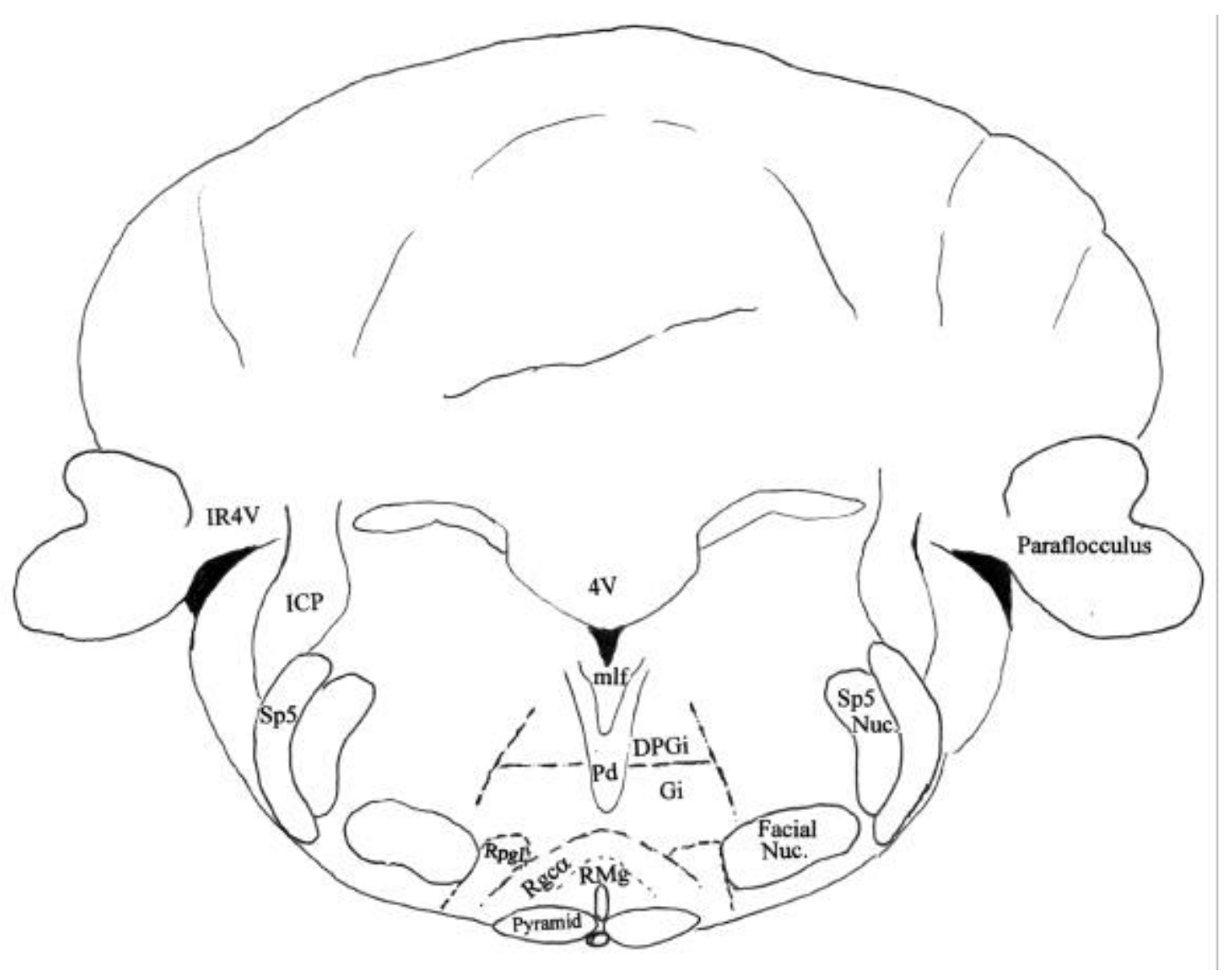


Figure 1. Illustration represents the anatomy of the rostral ventromedial medulla (RVM) in the rat. The illustration is based on Paxinos and Watson, 1986, and represents a coronal section of the brainstem $2.00 \mathrm{~mm}$ posterior to the interaural line. The RVM contains several nuclei including the nucleus raphe magnus $(\mathrm{RMg})$, nucleus reticularis gigantocellularis pars alpha $(\mathrm{Rgc} \alpha)$, nucleus reticularis gigantocellularis $(\mathrm{Gi})$ and nucleus reticularis paragigantocellularis lateralis (Rpgl). The RVM's rostrocaudal extent is from the caudal pole of the facial nucleus to the level of the trapezoid body. Also illustrated are dorsal paragigantocellular nucleus (DPGi), superior cerebellar penduncle (SCP), inferior cerebellar penduncle (ICP), facial nucleus, inferior recess of the fourth ventricle (IR4V), medial longitudnal fasciculus (mlf), spinal trigeminal nucleus (Sp5 Nuc.), spinal trigeminal tract (Sp5) and the predorsal bundle (pd). 
Gebhart, 1990a), and neurotensin (Behbehani, 1992; Clineschmidt et al., 1979; Fang et al., 1987; Kalivas et al., 1982) all have been demonstrated to produce antinociception. The RVM has also been associated with facilitating nociceptive responses as some of these same neurotransmitters have been observed to produce a facilitation of responses to noxious stimuli. Microinjection of neurotensin (Smith et al., 1997; Urban and Smith, 1993; 1994; Urban et al., 1996b) and glutamate (Zhuo and Gebhart, 1990a; 1992) into the $\mathrm{RVM}$, at doses lower than those producing antinociception, produces a reduction in tail flick latency (facilitation). In addition, the RVM has also been implicated in hyperalgesia (an increased response to a noxious stimulus) or sensitization (Pertovaara, 1998; Urban et al., 1996a) as well as neuropathic pain (Pertovaara et al., 1996). Furthermore, RVMevoked facilitation of dorsal horn neuron responses to noxious heat as well as the tail flick reflex has been demonstrated (Light et al., 1986; Urban and Gebhart, 1997; Zhuo and Gebhart, 1990a; 1992; 1997)(see section of this document entitled Modulation of nociception within the rostral ventromedial medulla for more information). The demonstration that the RVM can modulate nociception, producing either facilitation or inhibition, coupled with the fact that it receives afferent projections from various supraspinal sites involved in pain modulation and is the major source of fibers that project in the DLF to the spinal cord, has led to the classification of the RVM as a major component of endogenous descending pain modulatory systems. Thus, its involvement in these descending systems means that its ability to modulate nociception, like the PAG, relies on the activity of output neurons.

The major efferent projections of the RVM are to the trigeminal nucleus caudalis and to the spinal cord via the DLF, where the efferent axons of the RVM then 
collateralize and terminate bilaterally in laminae I, II, and V of the trigeminal nucleus, and I, II, V, VI and VII of the spinal dorsal horn at all levels (Basbaum et al., 1978; Basbaum and Fields, 1979; 1986; Holstege and Kuypers, 1982; Martin et al., 1981). The RVM in addition to having projections to the level of the spinal cord where it can modulate nociception also makes reciprocal connections with the PAG (Marchand and Hagino, 1983). These reciprocal projections could possibly serve as a feedback loop to regulate nociceptive information at the level of the PAG.

The location and terminations of these projections are important, as the location of these axons in the DLF from the RVM to the spinal cord correlates well with the optimal placement of a lesion required to block SPA and OA (Basbaum and Fields, 1978). In addition, the terminal fields of these axons are concentrated in the same area as those containing primary afferent nerve terminals and cells of origin for the spinothalamic tract (Cervero and Iggo, 1980; Dubner and Bennett, 1983; Light and Perl, 1979a; 1979b). Antinociception generated by electrical or opioid stimulation of the RVM, has been shown to be mediated through an inhibition of dorsal horn neurons (Dickenson et al., 1979; Haber et al., 1978; Oliveras et al., 1975; Zhuo and Gebhart, 1990a; 1990b; 1992; Zorman et al., 1981), and can be attenuated by ipsilateral lesions of the DLF, and abolished by bilateral lesions (Fields et al., 1977; Willis et al., 1977). Furthermore, electrophysiological studies have demonstrated that RMg stimulation results in a selective inhibition of dorsal horn neurons, as neurons that respond to noxious inputs are inhibited while those that respond to non-noxious mechanical stimulation are not (Basbaum et al., 1976; Fields et al., 1977).

The ultimate site of action of descending pain modulatory pathways, where 
nociceptive input can be blocked, is at the level of the spinal cord dorsal horn or its trigeminal equivalent (trigeminal nucleus caudalis). In regard to the spinal cord, the study of mechanisms for the actions of descending pathways (possible neurotransmitters and their effects) is very complicated. This is because many neurotransmitters that are associated with the terminals of descending axons are also generated from primary afferent nociceptive neurons from the periphery (C-fibers) and intrinsic neurons of the dorsal horn. The neurotransmitters acetylcholine (Bowker et al., 1983), cholecystokinin (CCK) (Skirboll et al., 1983), dopamine (Hokfelt et al., 1979a; Skagerberg et al., 1982), enkephalin (Hokfelt et al., 1979b), glutamate (Liu et al., 1995), neuropeptide Y (NPY) (Gibson et al., 1984; Holets et al., 1988; Minson et al., 1994), epinephrine (Carlton et al., 1991; Ross et al., 1981), norepinephrine (Basbaum and Fields, 1979; Dahlstrom and Fuxe, 1965; Kuypers and Maisky, 1975; Nygren and Olson, 1977; Proudfit and Hammond, 1981; Westlund et al., 1982), serotonin (Bowker et al., 1982a; 1982b; Dahlstrom and Fuxe, 1965), as well as substance $\mathrm{P}$ and thyrotropin-releasing hormone (TRH) (Arvidsson et al., 1990; Bowker et al., 1983) are all found at the level of the spinal cord and have been identified in the terminals of axonal projections from supraspinal sites. A number of other neurotransmitters have been localized in the spinal cord and have been shown to be produced intrinsically. These local transmitters also appear to be involved in modulating nociception at the level of the spinal cord, as GABA, enkephalin, dynorphin A, and adenosine suppress dorsal horn neurons, while neurotensin and glutamate stimulate or enhance the discharge of dorsal horn neurons (see reviews by Coderre et al., 1993; Yaksh and Malmberg, 1993). Furthermore, excitation of primary afferent axons is associated with the release of substance $\mathrm{P}$, calcitonin gene related 
peptide (CGRP), glutamate, vasoactive intestinal polypeptide (VIP), neurokinin A, galanin, somatostatin and bombesin in the spinal cord which evoke hyperalgesia or produce pain related behavior including caudally directed biting and licking as well as hindlimb scratching (see reviews by Coderre et al., 1993; Yaksh and Malmberg, 1993). Lastly, cannabinoid receptors have been localized within the dorsal horn of the spinal cord (Herkenham et al., 1991). While the endogenous ligand(s) for these receptors is (are) still unclear and therefore their source of input uncertain, cannabinoid agonists inhibit responses of dorsal horn neurons in response to noxious stimulation (Hohmann et al., 1995), while cannabinoid antagonists can produce hyperalgesia (Richardson et al., 1998).

The sources of the aforementioned neurotransmitters found in supraspinal projections to the spinal cord are as diverse as their effects on nociceptive processing within the cord. However, a number of investigations have been done on each in order to characterize the source of their input and to examine their effects on nociceptive processing.

Serotonergic projections to the spinal cord have been identified from the nucleus raphe obscurus (B1 cell group), nucleus raphe pallidus (B2 cell group) as well as from the RVM including the RMg (B3 cell group), Rpgl and the adjacent reticular formation (Bowker et al., 1981a; 1981b). Attempts to quantify these projections have revealed that of all of the raphe-spinal neurons (raphe-spinal neurons include all of the projections to the spinal cord from all raphe nuclei) $82-83 \%$ were found to contain serotonin (Bowker $e t$ al., 1982a; 1983). In addition, $70 \%$ of the 5HT containing neurons in the RVM were found to project to the spinal cord (Bowker et al., 1982a; 1982b). Furthermore, serotonin 
has an effect on nociceptive processing at the level of the spinal cord and has been demonstrated to be involved in descending pain modulatory pathways at this level as well. Intrathecal administration of serotonin has been shown to produce antinociception in the tail flick and hot plate tests (Yaksh and Wilson, 1979). Electrical or opioid stimulation of the RMg results in an increase in the concentration of 5HT and its metabolite, 5-hydroxyindolacetic acid (5HIAA), within the spinal cord (Hammond et al., 1985; Yaksh and Tyce, 1979). In addition, SPA from the RVM can be attenuated by depleting spinal 5HT (Rivot et al., 1980), or by the intrathecal administration of 5HT receptor antagonists (Hammond and Yaksh, 1984; Jensen and Yaksh, 1984). Electrical stimulation of the Gi or $\operatorname{Rgc} \alpha$ at low intensities, which produces a facilitation of tail flick responses, can be antagonized by the intrathecal administration of the non-selective 5HT receptor antagonist methysergide, but not by lesions of the DLF (Zhuo and Gebhart, 1991). However, SPA from the PAG is only partially reversed by i.t. 5HT antagonist administration (Hammond and Yaksh, 1984). Accordingly, antinociception resulting from opioid microinjection into the PAG is only partially reduced by depleting spinal 5HT (Yaksh, 1979). Thus, it appears that while serotonin mediates nociceptive modulation from these sites and therefore plays a role in endogenous descending systems at the level of spinal cord, it is not the sole mediator of these systems. Indicating that other neurotransmitters may be involved at the level of the spinal cord.

Noradrenergic and adrenergic supraspinal projections to the cord have been identified as well. Retrograde transport studies in combination with immunocytochemical staining have identified axonal projections containing norepinephrine originating in the A5 area (neurons in the ventrolateral brainstem dorsal 
and lateral to the superior olivary and facial nuclei), A6 area (the nucleus locus coeruleus) and A7 area (the nucleus subcoeruleus, as well as the medial and lateral parabrachial nuclei and the nucleus of Kolliker-Fuse) noradrenergic cell groups (Basbaum and Fields, 1979; Dahlstrom and Fuxe, 1964; 1965; Kuypers and Maisky, 1975; Nygren and Olson, 1977; Proudfit and Hammond, 1981; Westlund et al., 1982), while epinephrine projections have been shown to originate in the $\mathrm{C} 1$ cell group region of the medulla (Carlton et al., 1991; Ross et al., 1981). These projections terminate in the dorsal and ventral horns, as well as the gray matter around the central canal at all spinal levels (Westlund and Coulter, 1980). Like 5HT, both norepinephrine and epinephrine have effects on nociceptive processing at the level of the spinal cord and have been demonstrated to be involved in descending pain modulatory pathways at this level as well. Intrathecal administration of norepinephrine has been demonstrated to inhibit dorsal horn neurons (Millar and Williams, 1989), and i.t. administration of clonidine (an alpha-adrenoceptor agonist) and norepinephrine produce antinociception in the tail flick test (Eide and Hole, 1992; Watkins et al., 1985a). In addition, electrical stimulation of the $\mathrm{RMg}$ results in an increase in the concentration of norepinephrine within the spinal cord (Hammond et al., 1985). Accordingly, SPA from the RVM can be attenuated by depleting spinal norepinephrine (Pang and Vasko, 1986), or by the intrathecal administration of phentolamine (an alpha-adrenoceptor antagonist) (Hammond and Yaksh, 1984). Furthermore, the i.t. administration of noradrenergic antagonists only partially reverses antinociception in the tail flick and hot plate tests induced by opioid microinjection into the PAG (Yaksh, 1979), suggesting that 5HT and norepinephrine may act together in mediating OA. 
The presence of enkephalinergic neurons and receptors has been demonstrated at all levels throughout the multiple descending pain modulatory projections (i.e. PAG, RVM and spinal cord). However, the role of spinally projecting enkephalin neurons in pain modulation still remains a question. Retrograde transport studies combined with immunofluoresence for enkephalin-like immunoreactivity (ELI) showed that a small fraction of enkephalinergic neurons that originate in the ventral $\mathrm{Gi}, \mathrm{Rpg} \alpha, \mathrm{RMg}, \mathrm{Rpgl}$ as well as from the superficial layers of the spinal trigeminal nucleus and nucleus tractus solitarius project to the spinal cord (Bowker et al., 1982a; Hokfelt et al., 1979b). The significance of these projections is questioned, because previous studies done by Hokfelt and coworkers (Hokfelt et al., 1977) have demonstrated that neither total transection of the cord nor dorsal rhizotomy have any significant effect on enkephalin content within the cord. Nonetheless, studies have demonstrated that enkephalins do act at the level of the spinal cord to modulate nociception. SPA from the RVM (Zorman et al., 1982) and foot shock-induced analgesia (FSIA) (Watkins et al., 1982) can be blocked by the intrathecal administration of naloxone (an opioid receptor antagonist), while i.t. administration of enkephalins inhibits the responses of spinothalamic tract neurons (Willcockson et al., 1986). Furthermore, i.t. administration of opioids (morphine) can inhibit the release of substance $\mathrm{P}$ from primary afferent neurons (Yaksh et al., 1980). Thus, opioids appear to be involved in descending pain pathways, either by acting as a neurotransmitter in descending axonal projections to the cord or as a messenger in a cascade mediating the effects triggered by projecting neurons to the cord (i.e. inhibiting dorsal horn neurons or preventing the release of transmitters from primary afferent nociceptive fibers). 
Neuropeptide Y (NPY) has also been demonstrated to play a role in nociceptive modulation at the level of the spinal cord. Even though NPY's existence and role in descending pain projections to the cord has not been directly demonstrated, it has been strongly implicated by several different important observations. First, NPY projections to the cord have been demonstrated to originate in areas of the CNS associated with descending pain modulation such as the ventral part of the Gi, Rpg, Rpgl, and the locus coeruleus, as well as neurons localized in the dorsal medial medulla, medial longitudinal fasciculus (MLF) and the nucleus tractus solitarius (Gibson et al., 1984; Holets et al., 1988; Minson et al., 1994). Intrathecal application of NPY produces antinociception in the hot plate and paw pressure tests (Hua et al., 1991), and has been demonstrated to decrease the release of substance $\mathrm{P}$ from primary afferent nociceptive fibers (Duggan $e t$ al., 1991). However, more recent studies examining NPY's ability to modulate nociception at this level has illustrated that the peptide has dose-dependent opposing effects on nociception. That is, administration of low doses of the peptide produce an initial period of facilitation with no subsequent suppression and administration of higher doses produce only an inhibition of the spinal nociceptive reflex (hamstring flexor reflex) in rats (Xu et al., 1994).

Facilitation of nociception (producing hyperalgesia) or anti-analgesic (inhibition or reduction of existing analgesic response) effects have been demonstrated for a number of other neurotransmitters; glutamate, CCK, TRH, and substance $\mathrm{P}$ are all capable of producing one of these effects. Both substance $\mathrm{P}$ and TRH projection neurons originate in neurons within the RVM, with TRH coming from the nucleus raphe pallidus and the adjacent reticular formation and substance $\mathrm{P}$ projections originating in the three midline 
raphe nuclei (pallidus, obscurus, and magnus) (Bowker et al., 1982a; 1983). In addition, TRH and substance $\mathrm{P}$ have been demonstrated to coexist in these neurons with each other as well as with 5HT (Johansson et al., 1981). Furthermore, TRH projections have been demonstrated to terminate on both sensory and motor nuclei within the spinal cord (Arvidsson et al., 1990). Interestingly, CCK and glutamate projections to the cord have been demonstrated to originate in other sites associated with descending pain modulation. CCK projections from the PAG to the spinal cord have been identified (Skirboll et al., 1983), while glutamate projections from the locus coeruleus, nucleus subcoeruleus and the parabrachial nuclei have been demonstrated in the cat (Liu et al., 1995). Although glutamate induces the firing of spinothalamic tract neurons when applied iontophoretically (Carlton et al., 1991), the role of glutamate projections to the cord is questioned (in much the same way as the enkephalins), as total transection of the spinal cord at the mid-thoracic level results in only a very small decrease in spinal glutamate content (Singer et al., 1981). However, CCK, TRH and substance P have all been implicated as mediators of descending pain processes.

Intrathecal administration of CCK has a dose-dependent bipolar effects on nociception in the tail flick test, with low doses of CCK producing an inhibition of the tail flick and higher doses facilitating the response (i.e. reducing the tail flick latency) (Urban et al., 1996b). Intrathecal administration of CCK has been demonstrated to produce anti-analgesia, as it antagonizes analgesia induced by supraspinal and spinal administration of opioids (Faris et al., 1983; Suberg and Watkins, 1987; Suh and Tseng, 1990; Suh et al., 1992; Tseng and Collins, 1992). Accordingly, the i.t. administration of proglumide (a non-selective CCK receptor antagonist) has no effect alone, but potentiates 
i.t. morphine-induced analgesia and foot shock-induced analgesia (FSIA) (Watkins et al., 1985b). More recent studies have identified this effect is mediated via the $\mathrm{CCK}_{\mathrm{B}}$ receptor subtype, as antagonists specific for this receptor subtype have been demonstrated to potentiate supraspinal and spinal opioid-induced antinociception (Valverde et al., 1994; Wiesenfeld-Hallin et al., 1990; Zhuo et al., 1993). In addition this same CCK receptor subtype has been proposed to mediate neurotensin-induced pain facilitation from the $\mathrm{RMg}$, as the i.t. administration of the $\mathrm{CCK}_{\mathrm{B}}$ receptor antagonist, L-365260, dosedependently inhibited the pain facilitatory response induced by neurotensin microinjected into the RMg (Urban et al., 1996b). Furthermore, CCK has been demonstrated to influence antinociception induced by i.t. administration of norepinephrine, as i.t. proglumide decreases the antinociceptive response to this transmitter in the tail flick test (Watkins et al., 1985a).

Like CCK, substance P and TRH may also possess the ability to mediate not only hyperalgesia but also act as anti-analgesic transmitters. Intrathecal administration of substance $\mathrm{P}$ has been shown to dose-dependently enhance primary afferent (A and cfiber)-evoked firing of dorsal horn neurons, an effect that can be antagonized in a dosedependent biphasic manner by the i.t. administration of [D-Pro2, D-Trp7,9]-SP (DPDT) (a substance P receptor antagonist) (Kellstein et al., 1990). Similarly, Radhakrishnan and Henry (1991) have demonstrated that i.t. administration of CP-96,345, a selective NK-1 tachykinin receptor antagonist, can inhibit the response of dorsal horn neurons to noxious heat. In addition, antinociception in the tail flick test induced by the i.t. administration of norepinephrine and serotonin can be attenuated by the i.t. administration of substance $\mathrm{P}$ (Eide and Hole, 1991; 1992). Furthermore, the intrathecal administration of TRH has 
been shown to decrease morphine analgesia, while i.t. treatment with antibodies for TRH has been demonstrated to potentiate morphine analgesia (Watkins et al., 1986).

Lastly, dynorphin and neuropeptide FF (NPFF), are found within the spinal cord (Cruz and Basbaum, 1985; Kivipelto and Panula, 1991) and appear to be involved in modulation of nociception at this level. Both dynorphin (Schmauss and Herz, 1987) and NPFF (Tang et al., 1984), when administered intrathecally, reduce i.t. morphine-induced analgesia (i.e. they are anti-analgesic). In addition, antiserum for NPFF administered intrathecally has been shown to prevent morphine tolerance (Lake et al., 1991) and potentiate morphine analgesia (Kavaliers and Yang, 1989). Whereas, intrathecally administered dynorphin reduces i.c.v. morphine-induced antinociception in the tail flick test (Fujimoto et al., 1990).

\section{Modulation of nociception within the rostral ventromedial medulla}

The RVM is an important region in the descending nociceptive modulatory pathways. It is involved not only in the relay of descending messages to the spinal cord, but also serves as a modulator or integrator of nociceptive processing, as it receives input from multiple sites within the CNS involved in pain modulation and is capable of exerting facilitatory or inhibitory actions on spinal cord dorsal horn neurons involved in the transmission of pain information. In addition, the RVM contains receptors and terminals for multiple neurotransmitters that are differentially involved at multiple levels within the CNS as well as within the RVM in modulating nociception. Taking this into account, it is not surprising that nociceptive modulation within the RVM is very complex. 
Electrical stimulation of the RVM has been demonstrated to produce bipolar effects on nociceptive modulation. That is electrical stimulation of the RVM at low intensities results in a facilitation of the tail flick reflex (reduction in TFL) and an increase in spinal unit responses to noxious heat, whereas stimulation at higher intensities results in an inhibition of the reflex and a reduction in spinal unit response to noxious heat (Zhuo and Gebhart, 1990b; 1991; 1992; 1997). Further characterization of these responses has demonstrated that they are mediated by the RVM through different spinal cord projections. The facilitatory actions appear to be conveyed to the spinal cord via the ventral/ventrolateral funiculi and can be attenuated by intrathecal administration of the 5HT receptor antagonist methysergide(Zhuo and Gebhart, 1991; 1997). In contrast, the inhibitory actions appear to be conveyed to the spinal cord via the DLF (Zhuo and Gebhart, 1997).

These same facilitatory and inhibitory circuits appear to also be activated following the administration of low and high doses (respectively) of glutamate (Zhuo and Gebhart, 1990b; 1991). The excitatory amino acid glutamate is found in projections from the PAG to the RVM (Wiklund et al., 1988), and is involved in mediating nociception within the RVM as well as opioid-induced analgesia from the PAG (Spinella et al., 1996). Antinociception in the tail flick test following the administration of glutamate (high dose) into the Gi and Rgc $\alpha$ can be attenuated by the intrathecal administration of atropine (a non-selective acetylcholine muscarinic receptor antagonist), methysergide, and phentolamine (an alpha adrenoceptor antagonist), but not by naloxone (Zhuo and Gebhart, 1990b). However, antinociception produced by glutamate injection into two other nuclei within the RVM show the involvement of different neurotransmitter systems, 
as the antinociceptive effect in the Rpg can be decreased by intrathecal phentolamine and phenoxybenzamine, but is not affected by methysergide, and antinociception in the $\mathrm{RMg}$ is decreased by i.t. methysergide but not phentolamine (Satoh et al., 1983). Furthermore, facilitation of the tail flick test following the application of glutamate (low dose) into these same nuclei ( $\mathrm{Gi}$ and $\operatorname{Rgc} \alpha$ ) can be attenuated by intrathecal methysergide but not atropine, xylamidine (a selective $5 \mathrm{HT}_{2}$ receptor antagonist) or MDL-72222 (a selective $5 \mathrm{HT}_{3}$ receptor antagonist) (Zhuo and Gebhart, 1991).

The physiological basis for the RVM having differential effects on nociception may be accounted for by the fact that three distinct classes of neurons ("on-cells", "offcells" and "neutral cells") exist within the RVM and can be identified based upon their changes in activity preceding and during the execution of noxious stimulus-evoked reflexes (i.e. tail flick test) (Fields et al., 1983a; 1988; 1991). Cells labeled "on-cells" demonstrate a sudden increase in firing rate just prior to the occurrence of the tail flick reflex and therefore cells of this class are said to exert a facilitatory effect on nociceptive transmission. Cells labeled "off-cells" are characterized by an abrupt pause in discharge rates just prior to the reflex response to the noxious stimulus and are believed to inhibit nociceptive responses. Lastly, cells labeled "neutral cells" display no change in their discharge rates associated with the reflex response and they are therefore generally not considered to be involved in nociceptive processing. Neurons from all three classes have been demonstrated to project to the spinal cord (Vanegas et al., 1984a), and no apparent difference in the topography of their terminal fields within the cord can be distinguished, as both "on-“" and "off-cells” project to laminae I, II and V (Fields et al., 1995). Moreover, both "on-cells" and "off-cells" can be antidromically activated from the spinal 
cord, further suggesting that both cell types are involved in descending modulation (Vanegas et al., 1984b).

Several observations involving opioid analgesia (OA) and withdrawal support the fact that "on-cells" facilitate and "off-cells" inhibit pain transmission. First, administration of morphine, in doses significant enough to produce antinociception, inhibits “on-cell” firing (Barbaro et al., 1986; Cheng et al., 1986). Second, "off-cells”, but no other cell type within the RVM, become active following the administration of antinociceptive doses of morphine either systemically (Fields et al., 1983b) or into the PAG (Cheng et al., 1986). Furthermore, activation of "off-cells" has been demonstrated to be a critical step in the analgesic actions of opioids (Heinricher et al., 1994; Heinricher and Tortorici, 1994). Moreover, hyperalgesia that is associated with reversal of morphine analgesia (i.v.) by naloxone results in "on-cell” activation (Bederson et al., 1990) and can be attenuated by injecting a local anesthetic into the RVM (Kaplan and Fields, 1990).

The identification and characterization of these cell classes within the RVM coupled with the ability to measure their neuronal responses to iontophoretically applied substances (neurotransmitters) has provided us with the ability to more succinctly define the role of each of the neurotransmitters contained within the RVM. In addition, results from these types of electrophysiological experiments in conjunction with the results from studies measuring the effect of microinjection of these same transmitters into the RVM on behavioral responses to noxious stimuli has allowed us to better understand the neuronal circuitry of the RVM, and its role in modulating nociception. However, these insights into the circuitry of the RVM have not made things more simplistic, but rather have just started to unravel a very complicated and complex system. 
One of the first questions we can say has been addressed and answered was what is responsible for causing the "off-cell pause" in response to noxious stimulation? The most obvious answer to this question was that there had to be some input to the "offcells" that is inhibitory in nature and that this input must be activated by noxious stimulation. Therefore, attention was turned to the known inhibitory neurotransmitters that are found within the RVM, namely GABA and the endogenous opioids, as cell bodies, receptors and terminals for GABA, the enkephalins and dynorphin are present within the RVM (see review by Fields et al., 1991 for references). However, studies have provided information that not only indicates that endogenous opioids do not play a role in this process, but actually act in the opposite manner (i.e. excite "off-cells"). If opioids were, in fact, the cause of this "off-cell" pause, then microinjection of opioids should enhance responses to noxious stimulation. However, microinjection of morphine or opioid peptides into the RVM produces antinociception and therefore prevents the "off-cell” pause or the activation of "on-cells" (Azami et al., 1982; Dickenson et al., 1979; Jensen and Yaksh, 1986; Levy and Proudfit, 1979). This observation coupled with the fact that iontophoretically applied morphine has an inhibitory effect on "on-cells" but no direct effect on "off-cells" (Heinricher et al., 1992) has eliminated the opioids as possible direct mediators of the "off-cell" pause. On the other hand, a number of other studies have demonstrated that GABA does, in fact, mediate this process and that there is a GABA mediated tonic inhibition of these cells. Administration of $\mathrm{GABA}_{\mathrm{A}}$ receptor agonists into the $\mathrm{RMg}$ results in a facilitation of nociceptive response to noxious stimulation, and administration of $\mathrm{GABA}_{\mathrm{A}}$ receptor antagonists into this same site results in antinociception (Drower and Hammond, 1988). In addition, it has been demonstrated 
that iontophoretically applied $\mathrm{GABA}_{\mathrm{A}}$ receptor antagonists inhibit the "off-cell pause" induced by the tail flick test (Heinricher et al., 1987), and that terminals containing GABA make contact with identified "off-cells" (Mason et al., 1990). The fact that opioids do not directly result in the "off-cell pause" does not mean that they do not have any influence on this process. It has been proposed by Fields and coworkers (1991) that opioids may exert their antinociceptive effect through a process of disinhibition. That is, it is possible that GABA containing "on-cells" exist and serve to inhibit "off-cells" when activated (i.e. activation of "on-cells" results in an inhibition of "off-cells). Opioids, therefore, by inhibiting "on-cell" activation may inhibit the inhibitory effect exerted by GABA on "off-cells" and lead to their excitation (see figure 2).

A number of RVM neurons contain serotonin (5HT) (Bowker et al., 1981b; 1983) and a large percentage of these ( $70 \%$ ) have been found to project to the spinal cord (Bowker et al., 1982a; 1982b). While much of the 5HT in the RVM appears to be produced intrinsically, the RVM also receives serotonergic projections from the PAG as mentioned earlier (Beitz, 1982a; 1982c), which supports its involvement in descending pathways rostral to the RVM. The role of 5HT in nociceptive modulation at the level of the RVM stems from several important observations. Microinjection of 5HT into the RVM produces antinociception (Inase et al., 1987; Llewelyn et al., 1983), which suggests that 5HT can excite "off-cells" or inhibit "on-cells". However, electrophysiological studies examining the effect on iontophoretically applied 5HT on RVM neurons are not conclusive as to its role in either exciting "off-cells" and/or inhibiting "on cells", as it has been demonstrated that 5HT can excite and inhibit the neuronal activity of all 3 classes of cells within the RVM in a biphasic manner (Roychowdhury and Heinricher, 1997). The 


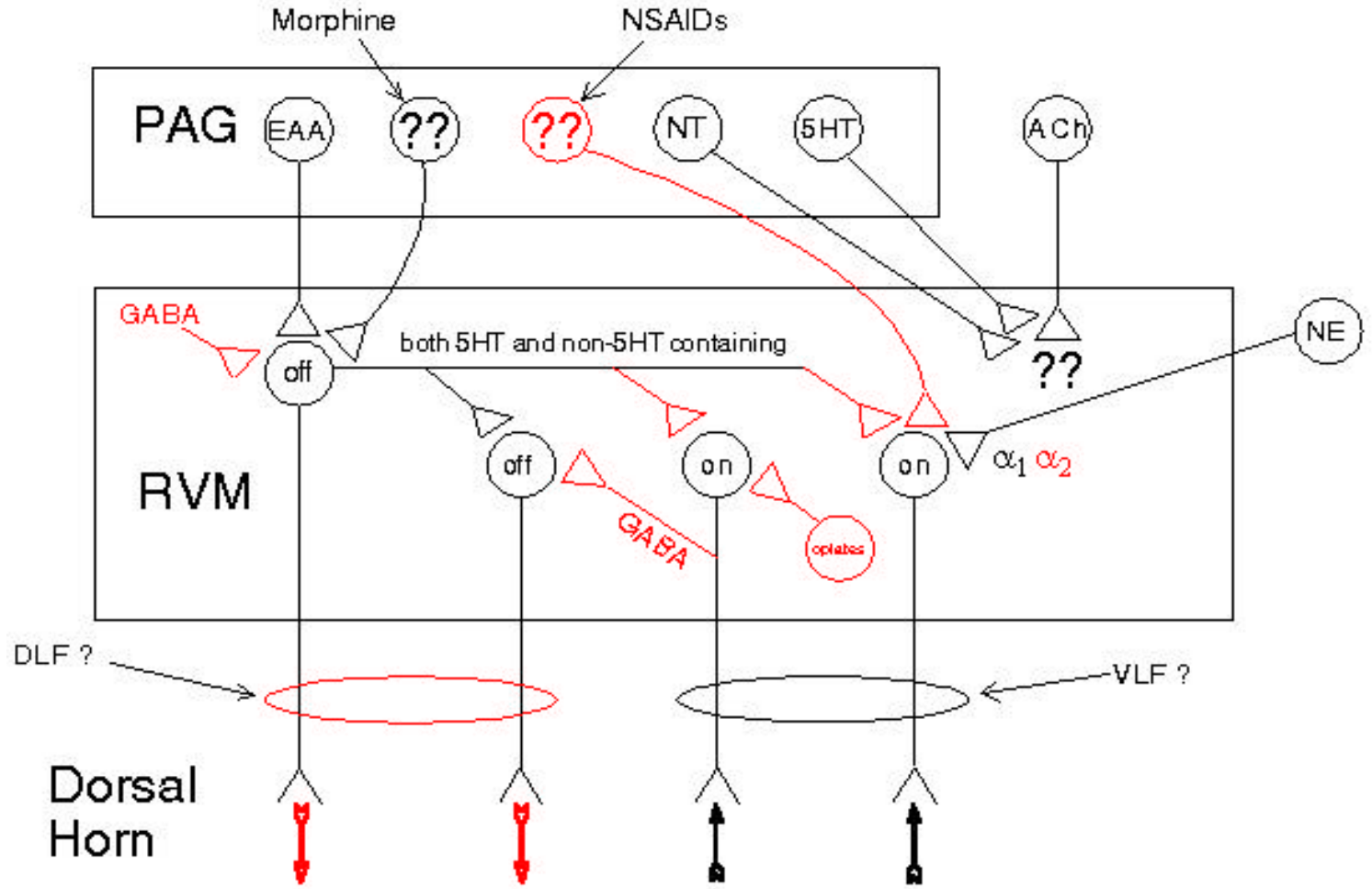


Figure 2. Illustration represents hypothesized connections and descending pain modulation as discussed in the text pertaining to the RVM. The illustration is based on the model of descending pain modulation reported by Fields and Coworkers, 1991. Net inhibitory effects are outlined in red. PAG-RVM neurons contain excitatory amino acids (EAA), serotonin (5HT) and neurotensin (NT). EAA projections from the PAG excite "off-cells" within the RVM. The "offcells", which appear to project through the DLF, in turn have a net inhibitory effect on nociceptive transmission at the level of the spinal cord dorsal horn. Microinjection of morphine into the PAG appears to excite these same "off-cells" (thus preventing the "off-cell" pause), whereas microinjection of NSAIDs into the PAG results in an inhibition of "on-cells". The "on-cells", which appear to project through the ventral/ventrolateral funiculi (VLF), in turn have a net facilitatory effect on nociceptive transmission at the level of the spinal cord. In addition to projections from the PAG, the RVM also receives cholinergic (ACh) and noradrenergic (NE) input. NE can evoke both excitation and inhibition of "on-cells", that is mediated via $\alpha_{1}$ - and $\alpha_{2}$-adrenoceptors respectively. Within the RVM "on-cells" appear to be inhibited by opiate containing cells as well as by activation of "off-cells" through both serotonergic and non-serotonergic mediated processes. Whereas, "off-cells" appear to be inhibited by GABA containing cells and by activation of GABA containing "on-cells". 
rationale for these dual effects of 5HT on RVM neurons has been proposed by Fields and coworkers (1991), and they suggest that it is possible that "off-cells" releasing 5HT could be simultaneously activating other "off-cells" while inhibiting "on-cells". In addition to having the ability to modulate these different neurons, serotonin also appears to be contained within "off-cells" of the RVM that project to the spinal cord. A number of experiments support this contention. (1) As stated previously SPA from the RVM can be attenuated by depleting spinal 5HT (Rivot et al., 1980), or by the intrathecal administration of 5HT receptor antagonists (Hammond and Yaksh, 1984; Jensen and Yaksh, 1984). (2) Morphine microinjection into the PAG causes the release of 5HT in the spinal cord (Yaksh and Tyce, 1979). (3) Only "off-cells" and no other cell type becomes activated following morphine administration into the PAG (Cheng et al., 1986). Regardless of whether 5HT excites or inhibits both "on-" and "off-cells" it is clear that it plays a role in nociceptive modulation at this level. In fact, 5HT appears to mediate opioid analgesia within the RVM, as administration of morphine into the PAG increases extracellular 5HT concentration in the RMg (Long et al., 1984), and morphine analgesia from the PAG can be inhibited by methysergide, ritanserin (a $5 \mathrm{HT}_{2 \mathrm{~A}}$ receptor antagonist) and ICS205930 (a 5HT 3 receptor antagonist) (Kiefel et al., 1991; 1992) administration into the RVM. Interestingly, while 5HT mediated processes in the RVM have been demonstrated to play a role in OA (see review by Fields et al., 1991) they do not appear to play role in SPA from supraspinal sites, as SPA from the PAG is not blocked by administration of 5HT receptor antagonists in the RVM (Aimone and Gebhart, 1986). Therefore, the involvement of serotonergic processes within the RVM may unmask one subtle difference between OA and SPA. However, a more recent study done by Gao and 
coworkers (Gao et al., 1998), presents data that are in direct contrast to this contention. In that study the investigators showed that physiologically identified serotonergic cells within the $\mathrm{RMg}$ are not involved in mediating systemic morphine analgesia, as they showed no alteration in their discharge rate in cases were analgesia occurred to morphine. However, one shortcoming in this study was of the inability of the researchers to monitor the discharge from physiologically characterized serotonin containing "off cells", as all of the characterized "off cells" that they studied lacked serotonin immunoreactivity. Therefore, it still remains a possibility that serotonin containing "off cells" may mediate OA.

Norepinephrine has also been shown to play a role in nociceptive modulation at the level of the RVM. Both "on-" and "off-cells" have been demonstrated to be targets of descending noradrenergic projection neurons (Meng et al., 1997). Moreover, both facilitatory and inhibitory effects on nociception have been demonstrated for noradrenergic compounds within the RVM, and appear to involve different receptor subtypes. Administration of prazosin (an $\alpha_{1}$ adrenoceptor antagonist) produces antinociception in the tail flick test (Sagen and Proudfit, 1985), while injection of phenylephrine (an $\alpha_{1}$ adrenoceptor agonist) produces facilitation of the tail flick reflex (Heinricher et al., 1988). In addition, it was demonstrated that administration of clonidine (an $\alpha_{2}$ adrenoceptor agonist) produces antinociception in the same model (Heinricher et al., 1988). Accordingly, administration of norepinephrine has been shown to have both excitatory and inhibitory effects on RVM neurons (Behbehani et al., 1981; Willcockson et al., 1983). A more recent study done by Heinricher and coworkers (1988) has illustrated that iontophoretically applied norepinephrine increases "on-cell" 
firing through an $\alpha_{1}$ adrenoceptor mediated process, and application of clonidine results in an inhibition of "on-cell" activity. Therefore, it appears that the antinociceptive effects of norepinephrine are mediated by $\alpha_{2}$ adrenoceptors, while the pain facilitatory effects are mediated via the $\alpha_{1}$ adrenoceptor.

Cholinergic agonists as well as neurotensin have similar effects to that of noradrenergic agents. That is they, too, have been demonstrated to produce facilitation and inhibition of nociception within the RVM. Iontophoretically applied acetylcholine excites RVM neurons and microinjection of carbachol into the RMg has been demonstrated to produce antinociception (Brodie and Proudfit, 1986). In contrast, microinjection of nicotine into the RVM produces a facilitation of the tail flick reflex (Sagen and Proudfit, 1985). In a manner similar to that of glutamate, neurotensin's effect on pain modulation within the RVM is dose-dependent and appears to involve different neurotransmitter systems as well as spinal cord projections. That is, low doses of neurotensin microinjected into the RVM result in a facilitation of tail flick reflex and appears to be mediated by CCKergic processes at the level of the spinal cord, as the response can be completely inhibited by i.t. administration of the non-selective CCK receptor antagonist proglumide (Urban et al., 1996b). Whereas, microinjection of higher doses of neurotensin into the RVM results in antinociception in the same model (Fang et al., 1987; Urban and Smith, 1993), an effect that is potentiated by the i.t. administration of proglumide (Urban et al., 1996b).

In addition to the aforementioned neurotransmitters, which have been identified within the RVM, studies have also implicated the possible involvement of other neurotransmitters. Martin and coworkers (1998) have demonstrated that administration 
of the cannabinoid agonists WIN55,212-2 and HU210 into the RVM produces antinociception in the tail flick test. Another study has shown that the administration of orphanin FQ (also termed nociceptin) exerts an anti-opioid effect, as it suppresses the firing of all classes of cells within the RVM and inhibits opioid-induced activation of “off-cells"(Heinricher et al., 1997).

Lastly, a number of studies centered around the RVM have focused on the role of this region in the development of hyperalgesia (as a result of inflammation) and sensitization to noxious stimuli associated with neuronal injuries (i.e. neuropathic pain). This stems from experiments that demonstrate that mechanical and thermal hyperalgesia, associated with the application of mustard oil (an irritant that produces inflammation) onto the paw of rats, can be inhibited by electrolytic lesion of the RVM (Urban et al., 1996a) or by the injection of a local anesthetic (lidocaine) into this same region (Pertovaara, 1998). Furthermore, a recent study shows that non-steroidal antiinflammatory drugs (NSAID's) may produce analgesia centrally through processes within the RVM, and that these agents inhibit the "off-cell pause" and "on-cell" activation (Tortorici and Vanegas, 1995). Similarly, lidocaine injection into the RVM has been demonstrated to attenuate allodynia (pain due to a stimulus that does not normally provoke pain) in neuropathic rats (Pertovaara et al., 1996).

\section{INTRODUCTION AND RATIONALE FOR THE PROJECT}

\section{Neurotensin's role in pain modulation}

Neurotensin is a tridecapeptide (p-Glu-Leu-Tyr-Glu-Asn-Lys-Pro-Arg-Arg-Pro- 
Tyr-Ile-Leu) that was originally isolated (Carraway and Leeman, 1973a; Kitabgi et al., 1976), sequenced (Carraway and Leeman, 1975b; Carraway et al., 1978) and characterized (Carraway and Leeman, 1976) from bovine hypothalamus extracts. It is distributed throughout the central nervous system (Carraway and Leeman, 1976; Uhl and Snyder, 1977a; 1977b), gastrointestinal tract (Carraway and Leeman, 1976; Schultzberg et al., 1980; Sundler et al., 1977), cerebrospinal fluid, adrenals, pancreas, and plasma (Fernstrom et al., 1980). Neurotensin has been demonstrated to fulfill the major criteria of a neurotransmitter or neuromodulator as (1) it is distributed in nerve cells, fibers and terminals throughout the brain and spinal cord (2) binds to specific, high affinity receptors in the CNS (3) effects the electrical activity of neurons in several brain areas (4) is associated with producing a wide range of biological functions and behavioral effects including alterations in locomotion, feeding, thermoregulation, muscle tone, gastric cytoprotection, blood pressure, endocrine function, learning, memory, antinociception and it may also play a role in some psychiatric disorders and (5) is inactivated by brain neuropeptidases (see review by Levant and Nemeroff, 1988). Although the peptide can produce a number of pharmacological effects within the central nervous system, studies have demonstrated that a major action of neurotensin may be to modulate pain transmission. Administration of neurotensin (i.c.v. or i.c.) has been shown to produce antinociception in a variety of test paradigms, including the hot plate test, acetic acid writhing test (Clineschmidt and Mcguffin, 1977), tail immersion test (Nemeroff et al., 1979), and the foot shock test (van Wimersma et al., 1982).

Anatomical and biochemical studies have shown that high concentrations of neurotensin are found in the periaqueductal gray region of the midbrain (Cooper et al., 
1981; Ghatei et al., 1984; Manberg et al., 1982). In addition, studies have demonstrated the existence of neurotensinergic projections originating in cells of the ventrolateral part of the periaqueductal gray/nucleus and terminating on cells located in the nucleus raphe magnus (RMg) in the rostroventral medial medulla (Beitz, 1982a; 1982b). Moreover, neurotensin microinjection into the PAG in rats has been found to increase the activity of RVM neurons, and induce a dose-dependent increase in reaction thresholds in both the hot plate and tail flick tests, an effect which can be attenuated by radiofrequency-induced lesions of the RMg (Behbehani and Pert, 1984).

Within the RVM, neurotensin's role in pain modulation is complicated, as it has been demonstrated that the peptide has dose-dependent bipolar effects on nociception. That is, neurotensin functions not only to inhibit pain transmission (Behbehani, 1992; Clineschmidt et al., 1979; Fang et al., 1987; Kalivas et al., 1982), but also serves to facilitate pain transmission (Smith et al., 1997; Urban and Smith, 1993; 1994; Urban et al., 1996b) in a dose-dependent manner. Low doses of neurotensin (pmol range) microinjected into the nucleus raphe magnus $(\mathrm{RMg})$ region of the $\mathrm{RVM}$ promote pain facilitation, reducing tail flick latency (Urban and Smith, 1993), facilitating spinal nociceptive unit responses (wide-dynamic-range and nociceptive-specific) to noxious heat (Urban and Gebhart, 1994; 1997) and increasing visceromotor responses to noxious visceral stimulation (Urban et al., 1996c). Microinjection of higher doses (nmol range) of neurotensin into the RMg has a pain inhibitory action, increasing tail flick (Fang et al., 1987; Urban and Smith, 1993) and hot plate latency and decreasing writhing induced by acetic acid (Clineschmidt et al., 1979).

In the past, studies examining the function of neurotensin in producing these 
effects on nociception have been limited by the non-availability of a selective neurotensin receptor antagonist. While many studies employed [D-Trp $\left.{ }^{11}\right]$-neurotensin, a partial neurotensin receptor agonist, to examine neurotensin receptor-mediated effects in these processes, the dosage ranges that could be used were limited by the intrinsic activity (ability to produce agonistic effects at higher concentrations) of this compound. Therefore, the development of SR 48692 \{2-[(1-(7-chloro-4quinolinyl)-5-(2,6dimethoxyphenyl)pyrazol-3-yl)carbonylamino]tricyclo(3.3.1.1. ${ }^{3.7}$ )decan-2-carboxylic acid\} (see figure 3 for structure), a selective non-peptide neurotensin receptor antagonist which lacks intrinsic activity and fully displaces ${ }^{125}$ I-labeled neurotensin binding (Gully et al., 1993), has provided researchers with a useful and much-needed tool to pharmacologically distinguish these neurotensin receptor-mediated effects. In addition, this antagonist has been demonstrated to inhibit a number of neurotensin-induced effects in vivo and in vitro. It has been shown to block neurotensin-evoked dopamine release in guinea pig striatal slices, neurotensin-induced calcium mobilization in HT-29 cells, neurotensin-induced turning behavior in mice (Gully et al., 1993), as well as neurotensinmediated IP1 and cGMP formation in HT-29 and N1E115 cells (Oury-Donat et al., 1995).

The use of this antagonist, SR 48692, in subsequent studies has provided a large amount of important information about neurotensin's role in pain mediation. It appears that neurotensin-induced pain facilitation physiologically predominates, since SR 48692 injected alone into RVM of rats produces a slight antinociceptive response in the tail flick test (Smith et al., 1997). Moreover, it appears that at least two different and distinct neuronal pathways exist and function to modulate the inhibitory and facilitatory actions 
of neurotensin at the level of the spinal cord. In support of this contention, Urban and Gebhart (1997) observed that inhibition of spinal unit responses to noxious heat produced by microinjection of neurotensin (300-3000 pmol) into the RVM could be decreased by ipsilateral or contralateral lesion of the DLF and completely blocked by microinjection of SR 48692 into the same site, whereas facilitation of spinal unit responses resulting from injection of a lower dose of neurotensin $(0.03 \mathrm{pmol})$ remained unaffected following bilateral transection of the DLF and microinjection of SR 48692 (only one concentration tested, $30 \mathrm{fmol}$ ). Furthermore, additional studies have shown that the pain facilitatory actions of neurotensin in the RVM can be blocked by the intrathecal administration of CCK receptor antagonists (Urban et al., 1996b), whereas neurotensin-mediated antinociception is potentiated by the i.t. administration of proglumide, a non-selective CCK receptor antagonist (Urban et al., 1996b).

The fact that neurotensin has a dose-dependent bipolar effects on pain modulation within the RVM, coupled with the fact that these modulatory actions appear to be mediated through separate neuronal projections, suggests a basis for involvement of multiple neurotensin receptor subtypes with varying affinity for the peptide in pain modulation. In fact, both high and low affinity neurotensin receptors, NTR1 (Tanaka et al., 1990; Vita et al., 1993) and NTR2 (Chalon et al., 1996), have been cloned to date. The low affinity receptor, NTR2 (unlike NTR1) recognizes levocabastine (a potent histamine $\mathrm{H} 1$ receptor antagonist) with high affinity and levocabastine inhibits the binding of neurotensin to this receptor (Chalon et al., 1996; Schotte et al., 1986). While very little work has been done to classify these two receptors with regard to their physiological effects, even less work has been done to discriminate between these two 


Figure 3. Illustration representing the chemical structure of the two non-peptide neurotensin receptor antagonists SR 48692 and SR 142948A. 
receptor subtypes in pain modulation.

A recent study using antisense oligodeoxynucleotides (ODNs) for the cloned NTR1 and NTR2 receptors illustrated that the antinociceptive effect (writhing test) of neurotensin in mice following i.c.v. administration is mediated solely by the NTR2 receptor (Dubuc et al., 1999). In direct contrast to this observation, Smith and coworkers (1997) demonstrated that the antinociceptive (tail flick test) effect of neurotensin within the RVM of rats is insensitive to levocabastine administration into this same site, which indicates that the NTR2 receptor is not involved at all in producing this response. While these two studies provide observations that are in direct contrast to one another with regard to the involvement of the NTR2 receptor in mediating neurotensin antinociception, it is conceivable that neurotensin's antinociceptive effects are mediated by different receptor subtypes across species, pain models and supraspinal sites (i.e. NTR2 in the PAG following i.c.v. administration and NTR1 within the RVM).

In regards to neurotensin-mediated pain facilitation, Smith and coworkers (1997) were able to indirectly demonstrate that this response of neurotensin is insensitive to levocabastine as well, since they did not observe any enhancement of the antinociceptive response to neurotensin in the presence of levocabastine. The investigators were unable to directly examine the effect of levocabastine on the pain facilitatory response of neurotensin, as in their test model (tail flick test) they were unable to resolve the pain facilitatory response of neurotensin reliably. The authors did address this issue. They stated that although the administration of a low dose (30 pmol) of neurotensin into the RVM has been previously demonstrated to produce a brief decrease in tail flick latency in a significant number of rats (Urban and Smith, 1993), the ability to demonstrate the 
hyperalgesic effect in subsequent studies with the tail flick test had been variable, and may not be expressed in a given group of rats (Smith et al., 1997). In addition, the investigators proposed that one reason for this variability in producing pain facilitation may be related to the minimal sensitivity of the tail flick test itself in resolving druginduced decreases in the threshold reaction, and thus, consistent expression of the painfacilitatory effect of neurotensin may require that the animal express some pain inhibitory tone. Support for this contention stems from studies examining another neuropeptide, $\beta$ endorphin, which have demonstrated that the pain facilitatory role for this opioid agonist is only distinguishable when the threshold to responding in the tail flick test is increased by stressing the rats (Hawranko et al., 1996a; 1996b). Regardless, it is apparent that any future evaluations of the pain facilitatory response of neurotensin may need to be done in a model that is able to better distinguish this action of the peptide.

Within the RVM, SR 48692 was shown to promote antinociception from this ineffective dose (30 pmol) of neurotensin, and to attenuate the antinociceptive response to a high concentration of neurotensin $(10 \mathrm{nmol})$ in a triphasic manner (Smith et al., 1997). Low doses (fmol range) of SR 48692 attenuate the antinociceptive response to neurotensin, while higher concentrations $(0.03-0.3 \mathrm{pmol})$ of SR 48692 reverse the inhibition, presumably by blocking the pain facilitatory component of neurotensin's action as this dose range is the same that resulted in antinociception from the low doses of neurotensin. A second inhibitory phase occurred as the concentration of SR 48692 was increased to doses in the high pmol range (3-300 pmol). However, this second inhibition remained incomplete even when the dose was increased over 100 fold, indicating a portion of neurotensin's antinociceptive action may be insensitive to SR 
48692. The finding that SR 48692 produces a triphasic inhibition of the response is not atypical, as SR 48692 triphasically inhibits other physiological actions of neurotensin (Poncelet et al., 1994). In addition, the inability of SR 48692 to produce a complete blockade of other neurotensin responses has also been demonstrated prior to this study (Steinberg et al., 1994). Taken together, these data indicate that not only are there multiple neurotensin receptors involved in producing pain inhibition that SR 48692 antagonizes, but also that a population of neurotensin receptors appears to exist that is insensitive to this antagonist. In another study, it was demonstrated that SR 48692 has a greater affinity for the high- as opposed to the low-affinity neurotensin binding site (Gully et al., 1993). These data, coupled with the finding that levocabastine does not effect the antinociceptive response to neurotensin, indicate that all of the effects of SR 48692 on the antinociceptive action of neurotensin, within the RVM of rats, are mediated through the NTR1 neurotensin receptor, or more likely through multiple subtypes of this neurotensin receptor. The fact that SR 48692 is selective for one type of neurotensin receptor is not surprising, as SR 48692 has been shown to discriminate between these neurotensin receptors in other studies (Steinberg et al., 1994). Further evidence for the existence and involvement of multiple neurotensin receptor subtypes in mediating antinociception comes from studies done by Labbé-Jullié and coworkers (1994). In this study seven metabolically stable neurotensin analogs were tested in vivo for their hypothermic and analgesic (tail flick test) effects after i.c.v. injection in the mouse, it was found that the analogs exhibited relative potencies that were completely different from those obtained in in vitro binding studies for the NTR1 neurotensin receptor. In fact, it was concluded that the hypothermic and analgesic actions of neurotensin in mice appear 
to be mediated through a receptor whose pharmacological properties are distinct from those of the NTR1 neurotensin receptor. The existence and involvement of multiple neurotensin receptors in pain modulation is only one possible explanation for the results of these studies, and it should be noted that additional pharmacological and behavioral studies need to be done to support or reject this hypothesis.

Recently, a second potent and selective non-peptide neurotensin receptor antagonist, SR 142948A [2-\{5-(2,6-dimethoxyphenyl)-1-(4-(N-(3-dimethyl aminopropyl)-N-methylcarbamoyl)-2-isopropyl-phenyl)-1H-pyrazole-3-carbonyl)amino \}adamantane-2-carboxylic acid, hydrochloride], was developed which shares many characteristics of the structurally related compound, SR 48692 (see figure 3 for structure). SR 142948A lacks intrinsic activity, has good bioavailability and penetrates into the CNS. Like its predecessor, SR 142948A antagonizes neurotensin-mediated signal transduction (IP1 formation and calcium mobilization) (Oury-Donat et al., 1995; Gully et $a l ., 1997)$ and dopamine-independent turning behavior induced by unilateral intrastriatal neurotensin administration (Gully et al., 1993; 1997; Poncelet et al., 1994). However, in contrast to SR 48692 (Dubuc et al., 1994), SR 142948A appears to block neurotensininduced hypothermia and analgesia following i.c.v. neurotensin administration (Gully et al., 1997). Further differences between SR 48692 and SR 142948A were observed in a study comparing their ability to block neurotensin-induced stimulation of striatal dopamine release (Heaulme et al., 1997). In this study, SR 48692 blocked the neurotensin-induced enhancement of $\mathrm{K}^{+}$evoked dopamine release but had no effect on neurotensin's enhancement of electrically evoked dopamine release, whereas SR 142948A was effective in blocking both. Thus, it appears that the antagonist may 
discriminate different subtypes of neurotensin receptors.

However, in antinociceptive studies already performed using this antagonist this trend is not apparent. It appears that both antagonists have similar effects upon pain modulation following systemic administration, as both SR 48692 and SR 142948A were found to potentiate the antinociceptive response to systemic morphine. The $\mathrm{ED}_{50}$ values (95\% CI) were $0.020(0.011-0.03)$ and $0.086(0.005-1.47) \mathrm{mg} / \mathrm{kg}$ respectively, which represents the dose of each of the two compounds required to produce 50 percent of the maximum response in an animal (manuscript in preparation). However, no statistically significant difference in potency was observed. This observation is surprising, as it is in direct contrast to what other studies would predict. SR 142948A has a greater relative affinity, than SR 48692, in binding assays for both the high- and low-affinity neurotensin receptors (Gully et al., 1997). Furthermore, SR 142948A appears to be more potent than SR 48692 in its ability to antagonize neurotensin-induced IP1 production in HT29 cells, intracellular calcium mobilization in CHO cells (Gully et al., 1997) and neurotensininduced cardiovascular effects (Schaeffer et al., 1998). Moreover, in contrast to SR 48692, which resolved a bell-shaped dose-response relationship in regard to its ability when administered systemically to enhance the antinociceptive effect of systemic morphine (Smith et al., 1997), SR 142948A only results in a dose-dependent enhancement of the effect of morphine with its effectiveness not being diminished at higher doses.

\section{Role of neurotensin in opioid-mediated pain modulation}

Systemic and supraspinal administration of opioids not only results in the 
activation of descending pain inhibitory processes, but also activates descending pain facilitatory processes (Hawranko and Smith, 1997; Maier et al., 1992; Watkins et al., 1985a). Thus, while the net effect of the administration of opioids is usually pain inhibition, pain facilitatory processes appear to attenuate this effect, thus decreasing their antinociceptive potency (Hawranko and Smith, 1997). Furthermore, the balance between opioid-induced pain facilitation and inhibition appears therapeutically significant, since evidence suggests that this balance may be tipped in favor of pain facilitation under selective environmental conditions, such as stress or anxiety (Goodman et al., 1995; Maier et al., 1992; Rothman, 1992).

Recently, it was demonstrated that neurotensinergic neuronal projections from the PAG to the RVM are specifically involved in opioid activated nociception (Smith et al., 1997; Urban and Smith, 1993). These studies have shown that an antagonistic dose of [D $\operatorname{Trp}^{11}$ ] neurotensin, neurotensin antiserum, or SR 48692 microinjected into the RVM of rats over a wide dose range, results in a potentiation of the analgesic response (tail flick test) of morphine sequentially administered to the PAG (Smith et al., 1997; Urban and Smith, 1993). In addition, studies done by Smith and coworkers (1997) demonstrated that antagonism of these same neurotensin receptors within the RVM by SR 48692, also results in the potentiation of the antinociceptive effect (tail flick test) of systemically administered morphine as well. Moreover, the data suggest that a significant portion of the neurotensin neurons activated by the PAG administration of morphine function to oppose the antinociceptive action of the opioid and should be classified as functionally anti-analgesic (Maier et al., 1992). Thus, it appears that not only is neurotensin involved in opioid analgesia, but understanding the mechanisms underlying the peptide's anti- 
analgesic effects may serve to produce drugs that optimize the analgesic effectiveness of narcotics and provide better pharmacological alternatives to the therapeutic management of pain.

\section{SUMMARY AND HYPOTHESES}

It is known that a balance exists between pain facilitation and pain inhibition. Regulation of this balance in the body is very complicated and appears to involve both endogenous and extraneous input. More importantly, this balance appears to be very sensitive not only to the physiological basis of injury or disease, but also to the psychological and emotional consequences of these conditions, the administration of pharmacotherapeutic agents and environmental conditions (e.g. stress). Therefore, understanding the neuronal systems involved and how they can be manipulated under various conditions has become one of the major goals of pain research.

For this reason, several recent studies have directly examined the physiological and pharmacological significance of the actions of neurotensin, a neurotransmitter found within endogenous descending pain modulatory pathways which appears to be involved directly in both pain inhibitory and facilitatory processes contributing to this balance. However, these initial investigations employing the two available neurotensin receptor antagonists, SR 48692 and SR 142948A, have demonstrated that these antagonists may have differential and selective affinity for the known neurotensin receptors. Furthermore, a study comparing the ability of these antagonists to potentiate morphine analgesia 
suggests that the two antagonists may have different underlying mechanisms (manuscript in preparation). The current set of experiments were designed to evaluate and compare the ability of these two receptor antagonists for their ability to alter neurotensin mediated pain facilitation and inhibition within the RVM. The comparisons were made under both normal physiological states as well as under conditions when the balance between pain facilitation and inhibition has been altered, such as following the administration of opioids or in the face of some environmental challenge (e.g. stress). Furthermore, the results from preliminary studies comparing these two antagonists suggest that they may have differential actions on neurotensin mediated processes under these conditions. Therefore, the results from these studies may serve to pharmacologically distinguish involvement of specific neurotensin receptor subtypes mediating their action and thus the action of neurotensin within the RVM. In summary, the following experiments were conducted to test the hypotheses that (1) the mechanisms underlying the ability of SR 142948A to potentiate morphine analgesia are different from those as previously described for SR 48692 (Smith et al., 1997), and that (2) the ability of SR 142948A to selectively block neurotensin-mediated antinociceptive and pain facilitatory effects differs from that of SR 48692 due to different receptor profiles of the antagonists. 


\section{MATERIALS AND METHODS}

\section{Supraspinal microinjection preparations and procedures.}

Male Sprague-Dawley rats weighing 325-350g from Hilltop Lab Animals, Scottsdale, PA, were prepared with indwelling 23 gauge hypodermic stainless steel tube guide cannulae purchased from Small Parts Inc., Miami Lakes, FL. These cannulae were stereotaxically (David Kopf stereotaxic apparatus) implanted in rats anesthetized with Ketamine hydrochloride (120-160 mg/kg-i.p.) and supplemented with atropine $(0.4$ $\mathrm{mg} / \mathrm{kg}$ i.p. $)$ to reduce secretions. Lidocaine $(0.15 \mathrm{ml}$ of a $1 \%$ solution $)$ was infiltrated under the skin on the skull to provide local anesthesia at the site of incision. In some experiments, a combination of Xylazine hydrochloride $(5-10 \mathrm{mg} / \mathrm{kg})$ and Ketamine hydrochloride $(40-80 \mathrm{mg} / \mathrm{kg}$ ) replaced the use of Ketamine alone. The guide cannulae were secured to the skull with acrylic dental cement and two stainless steel screws. Each cannula was fitted with a 30 gauge stainless steel stylet to avoid contamination. Rats were given at least 7 days to recover from the surgery before testing.

With the rats loosely restrained in wire cages, microinjections into the PAG, $\mathrm{RMg}$ or third ventricle were performed by lowering a 30 gauge needle into the guide cannula and delivering $0.5 \mu \mathrm{l}$ of a drug solution over 30 seconds, then allowing the needle to remain in place for a period of 60 seconds to allow adequate time for diffusion away from the needle tip. The injection rate was controlled using a Harvard model 975 infusion pump equipped with a $10 \mu \mathrm{l}$ Hamilton syringe. In order to minimize the volume of drug solution needed, the syringe and a portion of the polyethylene tubing connected to the 
infusion needle were filled with distilled water and a small air bubble was maintained between the water and the drug solution. Injection was verified by movement of the air bubble with absence of any leaks.

Neurotensin was dissolved in physiological saline and injected. Results are reported at the time point of peak agonist (neurotensin) response. Antagonists were dissolved in DMSO and administered 20 minutes before the agonist so that an effective concentration of the antagonist was present during the peak action of the agonist.

Correct cannula placement, for PAG and RVM microinjection was verified in each rat by removing the brain and treating the brain overnight with $10 \%$ formalin, then grossly examining frozen cryostat sections. Correct cannula placement for i.c.v. microinjection was determined by examining fluid movement through an injection needle inserted through the guide cannula at the proper depth.

\section{Preparation of animals for microinjection into the rostral ventromedial medulla (RVM).}

All guide cannulae for injection into the RVM were targeted for the Nucleus raphe magnus $(\mathrm{RMg})$. The guide cannulae were positioned $3 \mathrm{~mm}$ above the $\mathrm{RMg}$. The final coordinates for the guide cannula were rostral caudal, $-2.0 \mathrm{~mm}$ (relative to the interaural line); medial lateral, $0 \mathrm{~mm}$; and dorsal ventral, $-9.5 \mathrm{~mm}$ (Paxinos and Watson, 1986).

\section{Preparation of animals for intracerebroventricular injection.}

The guide cannulae were positioned $3 \mathrm{~mm}$ above the lateral ventricle. The final coordinates for the guide cannula were rostral caudal, $+8.08 \mathrm{~mm}$ (relative to the 
interaural line); medial lateral, $1.4 \mathrm{~mm}$; and dorsal ventral, -2.6 mm (Paxinos and Watson, 1986).

\section{Preparation of animals for microinjection into the midbrain periaqueductal gray region.}

The guide cannulae were positioned $3 \mathrm{~mm}$ above the PAG. The final coordinates for the guide cannula were rostral caudal, $+1.7 \mathrm{~mm}$ (relative to the interaural line); medial lateral, $0.5 \mathrm{~mm}$; and dorsal ventral, -3.4 mm (Paxinos and Watson, 1986).

\section{Antinociceptive testing}

The Tail Flick Test. The threshold to thermal nociceptive stimuli was measured using a modified version of the tail flick test (D'Amour and Smith, 1941) and a Model 33 Analgesia Meter (IITC, Inc., Woodland Hills, CA). The tail (blackened with India ink) was placed in a depression covering a photocell that acts as an off-switch on a timer when exposed to light. The time required for each rat to remove its tail from the focused light source was expressed as the tail flick latency (TFL). In all experiments the initial baseline TFL value was used as the pre-drug latency. The light source was set at an intensity such that baseline values of 2.5 to 3.5 seconds were obtained. A 10 second maximum exposure to the heat source was used to prevent tail tissue damage. Rats that did not respond before the 10 second "cut-off" were assigned a latency of 10 seconds.

\section{Assessment of alterations in tail temperature.}

It has been reported that consistent responses to thermal nociceptive stimuli are only seen when the surface tail skin temperature remains constant (Berge et al., 1988). 
Therefore, the tail temperature and ambient room temperature were monitored throughout all experiments using an Omega DP 80 Series Digital Indicator equipped with a $0.05 \mathrm{~mm}$ diameter wire Copper Constantan Thermocouple. In addition, initial microinjection of saline, DMSO, neurotensin and SR 48692 has been demonstrated to produce an elevation in tail temperature, which lasts for a duration of 15 minutes. These changes in tail temperature are not observed following subsequent microinjections 20 minutes after the first injection (Smith et al., 1997). For this reason, in all experiments in the current study, evaluations were made at least 20 minutes after any initial injection into the RVM.

\section{Assessment of core body temperature.}

It has been reported that intracerebroventricular injections of neurotensin produce hypothermia in mammals (Lipton et al., 1977; Nemeroff et al., 1977; Nemeroff et al., 1979; Prange et al., 1979). Therefore, in addition to monitoring tail temperature for reasons describe previously, rectal temperature was monitored in experiments where neurotensin was injected intracerebroventricularly. The rectal temperature was monitored and recorded at 10 minute intervals using a Yellow Springs Inst. 73 ATD equipped with YSI Series 400 rectal probes.

\section{Application of environmental stressors}

Hot Plate Stress Model: In this stress model rats were repetitively exposed to the standard hot plate analgesia test (Woolfe and Macdonald, 1944). The rats were exposed to the hot plate every ten minutes for ninety minutes, immediately following the measurement of the tail flick latency. Both the tail flick latency and latency to the 
response on the hot plate were recorded (Hawranko et al., 1994). Control rats were handled minimally and subjected to the tail flick test alone every ten minutes for ninety minutes. During the testing procedure rats were kept in wire mesh injection cages in which they could move freely except for the time when exposed to the hot plate. Previous experiments in the laboratory had shown that the rats show no aversion to these cages and willingly enter them both before and after hot plate exposure.

The threshold to thermal nociceptive stimuli was measured using the hot plate test and a Model 39D Hot Plate Analgesia Meter (IITC, Woodland Hills, CA). Rats were placed on a heated surface $\left(52.5^{\circ} \mathrm{C}\right)$, and the plate was wiped clean of feces and urine between latency determinations. Baseline latencies were taken, and a cut-off HPL of 30 seconds was used to prevent tissue damage. The time required for the rat to lick its hind paw or jump with all four paws off the plate was recorded. After the reaction, or upon attainment of the cut-off time the rats were quickly removed from the apparatus and returned to their injection cage.

\section{Analysis of data from antinociceptive testing.}

Antinociception was quantified by calculating changes in latencies (tail flick, paw withdrawal) from baseline values. Agonist dose-response data are expressed as a percentage of the maximal possible effect $(\% \mathrm{MPE})$, where $\% \mathrm{MPE}=($ Experimental latency - Baseline latency) / (Cut-off latency - Baseline latency) X 100. Agonist doseresponse curves will be constructed by plotting the \% MPE against the agonist dose.

In some instances the area under the time response curve was calculated using the trapezoidal rule (Tallarida and Murray, 1987) to demonstrate the effect of a drug or condition upon the duration of the effect. 
Drug-induced alterations in antinociceptive threshold were assessed using a one way ANOVA (analysis of variance) followed by Fisher's LSD (P>0.05) post hoc test comparing \% MPE in animals given various doses of the drug or drugs to values obtained in animals receiving vehicle control. A two-way ANOVA was employed with contrasts on the differences between the levels of response to different doses of neurotensin under different test conditions and with or without antagonists. A P value of less than 0.05 was considered significant in all of these tests. The JMP Statistics and Graphics Guide version 3.1 (SAS Institute Inc., Cary, NC, 1995) was used as the resource text for the statistical analyses.

\section{Analysis of dose-response data.}

Agonist dose-response curves: Agonist dose-response curves were constructed by plotting the \% MPE against the agonist dose, where baseline latency is defined as the tail flick value prior to the induction of stress and/or drug administration. Only one dose of agonist or one agonist-antagonist pair was tested per rat. This procedure was used to avoid the possibility of desensitization that may occur with neurotensin.

Experimentally induced changes in dose-response relationships were analyzed using a two-way ANCOVA (analysis of covariance, SAS), with the dose as the covariant, following a linear transformation of the data. A test for the significance of the group and the condition effects, as well as the interaction between them (to test for parallelism) was also conducted. When the curves are parallel, an equal degree of change in the response occurs at all doses. In this case the ANCOVA can estimate the magnitude of the shift.

On the other hand, analysis of the dose-response curves may be more complex. 
Consistent with the hypothesis, the response to neurotensin involves multiple receptors. Thus, the dose-response curve to an agonist may be multiphasic and experimental manipulations may not yield parallel shifts of the entire dose-response curve. In this instance, specific segments of the curve may need to be analyzed.

\section{Determination of the apparent potency of antagonists to the pain facilitatory and}

inhibitory processes: The dose-response relationship for the antagonism of pain facilitatory (anti-analgesic) and inhibitory processes by antagonists of neurotensin's receptors was determined. A graph expressing the response to the agonist, as a $\%$ of its maximum effect, against the dose of antagonist was constructed. 


\section{RESULTS}

\section{The influence of the microinjection of SR 142948A into RVM on the antinociceptive response to neurotensin within the RVM.}

Microinjection of various doses of SR 142948A, over a wide dose range $(0.002$ fmol to 2000 pmol), alone into the RVM did not result in an alteration of the tail flick response at any time post administration (repeated-measures ANOVA, p < 0.05) (Figure $4 \mathrm{~A}$ and B). Several doses of SR 142948A were used to determine the ability of the antagonist to modify the antinociceptive response to neurotensin, as previously described for SR 48692 (Smith et al., 1997). Initially, it was demonstrated that 20 pmol of SR 142948A was effective in blocking this response to neurotensin. Therefore this dose was used to determine the onset, peak effect and duration of action of the antagonist by staggering its administration relative to neurotensin. The results demonstrated that the response to neurotensin $(10 \mathrm{nmol})$ alone produced a significant increase in the TFL (one way ANOVA, $\mathrm{p}<0.05)$ that peaked between 20 and 90 minutes, illustrated as \% MPE in Figures 5A, 5B (-A-) and 6A ( $\square)$ and as the area under the response curve in Figure 6B ( $\square$, from 20 to 80 minutes) and 6C ( $\square$, from 20 to 140 minutes). When SR 142948A was administered at staggered times relative to neurotensin, SR 142948A was found to have an onset of action of $\sim 10$ minutes and remained effective for a duration of 60 minutes with the response diminishing at time points thereafter. Therefore, SR 142948A was microinjected 20 minutes prior to the administration of neurotensin. The antagonist was 
found to dose-dependently and completely (values not significantly different from baseline established by the administration of vehicle alone, Figures $6 \mathrm{~A}$ and $6 \mathrm{~B}$ ), inhibit this antinociceptive response of neurotensin. Significant antagonism occurred between 2 $\mathrm{X} 10^{-1}$ and $2 \times 10^{2} \mathrm{pmol}$ of SR 142948A (two way ANOVA with contrasts, $\mathrm{p}<0.05$ ). The dose-response relationship of the antagonist can be seen more clearly in Figure 6A, $\mathrm{B}$ and $\mathrm{C}$, where the dose-response is plotted as $\% \mathrm{MPE}$ at 30 minutes post injection of neurotensin and as the area under the curve from 20 to 80 and 20 to 140 minutes post injection of SR 142948A respectively. The response was biphasic and complete reversal of the antagonism occurred at a dose of $2 \times 10^{3}$ pmol of SR 142948A. In addition to those doses of the antagonist that are plotted, two lower doses $\left(2 \times 10^{-7}\right.$ and $2 \times 10^{-8}$ pmol) and two higher doses $\left(2 \times 10^{4}\right.$ and $\left.2 \times 10^{5} \mathrm{pmol}\right)$ were tested (in a small subset of animals) to insure that neither an additional inhibitory action of the compound existed at lower doses, nor that there was a potentiation of neurotensin's antinociceptive effect with increasing doses. Neither the lower or higher doses tested had any significant effect on neurotensin-mediated antinociception. In Figure 6C, the reversal appears to be incomplete, but this is consistent with the pharmacokinetic profile of SR 142948A, since the response to neurotensin peaked between 20 and 90 minutes after its administration (40 and 110 minutes after the administration of SR 142948A), a time frame that far exceeds the duration of action of the antagonist. 


\section{Figure 4}
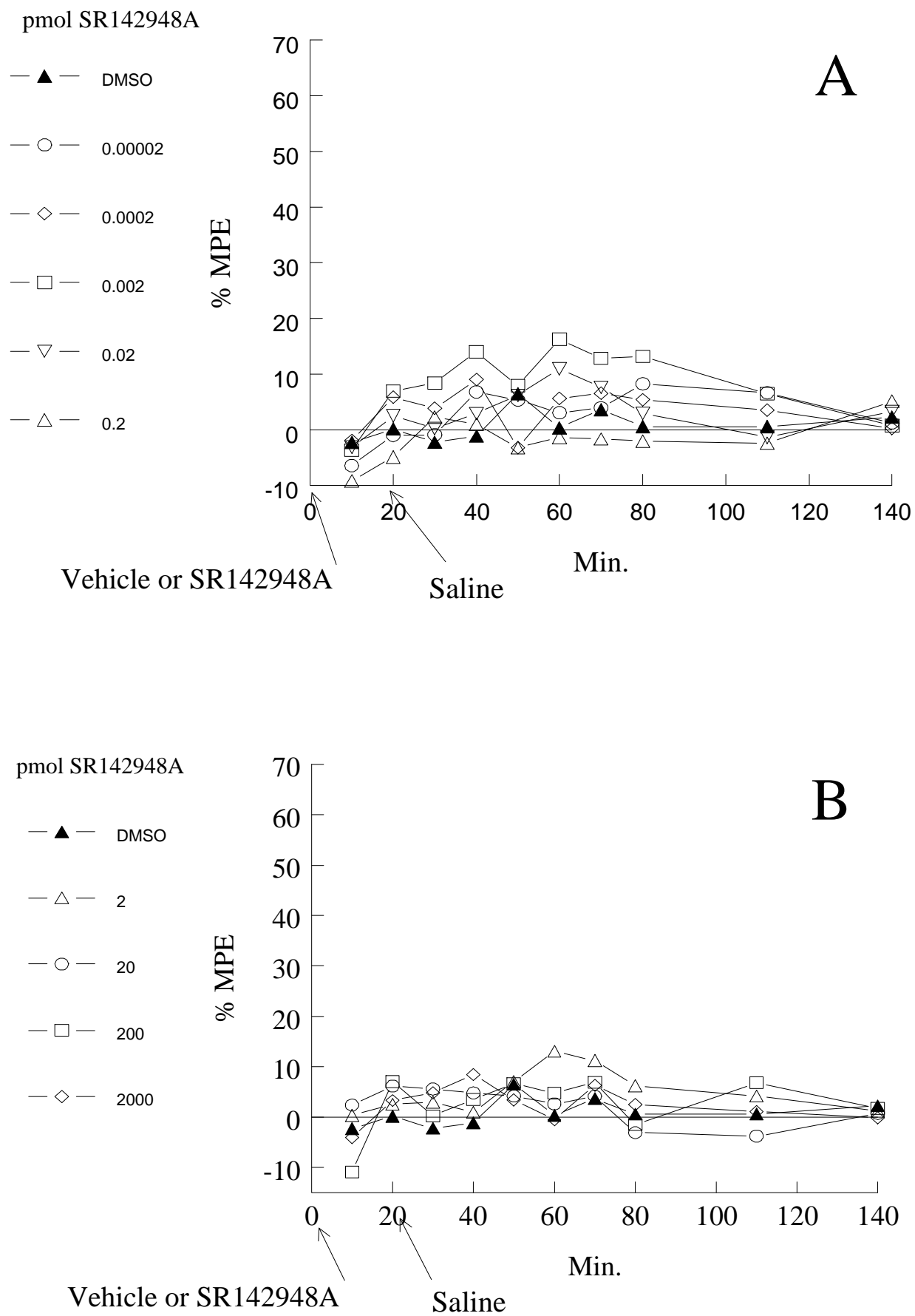
Figure 4. Dose-response relationship for SR 142948A injected into the RVM. SR 142948A was injected at time 0 and saline (neurotensin vehicle) was injected 20 minutes later at a time which corresponding to when neurotensin was administered in the remainder of the experiment. The response is illustrated as percent of the maximum possible antinociceptive effect (MPE), and the mean values are plotted without S.E. for clarity (S.E.s are expressed in Figures 6A, 6B and 6C). Time is expressed in minutes after the injection of SR 142948A. No significant alteration in the tail flick response was measured at any time post-SR 142948A administration at any concentration (repeatedmeasures ANOVA, $\mathrm{p}<0.05)$. 


\section{Figure 5}
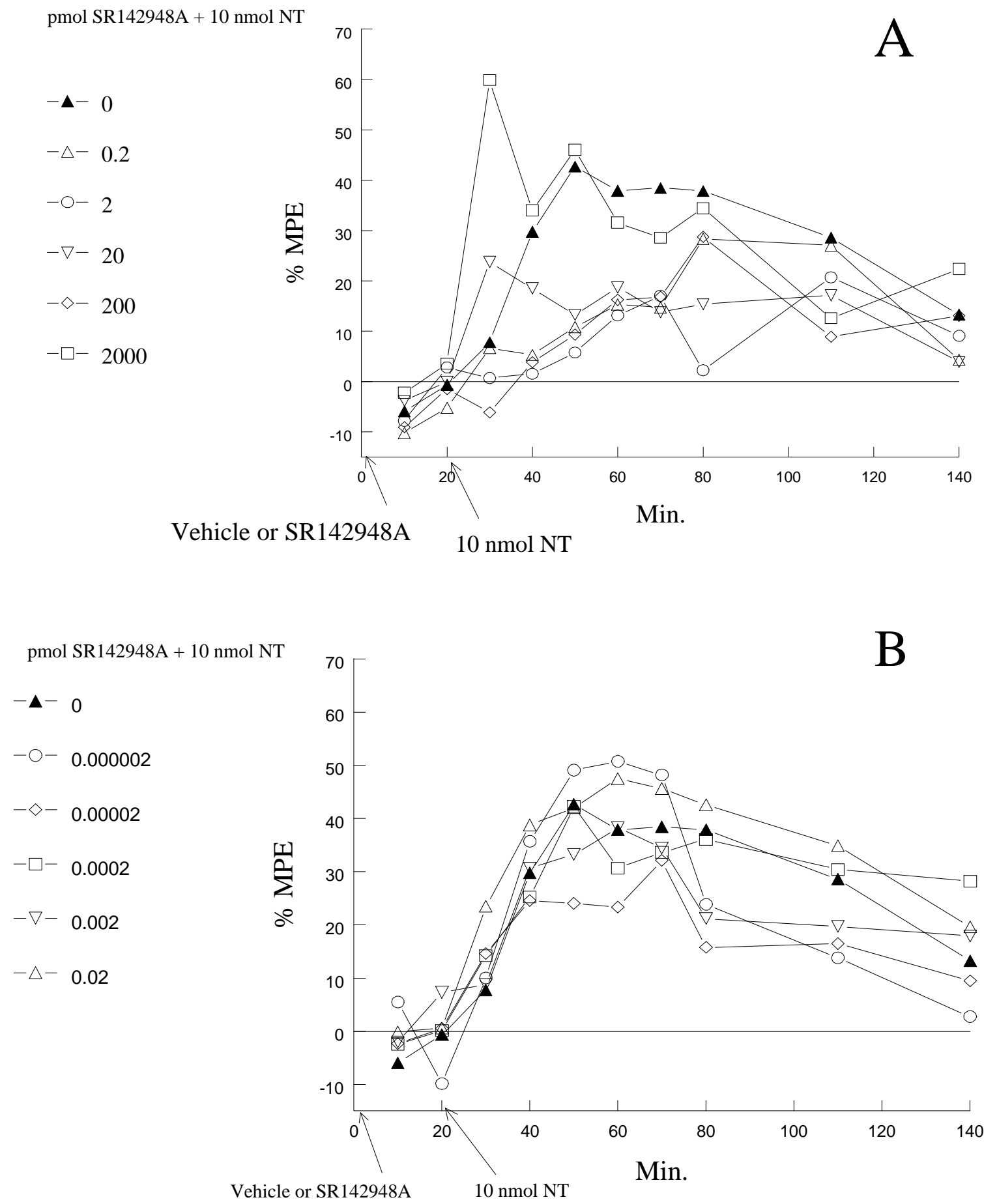
Figure 5. The influence of SR 142948A microinjected into the RVM on the response to an antinociceptive dose $(10 \mathrm{nmol})$ of neurotensin injected into the RVM. A, data with doses of SR 142948A from 0.2 to 2000 pmol. B, data with doses of SR 142948A from 0.000002 to 0.02 pmol. In both A and B, SR 142948A or vehicle (DMSO) was injected at time 0 and neurotensin was injected 20 minutes later. The response is illustrated as $\%$ MPE and the mean values are plotted without S.E. for clarity (S.E.s are expressed in Figures 6A, 6B and 6C). Time is expressed in minutes after the injection of SR 142948A or vehicle. Doses of SR 142948A between 0.2 and 200 pmol resulted in a significant inhibition of the response to neurotensin for at least the initial 80 minutes (repeatedmeasures ANOVA with contrasts, $\mathrm{p}<0.05)$. 


\section{Figure 6}
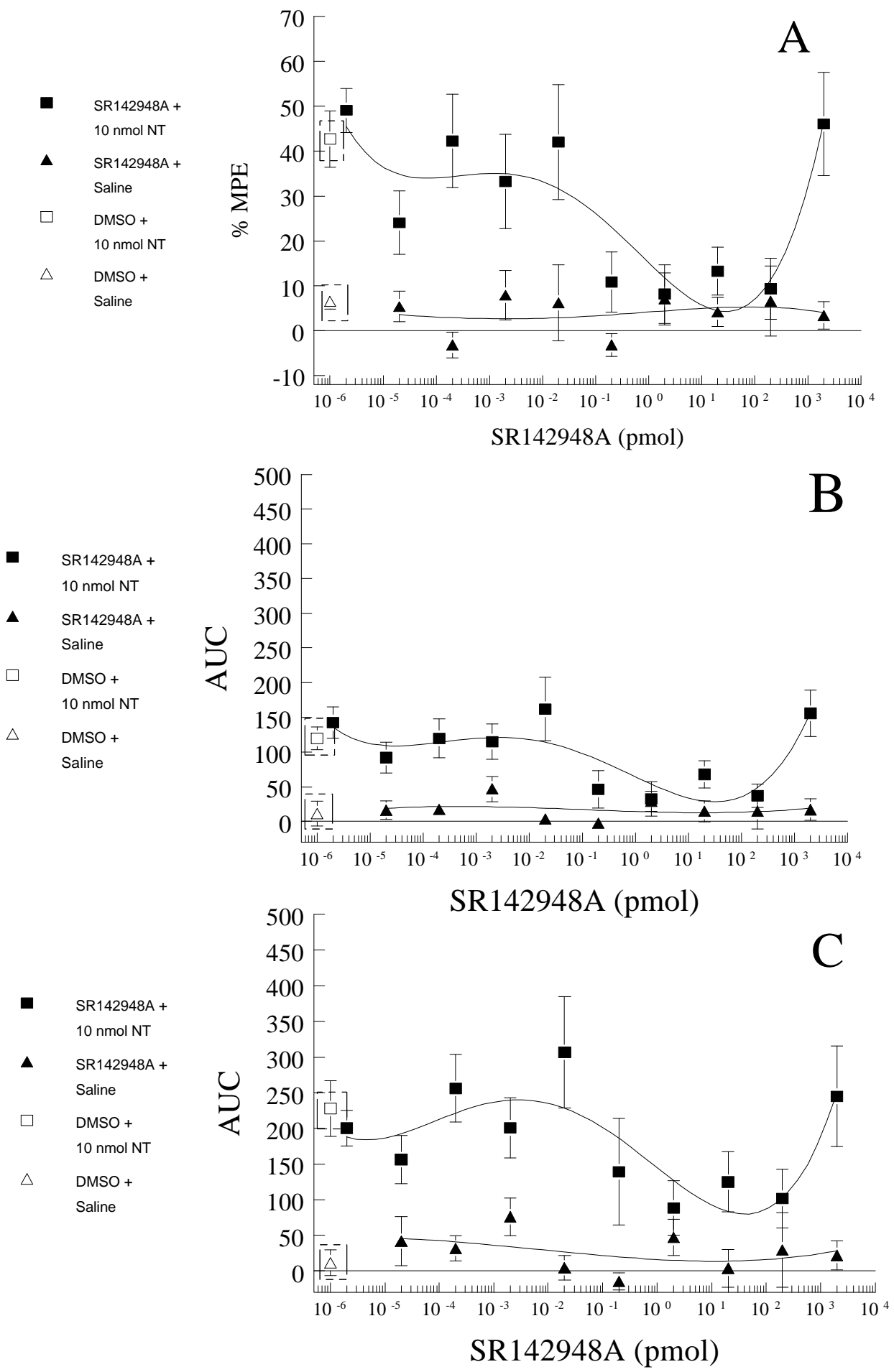
Figure 6. The dose-response relationship for the influence of administration of SR $142948 \mathrm{~A}$ into the RVM on the response to an antinociceptive dose $(10 \mathrm{nmol})$ of neurotensin injected into the RVM. A, the dose-response relationship of SR 142948A illustrated as \% MPE 30 minutes after the injection of neurotensin. B and C, the doseresponse relationships of SR 142948A derived from data in Figure 4A and B and illustrated as the area under the response curve (AUC). B, represents AUC from 20 to 80 minutes. C, represents the AUC from 20 to 140 minutes. In A, B and C the data are expressed as the mean values \pm S.E.. The open square $(\square)$ and triangle $(\Delta)$ represent the responses of neurotensin preceded by SR 142948A vehicle, and SR 142948A vehicle (DMSO) followed by neurotensin vehicle (saline) respectively. The closed squares ( represent neurotensin preceded by various doses of SR 142948A. The closed triangles (A) illustrate the response to various doses of SR 142948A alone followed by neurotensin vehicle. 


\section{The influence of the microinjection of SR 142948A into the RVM on the pain facilitatory response to neurotensin within the RVM.}

The following set of experiments were conducted in order to evaluate the ability of SR 142948A to inhibit the pain facilitatory responses of neurotensin within the RVM. These experiments were conducted in three distinct models where a neurotensin-mediated facilitation can be resolved. First we examined the ability of SR 142948A to shift the nociceptive dose-response relationship to neurotensin within the RVM to the left (i.e. causing an ineffective dose of neurotensin in the tail flick test to become antinociceptive), an effect which has been associated with the ability of another neurotensin antagonist, SR 48692, to block neurotensin-mediated facilitation of nociception (Smith et al., 1997). Second, we examined the ability of SR 142948A to inhibit the anti-analgesic action of exogenously administered neurotensin within the RVM of stressed rats. Lastly we examined the ability of SR 142948A when administered into the RVM to potentiate the antinociceptive effect of systemically administered morphine, an effect which has been associated with the ability of SR 48692 to block morphine-induced neurotensin-mediated facilitation of nociception (Smith et al., 1997). 


\section{A. The influence of the microinjection of SR 142948A into RVM on the response to a low dose of neurotensin within the RVM.}

In the current experiment, microinjection of neurotensin $(30 \mathrm{pmol})$ did not produce any significant alteration in the TFL (Figures 7 (represented by $\mathbf{\Delta}$ ) and 8 (represented by $\square$ )). The response to neurotensin is illustrated as \% MPE in Figures 7A, $7 \mathrm{~B}$ and $8 \mathrm{~A}$ and as the area under the response curve from 20 to 140 minutes in Figure 8B. Microinjection of SR 142948A $(\mathrm{t}=0) 20$ minutes prior to the administration of neurotensin had no effect (repeated-measures ANOVA with contrasts, $\mathrm{p}<0.05$ ) in combination with neurotensin, and did not produce significant antinociception at any dose or time studied (Figures 7A, 7B, 8A and 8B) 


\section{Figure 7}
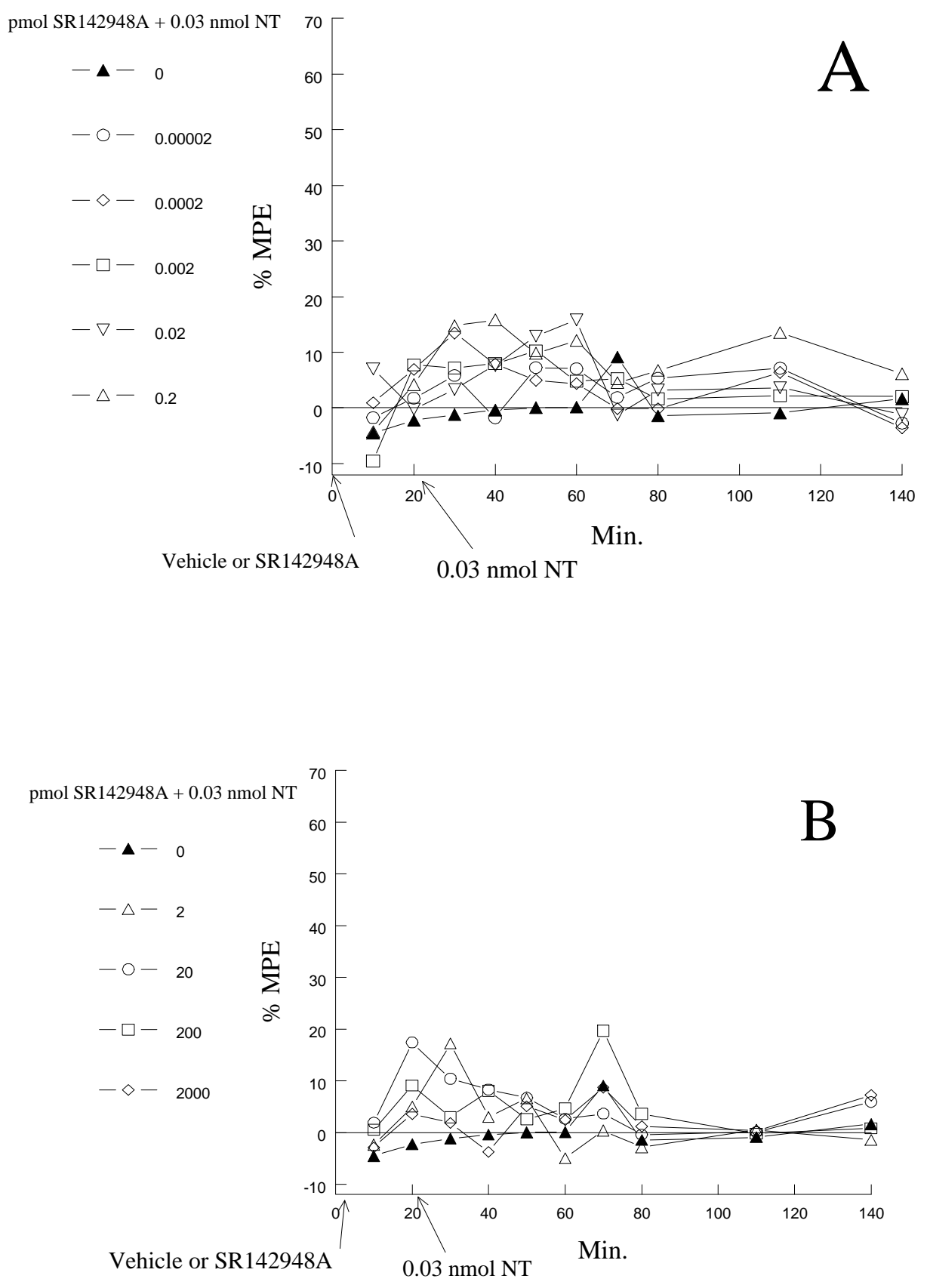
Figure 7. Time effect curves for various doses of SR 142948A microinjected into the RVM prior to a low dose $(30 \mathrm{pmol})$ of neurotensin. A, data with doses of SR $142948 \mathrm{~A}$ from 0.00002 to 0.2 pmol. B, data with doses of SR 142948A from 2 to 2000 pmol. In both A and B, SR 142948A or vehicle (DMSO) was injected at time 0 and neurotensin was injected 20 minutes later. The response is illustrated as \% MPE and the mean values are plotted without S.E. for clarity (S.E.s are expressed in Figures 8A, and 8B). Time is expressed in minutes after the injection of SR 142948A or vehicle. No significant change in the tail flick response was observed following neurotensin injection alone (matched pairs $t$ test) or the injection SR 142948A followed by the injection of neurotensin (repeated-measures ANOVA with contrasts, $\mathrm{p}<0.05$ ). 


\section{Figure 8}

- - SR142948A + $0.03 \mathrm{nmol} N \mathrm{NT}$

- $\Delta$ - SR142948A + Saline

$-\square-\mathrm{DMSO}+$ $0.03 \mathrm{nmol}$ NT

$-\triangle-\mathrm{DMSO}+$ Saline
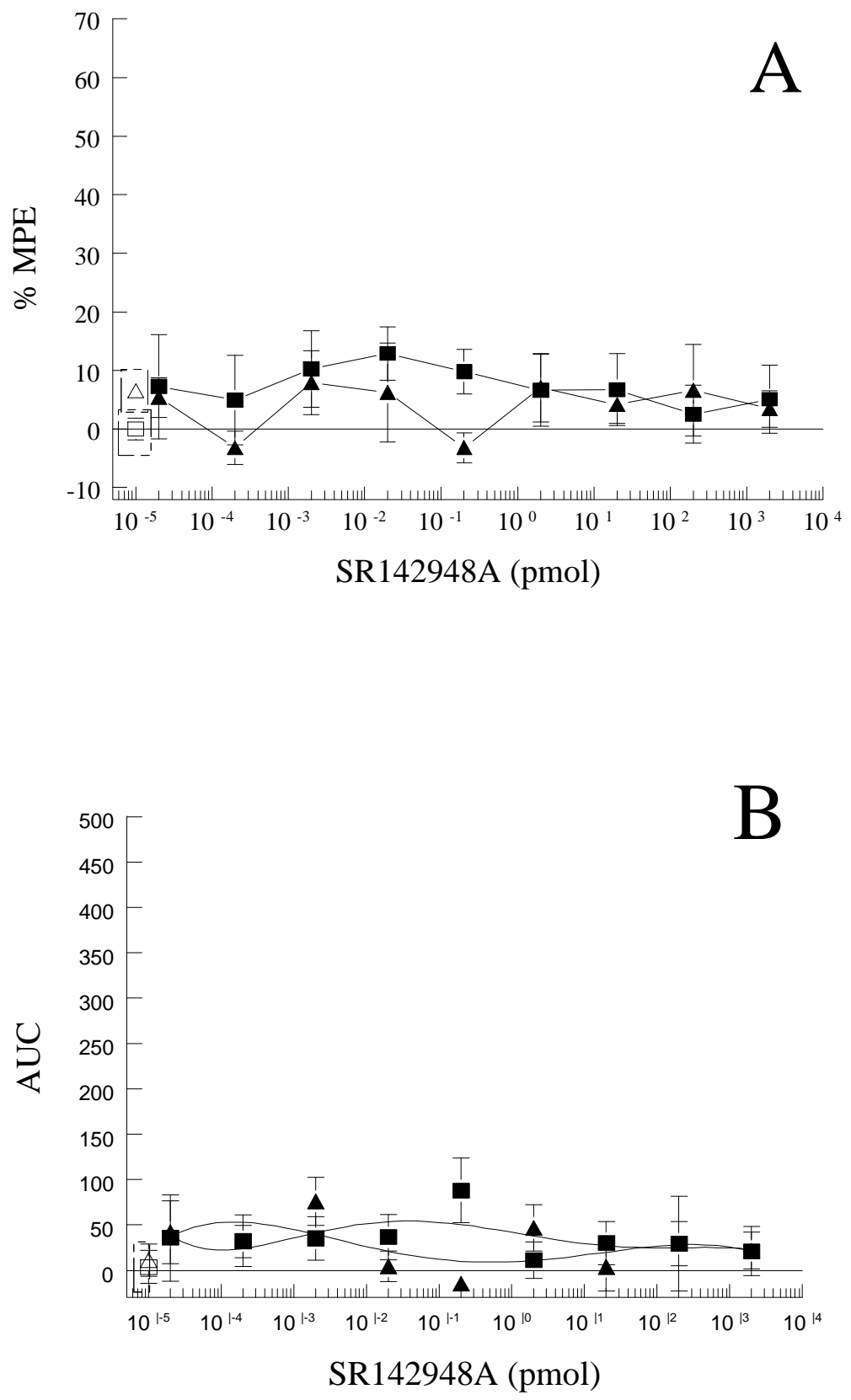
Figure 8. Lack of influence of various doses of SR 142948A microinjected into the RVM on a low dose $(30 \mathrm{pmol})$ of neurotensin. A, the dose-response relationship of SR 142948A illustrated as \% MPE 30 minutes post injection of neurotensin. B, the doseresponse relationship of SR 142948A derived from data in Figure 6A and B and illustrated as AUC from 20 to 140 minutes. In both A and B the data is expressed as the mean values \pm S.E.. None of the concentrations tested (0.00002 to 2000 pmol) resulted in any significant expression of an antinociceptive response to the agonist (repeatedmeasures ANOVA with contrasts, $\mathrm{p}<0.05)$. The open square $(\square)$ and triangle $(\Delta)$ represent the responses of neurotensin preceded by SR 142948A vehicle, and SR 142948A vehicle (DMSO) followed by neurotensin vehicle (saline) respectively. The closed squares ( $\mathbf{\square}$ ) represent neurotensin preceded by various doses of SR 142948A. The closed triangles $(\boldsymbol{\Delta})$ illustrate the response to various doses of SR 142948A alone followed by neurotensin vehicle. 


\section{$B$. The influence of the microinjection of SR 142948A on the anti-analgesic response to neurotensin within the RVM of the stressed rat.}

The dose-response relationship of neurotensin administration into the RVM in the stressed rat.

When rats were exposed repetitively to both the hot plate and the tail flick test (see methods section 7, hot plate stress model), an increase on the order of 1.5-2.5 seconds in the tail flick latency occurred $(\cong 30 \% \mathrm{MPE})(-\bullet$ - in Figure $9 \mathrm{~A}$ and $-\mathrm{O}-$ in Figure 9B). This stress-induced analgesia is of the magnitude reported by Hawranko and coworkers (1997). Rats were exposed to both the hot plate and the tail flick test every ten minutes for a period of 90 minutes. After the fourth exposure to the hot plate test (30 minute time point), rats received an injection of one dose of neurotensin $(0.3,3,30,300$, 3000 , or $30000 \mathrm{pmol}$ ) or saline (neurotensin vehicle) into the RVM. Following the injection rats were exposed to the tail flick and hot plate tests in sequence every 10 minutes for an additional 60 minutes. Figure 9A illustrates the time effect curves for all doses of neurotensin and saline for the 60 minute time period following their injection. The response is illustrated as mean MPE. Injection of low doses ( 3 and 30 pmol) of neurotensin produced a significant anti-analgesic (reduction in stress-induced analgesia, saline control) response (one way ANOVA, $\mathrm{p}<0.05$ ), with both concentrations reaching a significant maximum effect around 20 minutes post administration. Further analysis demonstrated a significant antianalgesic effect for $30 \mathrm{pmol}$ at 20 minutes post injection, while 3 pmol of neurotensin produced an anti-analgesic effect that began at 20 minutes post injection and lasted up to the 50 minute time period, with the response fading at time points thereafter (repeated-measures ANOVA, $\mathrm{p}<0.05$ ). In contrast, administration of 
higher doses of neurotensin $(\geq 3000 \mathrm{pmol})$ resulted in a significant antinociception (relative to baseline established by 3 pmol dose of neurotensin). The ability of these higher doses to produce this effect was significant beginning 20 minutes after administration and lasting through at least the 50 minute time point, with both concentrations reaching an apparent maximum between 30 and 40 minutes after injection. This response was also shown to be significantly elevated above the levels of stressinduced analgesia at all times points beginning 30 minutes after injection for the 30000 pmol dose (repeated-measures ANOVA, $\mathrm{p}<0.05$ ).

These dose-related effects of neurotensin are seen more clearly in figure 9B, where the bipolar nature of neurotensin's response is demonstrable. In this figure, the dose-response of neurotensin is illustrated as \%MPE and the mean values from each dose are represented \pm S.E. at 30 minutes post administration of neurotensin or vehicle. Analysis conducted at this 30 minute time point, resolved a significant anti-analgesic effect for a dose of $3 \mathrm{pmol}$ neurotensin (reduction in stress-induced analgesia, saline control) and significant antinociceptive response for 3000, 10000 and 30000 pmol of neurotensin (relative to baseline established by 3 pmol dose of neurotensin) (one way ANOVA, $\mathrm{p}<0.05)$.

In addition, hot plate latencies (HPL) were also recorded and analyzed. In contrast to Hawranko and coworkers (1997), a slight and highly variable increase in the HPL was observed following the induction of stress. However, no consistent change in HPL was observed with neurotensin and/or antagonist administration at any time period or concentrations studied. 
Figure 9

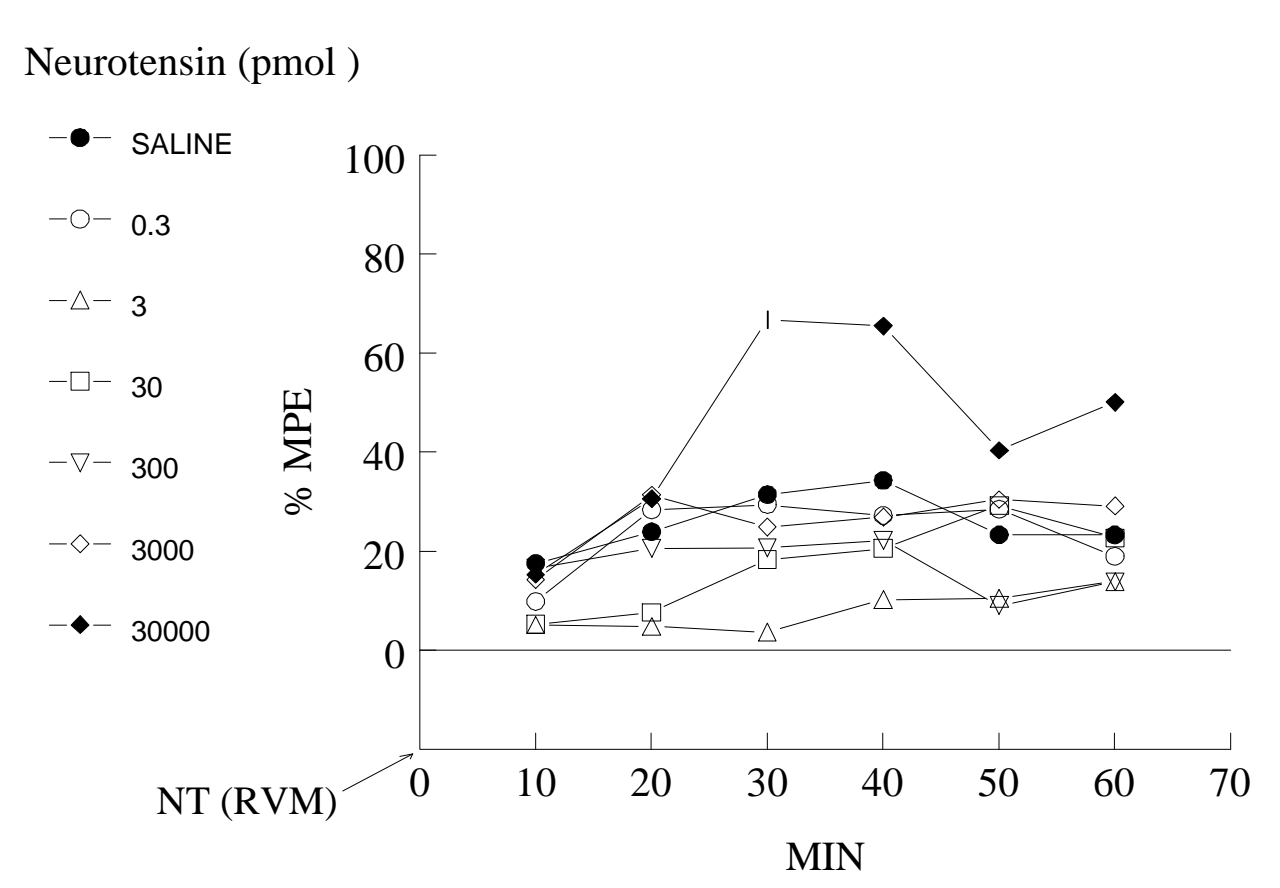

A

- - SALINE

- NEUROTENSIN




Figure 9. The dose-response relationship for anti-analgesic and antinociceptive responses to neurotensin in the RVM of the stressed rat. In both A and B, rats were exposed to hot plate stress paradigm for thirty minutes prior to any RVM injection. All groups have $\mathrm{n}=6$ except for the $3 \times 10^{3}$ and $1 \times 10^{4}$ pmol concentration, which have an $\mathrm{n}$ of 5 and 3 respectively. A, time effect curves for saline (neurotensin vehicle) and doses of neurotensin from 3 to $3 \times 10^{4}$ pmol. Time is expressed in minutes after the injection of neurotensin or vehicle. A significant anti-analgesic effect was demonstrated by 30 pmol neurotensin at 20 minutes post injection and 3 pmol from 20-50 minutes, while a significant antinociception was demonstrated by $3 \times 10^{3}$ pmol from 20-50 minutes and 3 $\mathrm{X} 10^{4}$ pmol beginning at 20 minutes and lasting through the remainder of the times tested. B, the dose-response relationship of neurotensin derived from data in A. These data are illustrated as \%MPE and the mean values from each dose are presented \pm S.E. at 30 minutes post administration of neurotensin or vehicle. $(*)$ Denotes significant reduction in stress-induced analgesia (one way ANOVA with contrasts, $\mathrm{p}<0.05) .\left({ }^{* *}\right)$ Denotes a significant antinociceptive effect (one way ANOVA with contrasts, $\mathrm{p}<0.05$ ). 
Comparison of SR 48692 and SR 142948A within the RVM for their ability to block neurotensin-mediated anti-analgesia in the stressed rat.

Both of the neurotensin antagonists were evaluated in stressed rats for their ability to block the anti-analgesic action induced by injection of 3 pmol neurotensin into the RVM after the development of stress-induced analgesia. Rats were exposed to both the hot plate and the tail flick test every ten minutes for a period of 90 minutes. After their second exposure to the hot plate they received an injection of one of the antagonists or antagonist vehicle (DMSO). After the fourth exposure to the hot plate (30 minute time point) rats received an injection of neurotensin ( $3 \mathrm{pmol})$ or saline (neurotensin vehicle) into the RVM. Three doses of SR 142948A (0.3, 3 and $30 \mathrm{pmol})$ and one dose of SR 48692 (3 pmol) were evaluated. The dose of SR 48692 was selected because it had been demonstrated in previous experiments to be effective in blocking neurotensin-induced pain facilitatory actions (Smith et. al., 1997). The doses of SR 142948A to be tested were selected for two reasons. First, the two antagonists, SR 48692 and SR 142948A, have similar affinities in binding studies for known neurotensin receptors (Gully et al., 1993; 1997). Second, previous studies done in the laboratory examining the ability of the two antagonists to potentiate systemic morphine antinociception, had demonstrated both compounds to be equipotent.

Since the antagonists were injected at a period of time prior to the full development of the stress-induced analgesia, the first part of this experiment compared and evaluated the ability of SR 48692 and SR 142948A when administered into the RVM, to alter the development of stress-induced analgesia. Clearly their possible ability 
to block stress-induced analgesia could have a profound effect on interpretation of the results. Figure 10A illustrates the time effect curves for the development of stressinduced analgesia (DMSO) and the effect of all doses of SR 142948A tested for the time period following the injection. No significant change in stress-induced analgesia (DMSO injection at 10 minutes followed by saline injection at 30 minutes) was noted at any time point following the RVM administration of SR 142948A at any of the concentrations tested $(0.3,3,30 \mathrm{pmol})$ (repeated-measures ANOVA, $\mathrm{p}<0.05)$. In contrast, SR 48692 (3 pmol) administration into the RVM resulted in a significant reduction of the stressinduced analgesia (Figure 10B). Further analysis of the data indicated that significant attenuation occurred at the 40 minute time point (repeated-measures ANOVA with contrasts, $\mathrm{p}<0.05)$. Furthermore, a significant attenuation occurred at time points exceeding the antagonist's duration of action (60 minutes). In this regard, both the 70 and 80 minute time points were found to be significantly reduced (repeated-measures ANOVA with contrasts, $\mathrm{p}<0.05)$.

Injection of 3 pmol of neurotensin into the RVM of stressed rats (time $=30$ minutes) produced a consistent and significant reduction in stress-induced analgesia from the 50 through the 80 minute time period (Figures 11A and B) (repeated-measures ANOVA with contrasts, $\mathrm{p}<0.016$ ). Injection of SR 142948A, 20 minutes prior to the injection of neurotensin, did not result in any significant alteration of the anti-analgesia induced by neurotensin in any of the concentrations tested (Figure 11A, repeatedmeasures ANOVA with contrasts, $\mathrm{p}<0.05)$. However, there was an apparent trend for the combination of SR 142948A and neurotensin to be elevated at the 60 minute time point. In this regard, the combined effect of SR 142948A (all concentrations tested) and 
neurotensin was not significantly different from the effect of neurotensin alone (- $\nabla-)$ or from stress-induced analgesia alone (-O-) at the 60 minute time period (repeatedmeasures ANOVA with contrasts, $\mathrm{p}<0.05)$. In contrast, injection of 3 pmol SR 48692, 20 minutes prior to the injection of neurotensin, resulted in a significant blockade of neurotensin's anti-analgesic effect from the 50 to the 80 minute time period (Figure 11B, repeated-measures ANOVA with contrasts, $\mathrm{p}<0.016)$. Furthermore, the combined effect of SR 48692 and neurotensin was not significantly different from the effect of stressinduced analgesia alone at the 40 and 50 minute time periods (one way ANOVA with contrasts, $\mathrm{p}<0.016)$. In addition to reversing neurotensin's anti-analgesic effect, the prior administration of SR 48692 increased the TFL to levels significantly greater than the latency observed with stress-induced analgesia at both the 60 and 70 minute time periods (one way ANOVA with contrasts, $\mathrm{p}<0.016$ ). Representing the ability of SR 48692 to promote antinociception from a low dose of neurotensin administered into the RVM. 


\section{Figure 10}
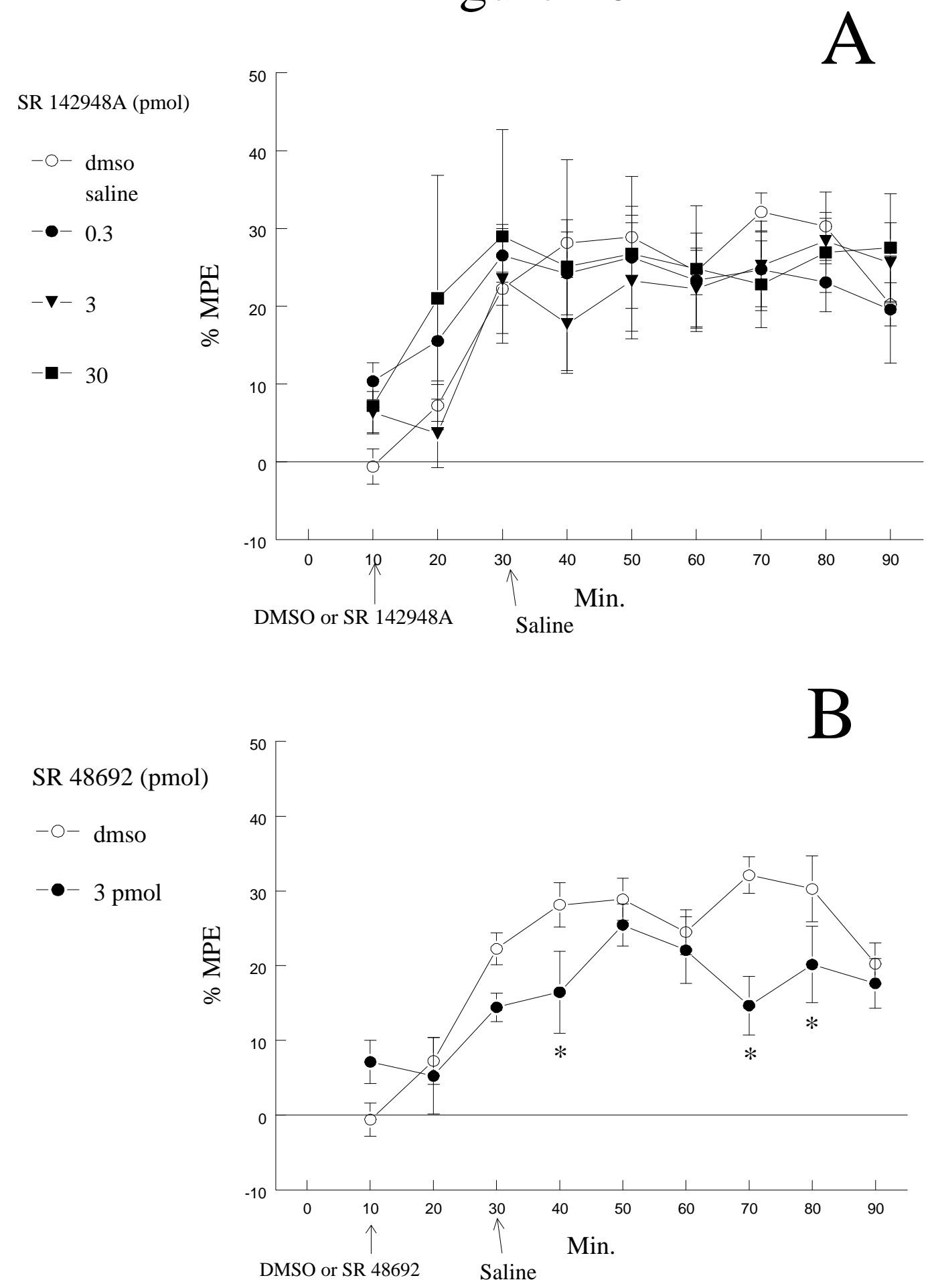
Figure 10. The influence of SR 142948A and SR 48692 microinjected into the RVM on the development of stress-induced analgesia. A, the inability of various doses of SR 142948A to alter stress-induced analgesia. B, time effect curve for the ability of 3 pmol SR 48692 to attenuate stress-induced analgesia. In both A and B, data are illustrated as the $\% \mathrm{MPE}$ and the mean values are plotted \pm S.E.. Time is expressed in minutes from the first exposure to the stress model (time $=0$ ). In A, no significant alteration in stressinduced analgesia was produced by administration of any of the doses of SR 142948A tested (repeated-measures ANOVA, $\mathrm{p}<0.05$ ). In $\mathrm{B}$, a significant reduction in stressinduced analgesia was produced by 3 pmol SR 48692 injected into the RVM at time 0 at the 40, 70, and 80 minute time periods (one way ANOVA with contrasts, $\mathrm{p}<0.05$ ). 
Figure 11
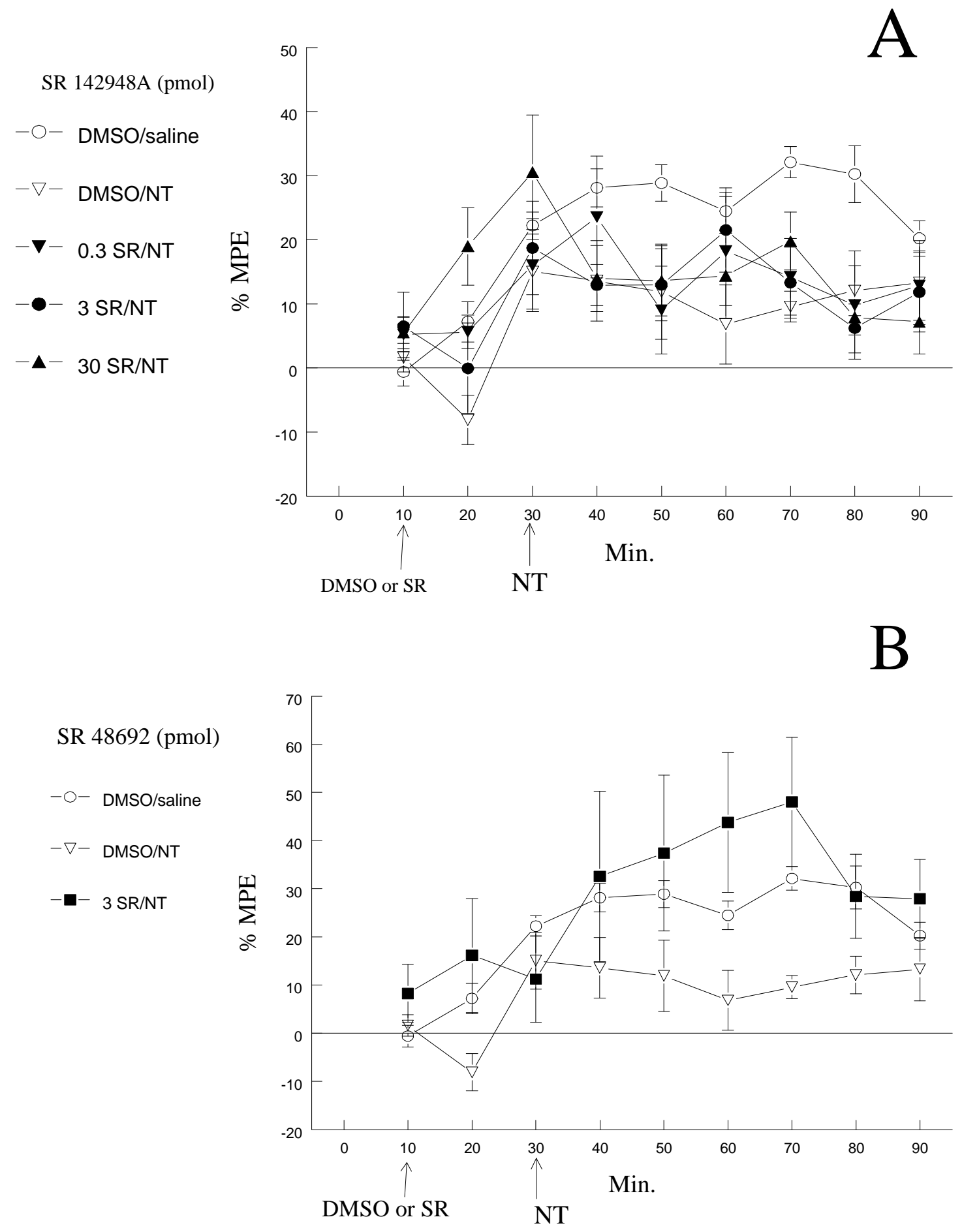
Figure 11. Comparison of SR 142948A and SR 48692 for their ability to block neurotensin-induced anti-analgesia in the stressed rat. A, the inability of SR 142948A microinjected into the RVM to block neurotensin-induced anti-analgesia in the stressed rat. B, the ability of SR 48692 (3 pmol) to block neurotensin's anti-analgesic effect in the stressed rat. In both $\mathrm{A}$ and $\mathrm{B}$, the response is illustrated as the \% MPE and the mean values are plotted \pm S.E.. Time is expressed in minutes after the first exposure to the stress paradigm. Injection of DMSO (SR vehicle, 10 minutes) followed by injection of neurotensin ( 3 pmol, 30 minutes) resulted in a significant reduction in the stress-induced analgesia (DMSO injection followed by Saline) from the 50 through 80 minute time period (repeated-measures ANOVA, $\mathrm{p}<0.016$ ). In A, no significant alteration in this reduction was evident for any of the concentrations of SR 142948A tested. In B, injection of SR 48692 into the RVM 20 minutes prior to neurotensin produced a significant blockade of the neurotensin-induced reduction back to levels that were not significantly different from vehicle control (repeated-measures ANOVA with contrasts, $\mathrm{p}$ $<0.016)$ at 40 and 50 minutes, and significantly elevated the stress-induced response at the 60 and 70 minute time periods. 


\section{Comparison of SR 48692 and SR $142948 A$ microinjected into the RVM to alter the antinociceptive response to systemically administered morphine.}

Morphine was administered systemically and SR 142948A was microinjected into the RVM. Furthermore, a positive internal control (SR 48692 administration into the RVM) was run in parallel with data collected on SR 142948A. Both of the antagonists were dissolved in DMSO and injected into the RVM 10 minutes prior to systemic administration of morphine $(2 \mathrm{mg} / \mathrm{kg})$ and responses were measured for 150 minutes.

Systemic administration of morphine resulted in an antinociceptive effect that peaked within 30 minutes and returned to predrug levels within 150 minutes ( $\square$ in Figures 12A and B). RVM administration of SR 48692, resulted in a significant and dose dependent potentiation of morphine's analgesic effect, with doses $\geq 30$ pmol being significantly different at all time points from 30 to 120 minutes (repeated-measures ANOVA, $\mathrm{p}<0.05)$. These observations are in agreement with those from a previous study (Smith et al., 1997). Administration of SR 142948A resulted in a potentiation of morphine analgesia dose-selectively, as only the 30 pmol dose of SR 142948A was significantly different, with doses 10 fold higher or lower being without effect (repeatedmeasures ANOVA, $\mathrm{p}<0.05$ ) (Figures 12A, C). An analysis of the AUC values (Figure 12C) from data presented in figures $12 \mathrm{~A}$ and $\mathrm{B}$ (20 minutes through 150 minutes) confirmed the interaction of SR 48692 and SR 142948A with morphine and illustrated that 30 pmol of both SR 142948A and SR 48692 result in a significant enhancement of morphine analgesia (one way ANOVA, $\mathrm{p}<0.05$ ). 


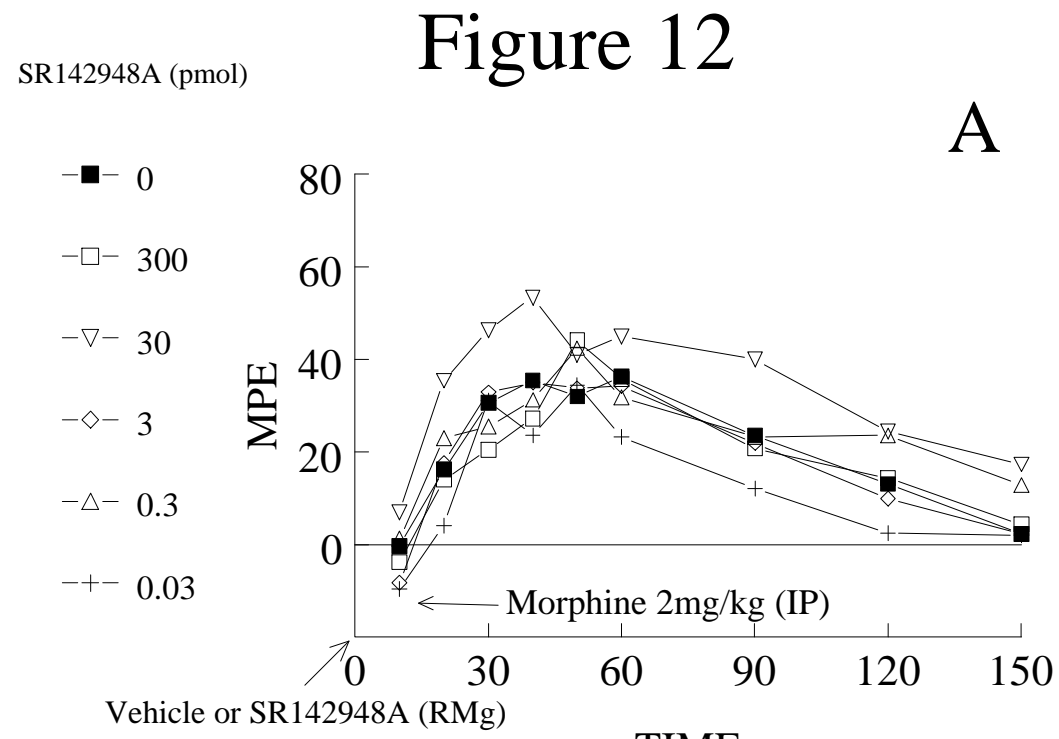

\section{TIME}
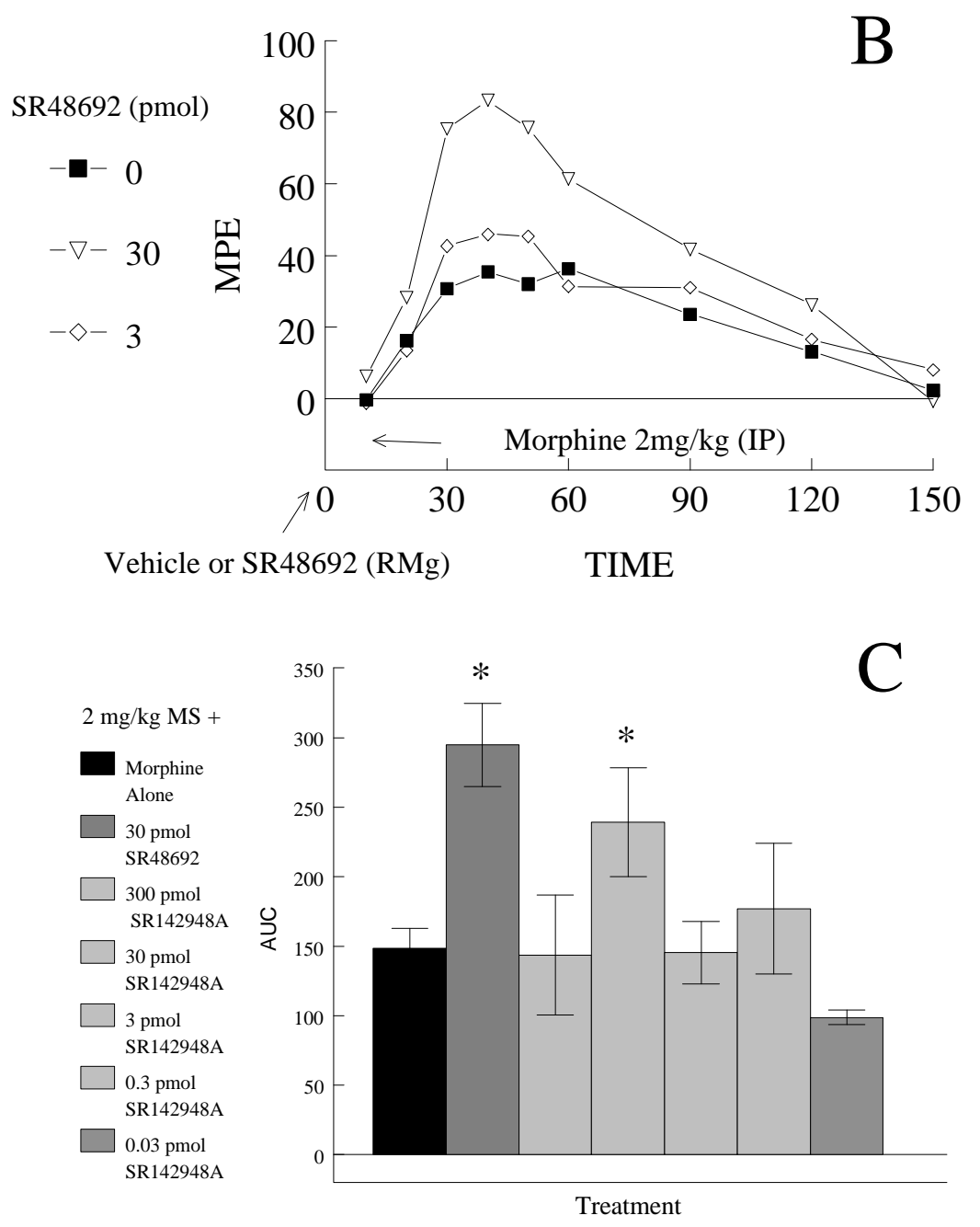
Figure 12. Influence of SR 48692 and SR 142948A administered into the RVM on the response to an antinociceptive dose of morphine $(2 \mathrm{mg} / \mathrm{kg})$ injected intraperitoneally. In A and B, SR 142948A or SR 48692 was injected at time 0 respectively, and morphine was injected 10 minutes later. The response is illustrated as \% MPE and time is expressed in minutes after the injection of SR 142948A or SR 48692 respectively. The response to morphine was enhanced by a single dose of SR 142948A (30 pmol, figure A) and SR 48692 (30 pmol, figure B). C, the data (mean values \pm S.E.) are expressed as AUC beginning at 20 minutes and extending to 150 minutes. 


\section{The influence of levocabastine (RVM) on the anti-analgesic (pain facilitatory) response to neurotensin ( $R V M)$.}

The ability of neurotensin to produce dose-dependent bipolar (facilitatory and inhibitory) effects on nociception within the RVM, raises an important pharmacodynamic question of whether these responses are mediated via different neurotensin receptors (i.e. NTR1 or NTR2) or subtypes of receptors. While Smith and coworkers (1997) have discriminated that the NTR2 is not involved in mediating the antinociceptive response to neurotensin within the RVM of rats, no direct investigation of the involvement of neurotensin receptors has been conducted on neurotensin's facilitatory action within the RVM. In experiments conducted in this report, targeted at investigating the ability of the two neurotensin receptor antagonists to block this same facilitatory action of neurotensin, it was clearly demonstrated that the facilitatory effect of a low dose of neurotensin injected into the RVM can be reproducibly shown in the stressed rat using the tail flick test. This action of neurotensin has been mimicked in another set of experiments conducted within our laboratory, as this same facilitatory (anti-analgesic) effect of neurotensin (within the RVM) was also reproducibly distinguished following morphine administration into the PAG (Figure 13). This procedure like the stress experiment takes advantage of producing a basal level of analgesia (increase in tail flick latency) prior to the injection of neurotensin. However, unlike the stress experiment where the animals need to be exposed repetitively to two noxious stimuli, in this protocol the animals only need to be subjected to the tail flick test.

In order to directly examine whether or not the NTR2 receptor mediates neurotensin's facilitatory action within the RVM the following experiment was 
performed. Using a modified version of the previously described model, where morphine is administered into the PAG and neurotensin administered into the RVM, an additional injection of levocabastine was made into the RVM. The time for administration of levocabastine was selected based on previous studies which indicate that an effect concentration of levocabastine will be present when the data is analyzed (Smith et al., 1997). Since, levocabastine prevents the binding of neurotensin to the NTR2 receptor $\left(\mathrm{IC}_{50}=7 \mathrm{nM}\right.$, Kitabgi et al., 1987), any blockade of neurotensin's anti-analgesic effect will therefore be indicative of this response being mediated via the NTR2 receptor.

Rats were injected with morphine $(6 \mathrm{nmol})$ into the PAG, levocabastine $(0.0001$ to $1000 \mathrm{pmol}$ ) or vehicle (DMSO) was injected into the RVM 10 minutes after morphine and neurotensin ( 3 pmol) or vehicle (saline) was injected into the RVM 20 minutes after injection of levocabastine. Furthermore, a positive internal control (SR 48692 administration into the RVM) was run in parallel with data collected on levocabastine. Both of the antagonists (SR 48692 and levocabastine) were dissolved in DMSO. Following the injections, antinociceptive responses were measured (tail flick test) for 90 minutes. Microinjection of morphine into the PAG resulted in a significant antinociceptive effect that peaked within 40 minutes and remained elevated through the remainder of the time period studied (90 minutes) (Figures 13, 14, 15 and 16). Microinjection of neurotensin ( 3 pmol) into the RVM resulted in a consistent and significant reduction in morphine-induced antinociception (repeated-measures ANOVA with contrasts, $\mathrm{p}<0.05)$. This response to neurotensin had a rapid onset, reaching a maximum within 10 minutes, and was significant from the 50 minute time period through the remainder of the time periods studied (90 minutes) (Figures 13, 15 and 16). 
Microinjection of levocabastine into the RVM alone did not result in any significant alteration of morphine-induced antinociception at any of the concentrations or time points tested (Figure 14, repeated-measures ANOVA with contrasts, $\mathrm{p}<0.05$ ). In addition, no significant change in neurotensin-mediated anti-analgesia was noted at any time point following the RVM administration of levocabastine in any of the concentrations tested (Figure 15, repeated-measures ANOVA with contrasts, $p<0.05$ ). In contrast, SR 48692 (30 pmol) administration into the RVM resulted in a significant blockade of neurotensin's anti-analgesic effect at all times after the injection of neurotensin. Further analysis of the data indicated that not only did SR 48692 result in a significant reversal of neurotensin's anti-analgesic effect, but administration of SR 48692 resulted in a significant potentiation of the antinociceptive response to morphine (Figure 16, repeated-measures ANOVA with contrasts). 
Figure 13

Figure 13. The ability of neurotensin injected into the RVM to reduce and increase the antinociceptive response produced by PAG administration of morphine. In both $\mathbf{A}$ and $\mathbf{B}$, rats were injected with morphine $(6 \mathrm{nmol})$ into the PAG at 10 minutes $(\mathrm{t}=10)$ and neurotensin or vehicle (Saline) was injected 30 minutes later $(t=40) . \quad \mathbf{A}$, time effect curves for morphine injection followed by injection of saline and doses of neurotensin from 0.0001 to $10 \mathrm{nmol}$. The response is illustrated as \% MPE and the mean values are plotted \pm S.E.. A significant anti-analgesic effect was demonstrated when 0.001, 0.003, 0.01, and $0.03 \mathrm{nmol}$ doses of neurotensin were injected into the RVM of rats given morphine into the PAG. A significant antinociception was demonstrated by doses of neurotensin $\geq 0.01 \mathrm{nmol}$. $\mathbf{B}$, the dose-response relationship of neurotensin derived from data in A. Mean MPE values from each dose are represented \pm S.E. at 10 minutes post administration of neurotensin or vehicle is plotted. (*) Denotes a significant reduction in morphine analgesia. $(* *)$ Denotes a significant antinociceptive effect relative to baseline established by $0.003 \mathrm{nmol}$ dose of neurotensin. 
Figure 14

MS



MS +100

MS +10

$\mathrm{MS}+1$

$\mathrm{MS}+0.1$

MS +0.01

$\mathrm{MS}+0.001$

$M S+0.0001$

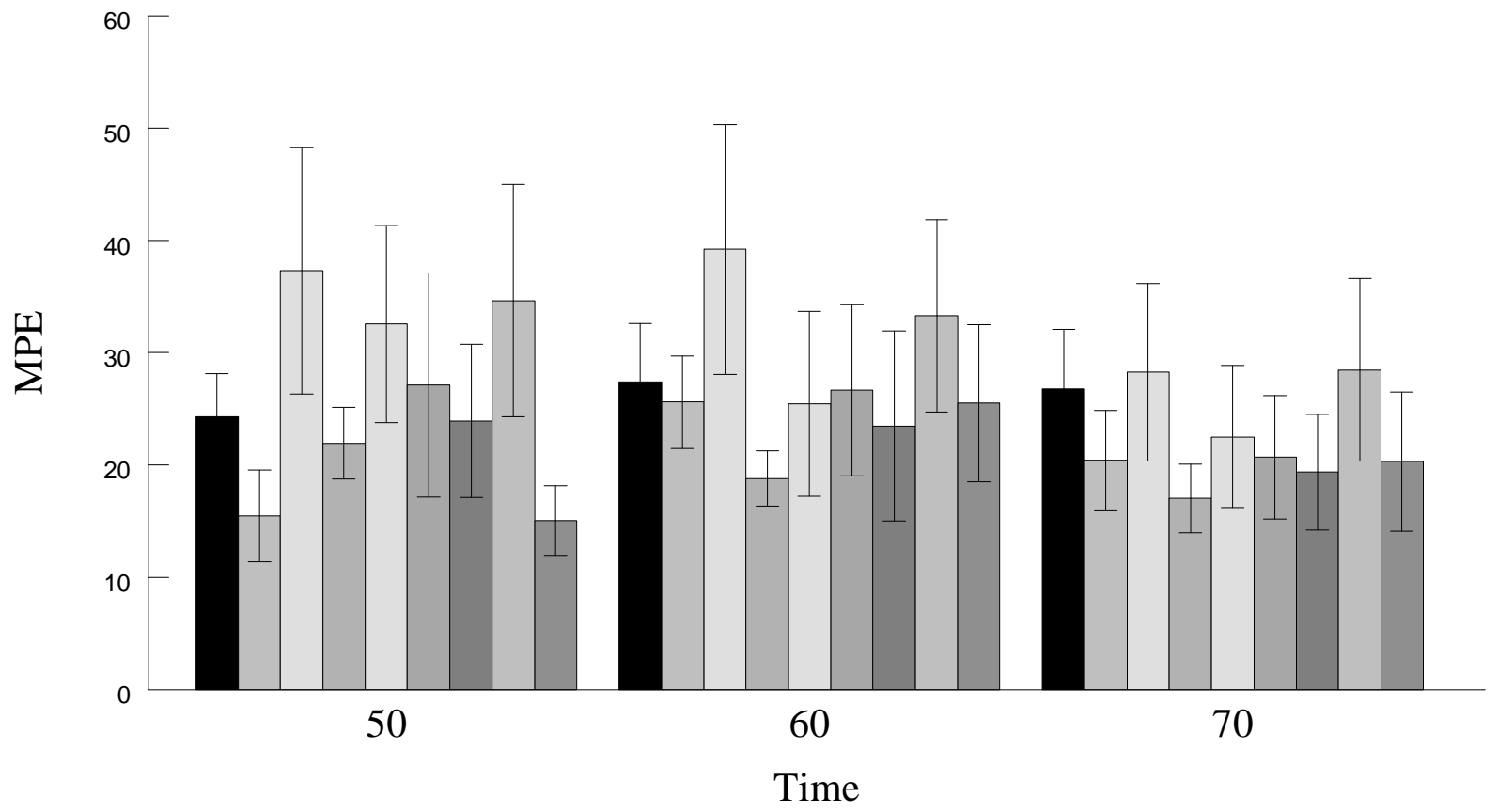


Figure 14. The inability of various doses of levocabastine to alter morphine-induced antinociception. Morphine $(6 \mathrm{nmol})$ was administered into the PAG at 10 minutes, various doses of levocabastine (0.0001 to $1000 \mathrm{pmol})$ or vehicle (DMSO) was administered into the RVM at 20 minutes, and saline (neurotensin vehicle) was administered into the RVM at 40 minutes. These data are illustrated as \% MPE and the mean values from each dose are represented \pm S.E. at 50, 60, and 70 minutes. No significant alteration of the morphine-induced response was measured at any time point following the administration of levocabastine at any concentration (repeated-measures ANOVA with contrasts, $\mathrm{p}<0.05)$. 
Figure 15




Figure 15. The inability of various doses of levocabastine to alter neurotensin-mediated anti-analgesia within the RVM. Morphine (6 nmol) was administered into the PAG at 10 minutes, various doses of levocabastine (0.0001 to $1000 \mathrm{pmol})$ or vehicle (DMSO) was administered into the RVM at 20 minutes, and neurotensin (3 pmol) or vehicle (saline) was administered into the RVM at 40 minutes. These data are illustrated as \% MPE and the mean values from each dose are represented \pm S.E. at 50, 60, and 70 minutes. Microinjection of neurotensin resulted in a significant attenuation of morphine-induced antinociception at all time points illustrated (repeated-measures ANOVA with contrasts, $\mathrm{p}<0.05)$. No significant alteration of neurotensin-induced anti-analgesia was measured at any time point following the administration of levocabastine at any concentration (repeated-measures ANOVA with contrasts, $\mathrm{p}<0.05) .(*)$ Denotes significant change from the response to morphine administration alone. 
Figure 16

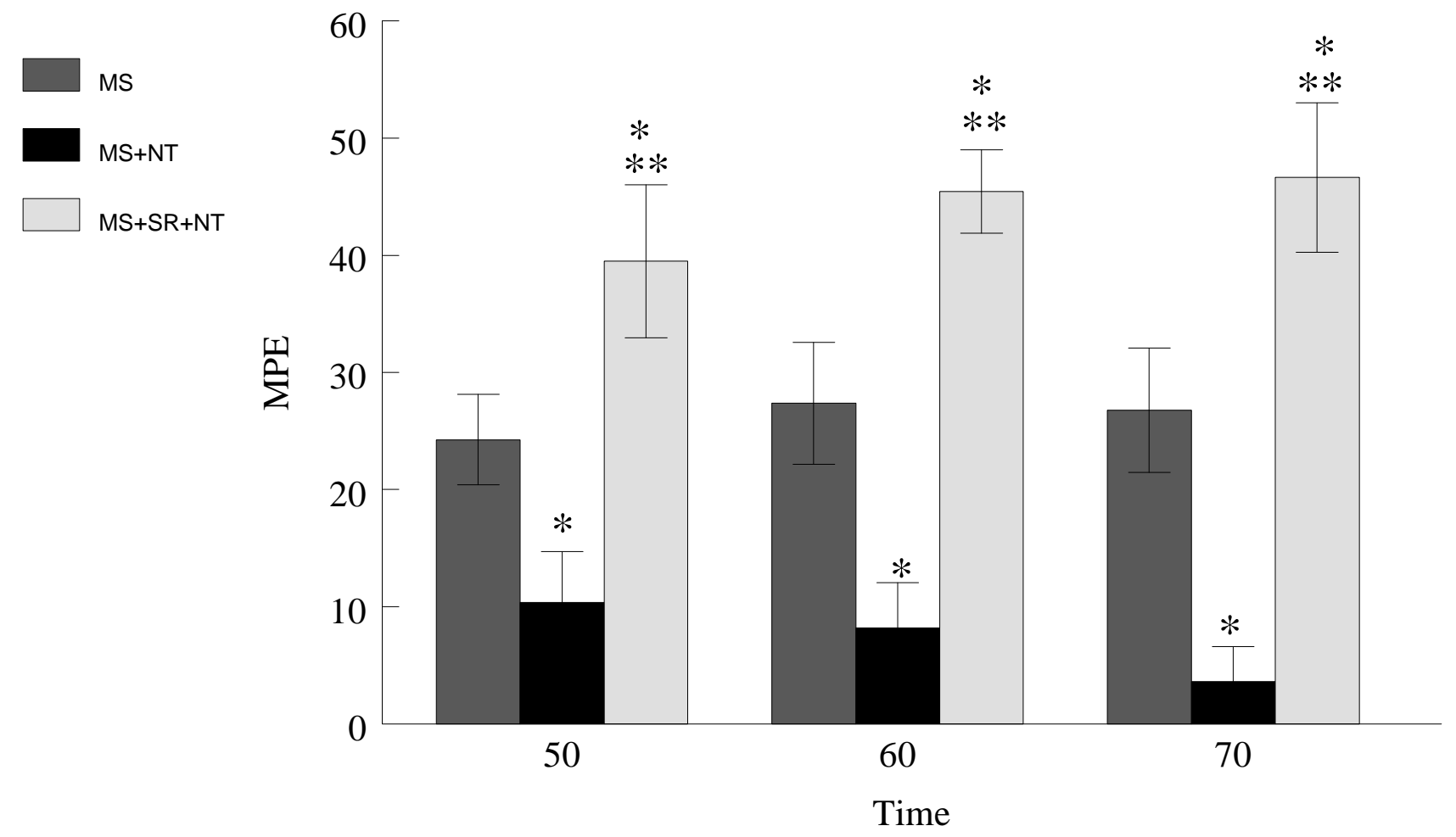


Figure 16. The ability of SR 48692 to alter neurotensin-mediated anti-analgesia within the RVM. Morphine (6 nmol) was administered into the PAG at 10 minutes, SR 48692 (30 pmol) or vehicle (DMSO) was administered into the RVM at 20 minutes, and neurotensin ( $3 \mathrm{pmol}$ ) or vehicle (saline) was administered into the RVM at 40 minutes. These data are illustrated as \% MPE and the mean values from each dose are represented \pm S.E. at 50,60 , and 70 minutes. Microinjection of neurotensin resulted in a significant attenuation of morphine-induced antinociception at all time points illustrated (repeatedmeasures ANOVA with contrasts, $\mathrm{p}<0.05$ ). Administration of SR 48692 was found to significantly reverse neurotensin-mediated anti-analgesia and result in a significant potentiation of morphine-induced antinociceptive response at all time points illustrated (repeated-measures ANOVA with contrasts, $\mathrm{p}<0.05) .(*)$ Denotes a significant change from the response to morphine administration alone. (**) Denotes significant change from the response to a combination of morphine and neurotensin administration. 


\section{Evaluation of intracerebroventricular administration of neurotensin on nociception, body temperature and tail temperature.}

The present study was conducted to establish whether neurotensin's pain facilitatory role could be distinguished following i.c.v. administration. In addition, since i.c.v. administration of neurotensin is known to cause persistent hypothermia (see review by Levant and Nemeroff, 1988), it was necessary to measure the tail temperature of the rats after administration of neurotensin to insure that tail flick latency changes were not due to tail temperature changes known to influence the tail flick reflex (see Methods).

Intracerebroventricular administration of neurotensin significantly and dosedependently produced antinociception (Figure $17 \mathrm{~A}$ and B, repeated-measures ANOVA, $\mathrm{p}<0.05)$. This effect of neurotensin was demonstrable beginning 10 minutes after injection and reached a maximum around 30 to 40 minutes, with the effective dosage range beginning at 3 and extending through $300 \mathrm{nmol}$ (the highest concentration tested). In addition, none of the neurotensin doses tested ( 0.003 to $300 \mathrm{nmol})$ produced a significant reduction in pain threshold (reduction in tail flick latency) at any time following its administration, suggesting that neurotensin-induced pain facilitation does not occur following i.c.v. administration and/or this effect is not able to be resolved with the use of the tail flick model alone.

Another interesting observation that was made in this experiment dealt with temperature changes that were induced by neurotensin administration.

Intracerebroventricular administration of neurotensin significantly and dose-dependently altered the core body temperature of rats without having an effect on tail temperature (Figure 18A, B and C) (repeated-measures ANOVA, $\mathrm{p}<0.05$ ). This effect was 
significant (doses $\geq 3 \mathrm{nmol}$ ) beginning at 20 minute time point and became more prominent with time for the remainder of the test period studied (90 minutes). 


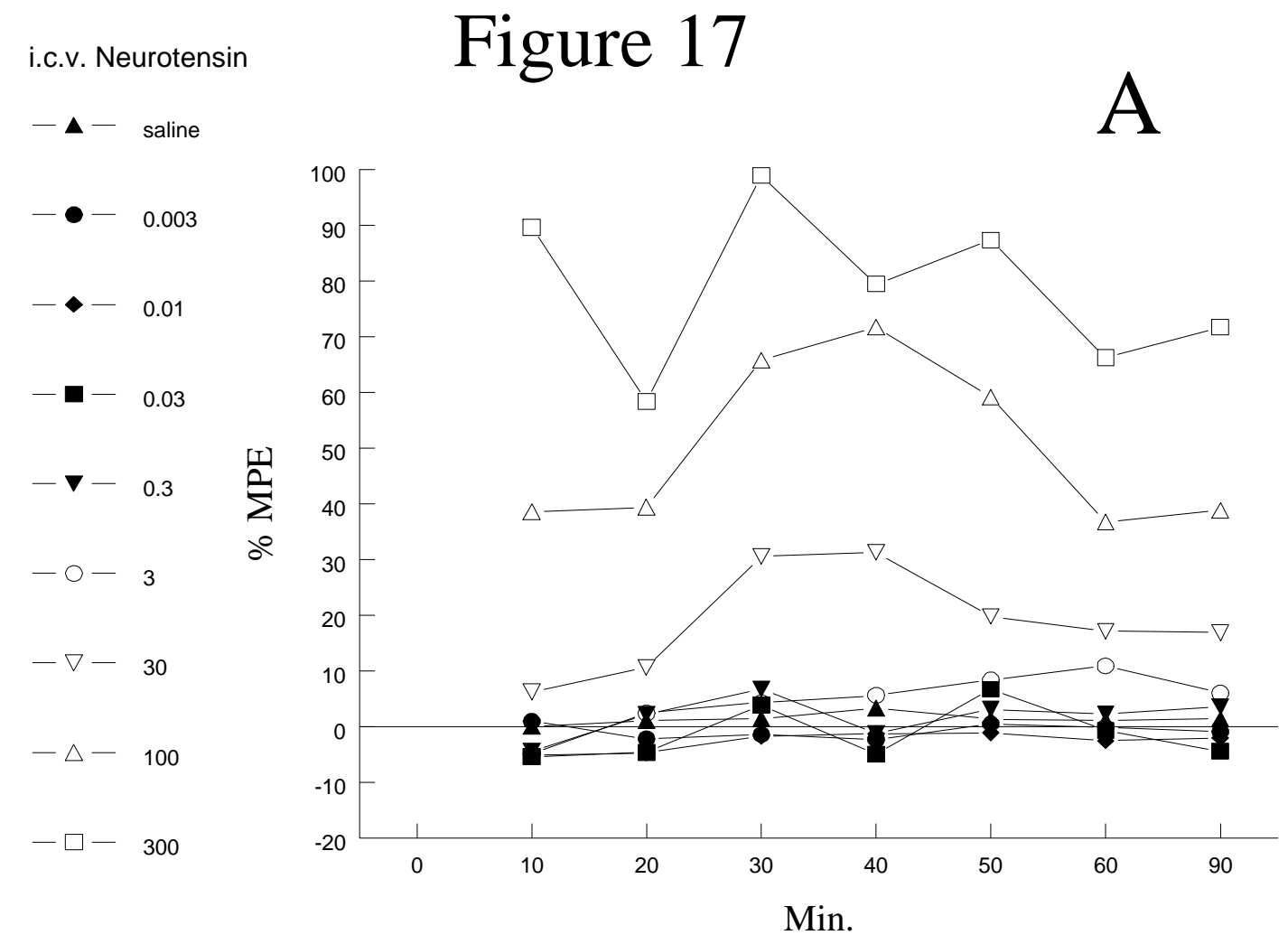

B




Figure 17. The dose-response relationship of neurotensin following intracerebroventricular administration. A, time effect curves for saline (neurotensin vehicle) and doses of neurotensin from 0.003 to $300 \mathrm{nmol}$. All groups have an $\mathrm{n}=6$ or 7 except for the 0.003 and 0.03 doses which have an $n=3$. Data are illustrated as the $\%$ MPE and time is expressed in minutes after the i.c.v. injection of neurotensin or vehicle. A significant antinociceptive effect was demonstrated by neurotensin at doses $\geq 3 \mathrm{nmol}$. $\mathrm{B}$, the dose-response relationship for neurotensin derived from data in A. These data are illustrated as $\%$ MPE and the mean values \pm S.E. at 30 minutes post administration of neurotensin or vehicle are plotted. (*) Denotes a significant antinociceptive effect (one way ANOVA, $\mathrm{p}<0.05)$. 
Figure 18
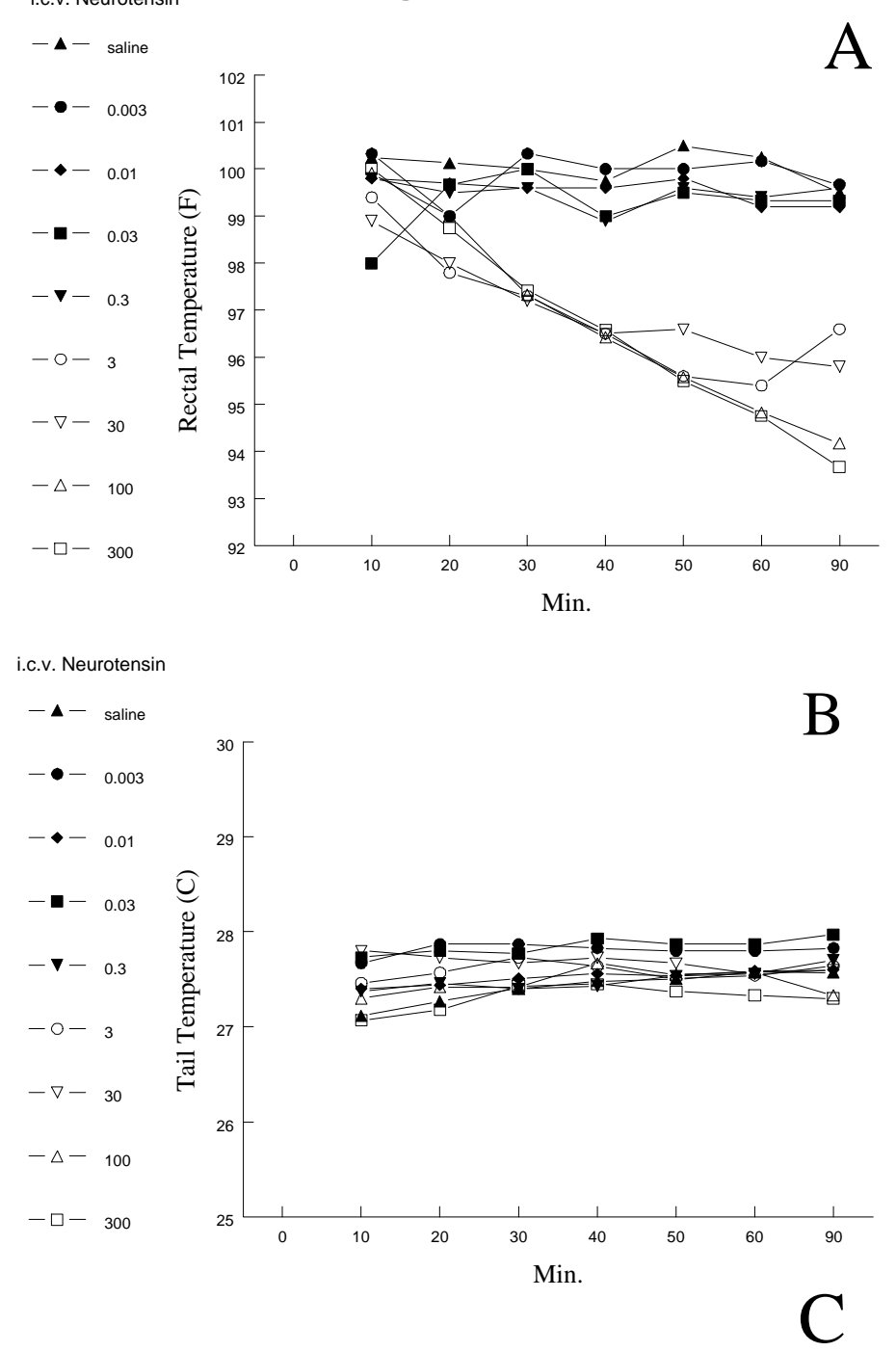

- Neurotensin (tail)

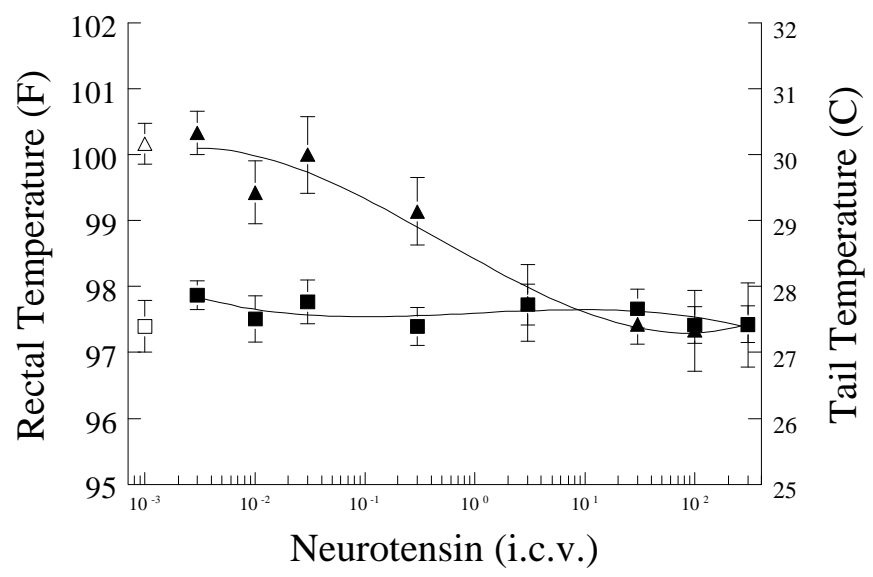


Figure 18. The effects of i.c.v. administration of neurotensin on rectal and tail temperature. A and B, time effect curves for saline (neurotensin vehicle) and doses of neurotensin from 0.003 to $300 \mathrm{nmol}$. Time is expressed in minutes post administration of neurotensin or vehicle. A, effects of i.c.v. neurotensin on the rectal temperature of rats. A significant reduction in rectal temperature was demonstrated by neurotensin and the effective dosage range was from 3 to $300 \mathrm{nmol}$. B, effects of i.c.v. neurotensin on the tail temperature of rats. No significant alteration of tail temperature was observed for any of the concentrations of neurotensin at any time point that was tested (0 to 90 minutes). C, the dose-response relationship for neurotensin derived from A and $\mathrm{B}$. The mean values \pm S.E. at 30 minutes post administration of neurotensin or vehicle are plotted. 


\section{The dose-response relationship of intracerebroventricularly administered neurotensin in the stressed rat.}

Since, it has been demonstrated by previous studies in this project investigating the role of neurotensin within the RVM, that neurotensin can exert anti-analgesic effects that can only be revealed (in the tail flick test) by inducing some baseline level of antinociception (stress-induced analgesia), the ability of i.c.v. neurotensin to produce anti-analgesia was investigated in the stressed rat.

These data show that when rats were exposed to both the hot plate and the tail flick test, and received an injection of saline (see Methods, section 7, hot plate stress model), an increase on the order of $1.5-2.5$ seconds in the tail flick latency occurred $(\cong 30$ $\%$ MPE) ("0" in Figure 19A and " $\Delta$ " in Figure 19B). After the fourth exposure to the hot plate, rats received an injection of one dose of neurotensin $(0.0003$ to $100 \mathrm{nmol})$ or saline (neurotensin vehicle) i.c.v.. Injection of a low dose (3 pmol) of neurotensin produced a significant anti-analgesic (reduction in stress-induced analgesia, saline control) response (one way ANOVA, $\mathrm{p}<0.05$ ), that peaked within 30 minutes after administration. In contrast, administration of higher doses of neurotensin (both 30 and $100 \mathrm{nmol}$ ) resulted in a significant antinociception (relative to baseline established by $0.003 \mathrm{nmol}$ dose of neurotensin), with both concentrations reaching an apparent maximum between 40 and 50 minutes after their administration. This response for the $100 \mathrm{nmol}$ dose of neurotensin was also shown to be significantly elevated above the levels of stress-induced analgesia at all times points beginning 40 minutes after injection (repeated-measures ANOVA, $\mathrm{p}<$ 0.05). It is important to note, that while the maximum observable antinociception 
occurred with a dose of $100 \mathrm{nmol}$, a higher dose $(300 \mathrm{nmol})$ was also studied. The data from this group are not presented because of limitations imposed on the test due to extraneous effects of neurotensin on motility, reflex performance. These effects were noted as a decrease in exploratory behavior, loss of other reflexes (step-up reflex) and in some cases ataxia. 
NT (nmol)

Figure 19

- o- saline

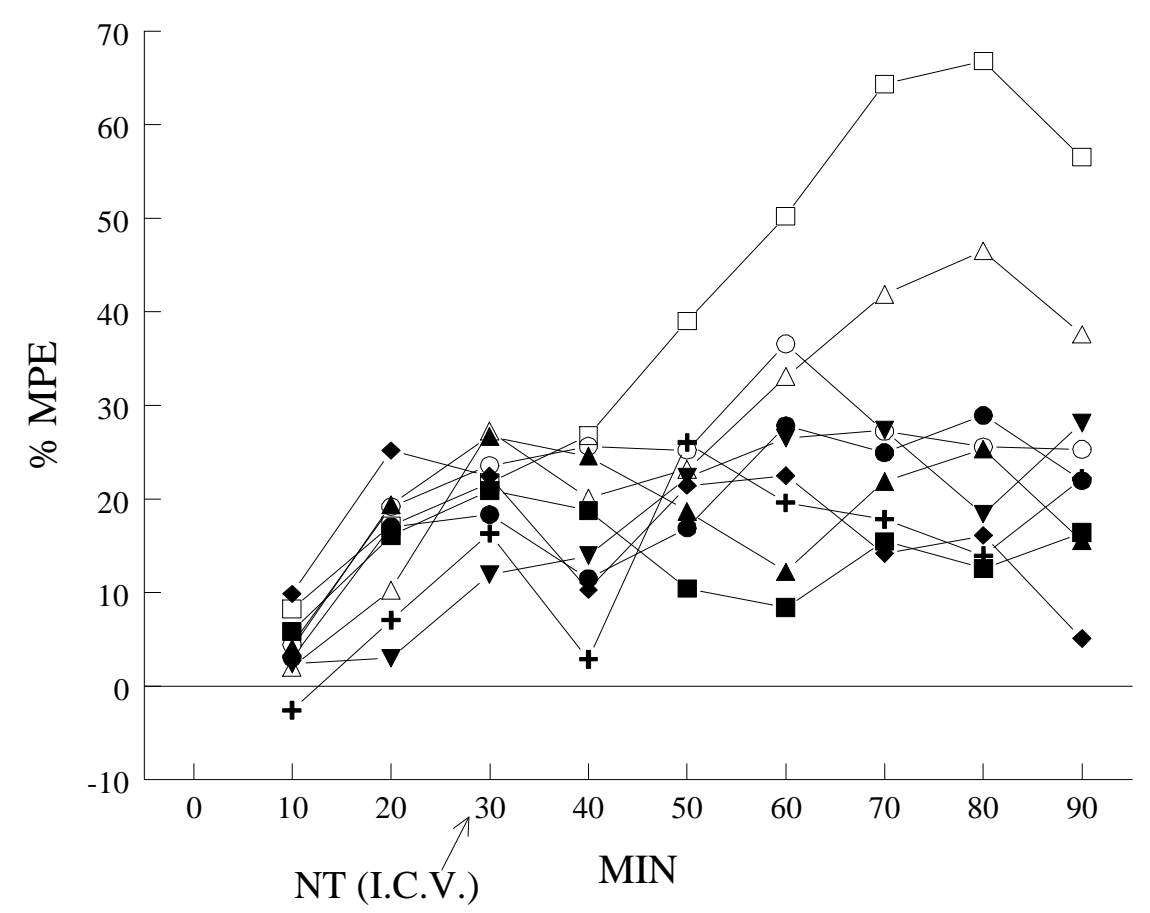

$-\bullet-0.0003$

$-\bullet 0.001$

- - 0.003

$-\mathbf{\nabla}-0.01$

$-\boldsymbol{\Lambda}-0.03$

$-+-0.3$

$-\triangle-30$

$-\square-100$

- Neurotensin

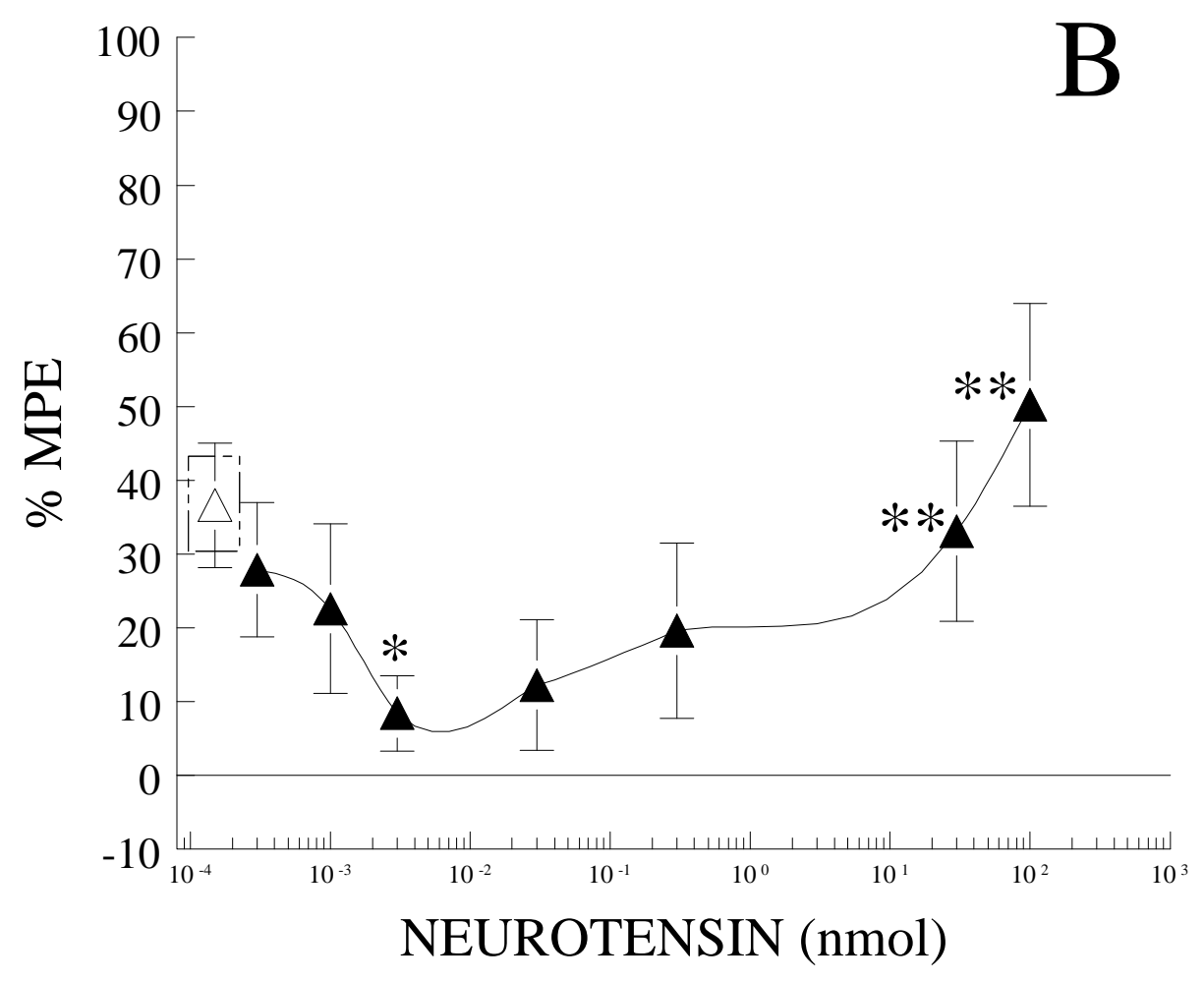


Figure 19. The dose-response relationship for the anti-analgesic and antinociceptive responses to neurotensin following i.c.v. administration in the stressed rat. In both A and B rats were exposed to hot plate stress paradigm for thirty minutes prior to any i.c.v. injection. A, time effect curves for saline (neurotensin vehicle) and doses of neurotensin from 0.0003 to $100 \mathrm{nmol}$. Data are illustrated as the \%MPE and time is expressed in minutes after the first exposure to the stress paradigm. A significant anti-analgesic effect was demonstrated by $0.003 \mathrm{nmol}$, while a significant antinociception was demonstrated by 30 and $100 \mathrm{nmol}$. B, the dose-response relationship of neurotensin derived from data in A. These data are illustrated as $\% \mathrm{MPE}$ and the mean values \pm S.E. at 30 minutes post administration of neurotensin or vehicle are plotted. 


\section{DISCUSSION}

The results of the current study confirm that neurotensin dose-dependently activates opposing pain-inhibitory and pain-facilitatory neuronal processes within the RVM. In addition, the current experiments also demonstrate neurotensin's ability to act in an anti-analgesic manner within the CNS, and confirm that endogenous neurotensinergic pathways may serve to reduce the antinociceptive potential of exogenously administered opioids. Furthermore, results of the current experiments employing the two neurotensin receptor antagonists, SR 48692 and SR 142948A, have demonstrated that the ability of neurotensin to produce its effects (antinociception and pain facilitation) relies on the ability of the peptide to interact with multiple neurotensin receptors or receptor subtypes within the RVM.

In a previous experiment Smith and coworkers (1997), suggested that the predominant physiological role for endogenous neurotensin is to act in a pain-facilitatory manner within the RVM, as the injection of SR 48692 in the absence of exogenous neurotensin only resulted in antinociception (see Figure 1, Smith et al., 1997). However, this effect of SR 48692, which is presumably due to the ability of this antagonist to block neurotensin receptors mediating this facilitatory response, is not seen in the current experiments examining SR 142948A (see Figure 4). In direct contrast to SR 48692 , microinjection of SR 142948A into the RVM does not produce an antinociceptive effect. Taken together, these results indicate that there is a neurotensin-receptor-mediated 
endogenous pain facilitatory tone, which is sensitive to SR 48692 but insensitive to SR 142948A. Therein lies the possibility for a neurotensin receptor subtype in the RVM that mediates pain facilitation, and has affinity for SR 48692, but not for SR 142948A. Further support for this contention arises from an additional comparison made between these two antagonists in the current experiments. Smith and coworkers (1997), demonstrated that neurotensin mediated facilitation underlies and serves to reduce the antinociceptive potential for exogenously administered neurotensin into the RVM, as administration of SR 48692 into the RVM dose-selectively causes an ineffective dose of neurotensin to become distinctively antinociceptive (see Figure 2, Smith et al., 1997). Whereas, in the current experiment, administration of SR 142948A into the RVM was without effect on this same concentration of neurotensin administered into the RVM (see Figures 7 and 8).

Interestingly, at first glance, there appears to be some discrepancy or controversy in the literature concerning the sensitivity of pain facilitatory action of neurotensin within the RVM to SR 48692. Smith and coworkers (1997) have demonstrated the ability of SR 48692 to block neurotensin-mediated pain facilitation within this region as described in the previous paragraph. In contrast, Urban and Gebhart (1997) observed that the antagonist was without effect on neurotensin-evoked facilitation of spinal unit responses to noxious heat produced by microinjection of neurotensin within this same supraspinal site. However, further examination of these two studies indicates that this observational difference in sensitivity to SR 48692 may simply be a dose-related issue. That is, Smith and coworkers report that doses of SR $48692 \geq 0.3$ pmol, microinjected into the RVM, are effective in blocking neurotensin-mediated pain facilitation following RVM 
administration. In the study performed by Urban and Gebhart only one concentration of SR 48692 (30 fmol) was examined. Therefore, the dose that was selected and examined by Urban and Gebhart should have been ineffective, as it represents a dose 10 fold lower than the minimum effective dose distinguished by Smith and coworkers. Thus, it is likely that Urban and Gebhart would have seen an effect of SR 48692 on the neurotensinevoked pain facilitation in their model had they chosen a dose of the antagonist in the effective range.

In addition to these neurotensin receptors mediating neurotensin pain facilitatory effects, multiple neurotensin receptors have also been pharmacologically shown to mediate neurotensin's antinociceptive response (Smith et. al., 1997). First, in this study the investigators demonstrated that the antinociceptive response to neurotensin within the RVM was not mediated by the known low affinity neurotensin receptor, NTR2, since levocabastine neither increased nor decreased this response to neurotensin when administered over a large dose range into the RVM (see Table 2 in Smith et al., 1997). In addition, the investigators demonstrated that SR 48692 inhibited the antinociceptive effect of neurotensin administered into the RVM $(10 \mathrm{nmol})$ in a triphasic manner. That is, low doses of SR 48692 (fmol range) partially inhibited the antinociceptive response to neurotensin, a reversal of this inhibition occurred at higher doses of SR 48692 (low pmol range), which corresponded to the effective dosage range for blocking neurotensininduced pain facilitation, then a second and incomplete inhibition occurred as the dose of SR 48692 was further increased (> 30 pmol) (see Figure 3 in Smith et al., 1997).

Considering the fact that all of neurotensin's antinociceptive effect, within the RVM, must be mediated through the non-levocabastine sensitive neurotensin receptors, of 
which only one has been cloned to date (Tanaka et al., 1990), coupled with the fact that a portion of neurotensin's antinociceptive response appears to be insensitive to SR 48692, the investigators proposed the existence and involvement of three distinct neurotensin receptors in mediating neurotensin's antinociceptive response (which are designated $\mathrm{NTR} 1_{\mathrm{A}}, \mathrm{NTR} 1_{\mathrm{B}}$, and $\mathrm{NTR} 1_{\mathrm{C}}$ respectively, in Table 1 in order to facilitate discussion). These receptors in contrast to those mediating neurotensin's pain facilitatory response all would exhibit lower affinity for neurotensin, relative to the receptors mediating the peptides pain facilitatory response, as a greater concentration neurotensin is required to produce this response in comparison to the pain facilitatory response within the same region. The first receptor then would exhibit a high relative affinity for SR 48692, as fmol doses SR 48692 effective in reducing this effect of neurotensin. The second would exhibit a low relative affinity for SR 48692, as a second inhibitory phase seen with high concentrations of SR 48692, $\geq 30$ pmol. Lastly, the third receptor would exhibit limited if any affinity for SR 48692, as a portion of neurotensin's antinociceptive response is not blocked by SR 48692.

In the current study, examination of SR 142948A for its ability to alter neurotensin-mediated antinociception within the RVM revealed that this antagonist has a completely different antagonist dose-response relationship and further displayed differences in receptor selectivity compared to SR 48692. That is SR 142948A dosedependently inhibits the antinociceptive response to neurotensin in a biphasic manner (see Figures 5 and 6) rather than in a triphasic manner as does SR 48692. Furthermore, the fact that SR 142948A completely inhibits the antinociceptive effect of neurotensin demonstrates two important findings in this study. First, it demonstrates that the 
Table 1: Hypothesized neurotensin receptors found Within the RVM That are Involved in Pain Modulation

\begin{tabular}{|c|c|c|c|c|c|c|}
\hline Receptor & $\begin{array}{c}\text { Nociceptive } \\
\text { Action }\end{array}$ & $\begin{array}{l}\text { Affinity for } \\
\text { neurotensin }\end{array}$ & $\begin{array}{c}\text { Affinity for } \\
\text { SR48692 }\end{array}$ & $\begin{array}{l}\text { Affinity for } \\
\text { SR142948A }\end{array}$ & $\begin{array}{c}\text { Affinity for } \\
\text { Levocabastine }\end{array}$ & Supporting evidence \\
\hline $\mathrm{NTR} 1_{\mathrm{A}}$ & Inhibition & Low & High & Moderate & None & $\begin{array}{l}\text {-High [ ] NT needed for activation } \\
\text {-Inhibited by low doses of SR } 48692 \\
\text {-Inhibited by SR 142948A }\end{array}$ \\
\hline NTR1 $1_{B}$ & Inhibition & Low & Low & Moderate & None & $\begin{array}{l}\text {-High [ ] NT needed for activation } \\
\text {-Inhibited by high doses of SR } 48692 \\
\text {-Inhibited by SR 142948A }\end{array}$ \\
\hline $\mathrm{NTR}_{\mathrm{C}}$ & Inhibition & Low & $\begin{array}{l}\text { Limited if } \\
\text { any }\end{array}$ & Moderate & None & $\begin{array}{l}\text {-High [ ] NT needed for activation } \\
\text {-Insensitive to SR } 48692 \\
\text {-Inhibited by SR 142948A } \\
\text { (Heaulme et al., 1997) }\end{array}$ \\
\hline NTR1 $1_{D}$ & Facilitation & High & Moderate & None & None & $\begin{array}{l}\text {-Low [ ] NT needed for activation } \\
\text {-Inhibited by moderate doses SR } 48692 \\
\text {-Insensitive to SR 142948A }\end{array}$ \\
\hline $\mathrm{NTR} 1_{\mathrm{E}}$ & Facilitation & High & Moderate & Limited & None & $\begin{array}{l}\text {-Low [ ] NT needed for activation } \\
\text {-Inhibited by moderate doses SR } 48692 \\
\text {-Blocked by } 30 \text { pmol dose SR } 142948 \text { A }\end{array}$ \\
\hline NTR2 & $?$ & Low & Low & High & High & $\begin{array}{l}\text {-Lower affinity for NT in binding } \\
\text { studies than NTR1, NT binding } \\
\text { completely inhibited by levocabastine, } \\
\text { SR } 48692 \text { and SR } 142948 \text { A }\end{array}$ \\
\hline
\end{tabular}


Table 1. Listing of the hypothesized neurotensin receptors found within the RVM that are involved in pain modulation. Receptor names have been classified by the author in order to facilitate discussion and do not reflect any currently used receptor nomenclature. Some of these receptor subtypes have been proposed previously by Smith and coworkers (1997) and have been either verified or further characterized by the current set of experiments. The relative affinities are a composite of binding data taken from previous publications (Betancur et al., 1998; Gully et al., 1993; 1997; Schotte et al., 1986) and the dose-response relationships generated by the current set of experiments as well as those reported by Smith and coworkers (1997). NT symbolizes neurotensin. [ ] symbolizes concentration or dose. 
previously described neurotensin receptor that lacks affinity for SR 48692 (e.g. portion of neurotensin's antinociceptive response that is insensitive to SR 48692) has affinity for SR 142948A (designated NTR $1_{c}$ in Table 1). Second, it demonstrates that all of the neurotensin receptors that mediate antinociception within the RVM (designated NTR $1_{\mathrm{A}}$, $\mathrm{NTR} 1_{B}$, and $\mathrm{NTR} 1_{\mathrm{C}}$ in Table 1 ) are sensitive to this antagonist (note that a moderate relative affinity for SR 142948A was assigned to these receptors in Table 1, as low and high concentrations of the antagonist were ineffective). Therefore, the current results support the contention that multiple neurotensin receptors (subtypes of the NTR1 receptor) are involved in mediating neurotensin's antinociceptive action within the RVM. The ability to demonstrate these subtypes neurochemically has been difficult and is yet to be completed (Le et al., 1996; Vincent, 1995). However, in order to explain the doseselective actions of various neurotensinergic compounds on neurochemical and physiological processes, it is generally conceded that they must exist (Gully et al., 1993; Labbe-Jullie et al., 1994; Le et al., 1996; Poncelet et al., 1994; Pugsley et al., 1995; Smith et al., 1997; Steinberg et al., 1994; Vincent, 1995).

Some controversy exists regarding the neurotensin receptor subtypes that are involved in mediating neurotensin's antinociceptive response. As previously described Smith and coworkers (1997) demonstrated that neurotensin's antinociceptive response within the RVM of rats is insensitive to levocabastine, but can be attenuated by SR 48692. Indicating, that neurotensin-induced antinociception within the RVM of rats is mediated through a receptor that does not share the characteristics of the known NTR2 receptor and is sensitive to SR 48692. Urban and Gebhart (1997) further supported this observation, as they observed that inhibition of spinal unit responses to noxious heat 
produced by the microinjection of neurotensin into the RVM of rats could be blocked by the microinjection of SR 48692 into this same site. However, the results of these two studies are in contrast to results from two additional studies. First, neurotensin-induced analgesia (writhing test) following i.c.v. administration in mice was shown to be unaffected by SR 48692 (Gully et al., 1993). In addition, Dubuc and coworkers (1999) using antisense oligodeoxynucleotides, for the cloned NTR1 and NTR2 receptor, demonstrated that neurotensin-induced analgesia (writhing test) following i.c.v. administration in mice is mediated solely by the NTR2 receptor. The reason for the discrepancies between these studies is not understood, however it appears that these studies may be resolving an important differences in neurotensin-mediated antinociception that exists between species (i.e. rat vs. mouse) or perhaps the involvement of different neurotensin receptor subtypes at varying supraspinal sites. In this regard, it is conceivable that neurotensin's antinociceptive effect is mediated via a NTR2 receptor following i.c.v. administration (i.e. within the PAG) or in mice and an NTR1 receptor following RVM administration or in rats. Additionally, these evaluations on neurotensin's antinociceptive effect were performed in drastically different pain models (visceral vs reflexive), in which completely different pain modulatory systems may be involved (Hammond, 1989). Thus, these conflicting observations may due to differences in the selectivity of the pain model chosen. However, it is clear that further studies need to be conducted both within the RVM of mice and following i.c.v. administration in rats to resolve the basis for these discrepancies.

The appearance of multiphasic dose-response curves for the ability of SR 142948A to inhibit neurotensin-mediated effects within the RVM raises another 
important issue that needs to be considered. In this regard, a bell-shaped (biphasic) doseresponse relationship was observed for the ability of SR 142948A to antagonize neurotensin's antinociceptive effect as well as to reverse neurotensin-mediated antianalgesia following systemic morphine administration. The reason for the reversal of the SR 142948A's effectiveness at higher doses (i.e. reinstatement of neurotensin's effect) is not clearly understood. However, these observations are consistent with the doseresponse relationship seen with this antagonist on other neurotensin-mediated processes within the central nervous system and resemble results and observations from previous studies examining the dose-response relationship of SR 48692 on the same neurotensininduced effects. For example, Smith and coworkers (1997) demonstrated that SR 48692 had a triphasic dose-response relationship in regard to its ability to alter neurotensininduced antinociception within the RVM. Likewise, a triphasic dose-response relationship for SR 48692 was demonstrated for the ability of the antagonist to inhibit neurotensin-mediated turning behavior in mice following intrastriatal administration (Poncelet et al., 1994). In this regard, the current set of experiments demonstrated SR 142948A to have a biphasic dose-response relationship to inhibit neurotensin-induced antinociception within the RVM, and Gully and coworkers (1997) have demonstrated the same biphasic dose-response relationship for SR 142948A to inhibit neurotensinmediated turning behavior in mice following intrastriatal administration. Interestingly, in both of these studies where the antagonists dose-response relationship in the RVM were similar to the dose-response relationship seen with antagonism of neurotensin-mediated turning behavior intrastriatally, the reinstatement of the turning behavior could be abolished by pretreating the animals with spiroperidol, a dopamine $\mathrm{D}_{2}$ receptor 
antagonist. Therefore, involvement of dopamine regulatory mechanisms has been proposed to account for the multiphasic dose-response relationships seen with these two antagonists (Gully et al., 1997; Poncelet et al., 1994; Smith et al., 1997). Moreover, since dopamine is a neurotransmitter known to be involved in pain modulation within the RVM (Phillips et al., 1986), and neurotensin receptors have been shown to be associated with dopaminergic synapses (Kitabgi, 1989) this contention is likely. However, additional studies still need to be performed to more adequately evaluate this possibility.

An experiment done in the current study was aimed at examining whether the pain facilitatory (anti-analgesic) effects of neurotensin are mediated by the NTR2 receptor or through an additional subtype of the NTR1 receptor. In this experiment, it was demonstrated that the anti-analgesic response to neurotensin within the RVM was not mediated by the NTR2 neurotensin receptor since levocabastine neither increased nor decreased this response to neurotensin when administered over a large dose range into the RVM. The fact that levocabastine does not have an effect on this response to neurotensin is consistent with other data collected in our laboratory indicating that that levocabastine neither increases or decreases the antinociceptive to neurotensin within the RVM. That is, if levocabastine was capable of inhibiting the pain facilitatory response to neurotensin, which underlies neurotensin's antinociceptive action, than we would have expected levocabastine administration to result in a potentiation of neurotensin-induced antinociception, which it did not (Smith et al., 1997). Furthermore, the results from the current experiment conducted in this study (in vivo) are in agreement with the current literature examining both neurotensin's ability to produce pain facilitation and neurotensin receptor(s) affinity in binding assays (in vitro). These studies have 
characterized the NTR2 receptor as having low affinity for neurotensin and its analogs (Chalon et al., 1996; Schotte et al., 1986). Whereas in the current study, the pain facilitatory response to neurotensin, within the RVM, appears to be induced by low doses of the peptide and thus is mediated by receptors expressing a high affinity for neurotensin (Smith et al., 1997; Urban and Gebhart, 1994; 1997; Urban and Smith, 1993; 1994; Urban et al., 1996b; 1996c). Therefore, it is reasonable to propose that the pain facilitatory response to neurotensin, in addition to the antinociceptive action of neurotensin within the RVM, is mediated via a neurotensin receptor that is a subtype or splice variant of the NTR1 receptor. Moreover, this receptor appears to be sensitive to SR 48692, but not to SR 142948 A and has yet to be cloned (NTR1 $1_{D}$ in Table 1).

This contention for a multiple NTR1 receptor subtypes with varying affinity for the two antagonists is also supported by the current literature examining neurotensin receptor binding and the ability of these two antagonists to alter other neurotensin receptor mediated physiological effects. First, binding studies utilizing the two identified and cloned neurotensin receptors, NTR1 and NTR2, have demonstrated that the two antagonists, SR 48692 and SR 142948A, have affinity for both receptors and completely displace neurotensin binding (Gully et al., 1993; 1997). Therefore selective differences in their ability to alter neurotensin-induced receptor-mediated effects must constitute a novel receptor or splice variant. Second, in direct contrast to SR 48692, SR 142948A has been shown to block both hypothermia and analgesia induced by i.c.v. injection of neurotensin in mice (Gully et al., 1997). Indicating another receptor subtype or splice variant that is sensitive to SR 142948A but not SR 48692 (perhaps corresponding to NTR1 $1_{C}$ in Table 1). On the other hand SR 48692 has been demonstrated to block 
dopamine release evoked by neurotensin injection into the ventral tegmental area (VTA) of rats (Steinberg et al., 1994), whereas SR 142948A is unable to modify neurotensinmediated dopamine release in this same protocol (Gully et al., 1997). Therefore suggesting the existence of a neurotensin receptor subtype, within the rat, that has affinity for SR 48692 but lacks affinity for SR 142948 A (corresponding to NTR $1_{D}$ or NTR $1_{E}$ in Table 1). Furthermore Heaulme and coworkers (1997) demonstrated that selective differences exist between the two antagonists when they examined their ability to alter neurotensin's action to potentiate $\mathrm{K}^{+}$- and electrically-induced $\left[{ }^{3} \mathrm{H}\right]$ dopamine release in guinea pig striatal slices. The usefulness of this preparation is that guinea pigs have been characterized to only have the NTR1 receptor (i.e. they are devoid of the NTR2 receptor), thus any discrimination made between the two antagonists reflects subtypes of the NTR1 receptor. In this experiment SR 48692 was shown to reduce the neurotensin-mediated potentiation of $\mathrm{K}^{+}$-induced dopamine release, but to have no effect on neurotensinmediated potentiation of electrically-induced dopamine release. In contrast to SR 48692, SR 142948A was shown to antagonize both of these effects of neurotensin and therefore further supported the notion that there are multiple NTR1 receptor subtypes. Moreover, the results from this experiment, examining the ability of SR 142948A to alter the antinociceptive response to neurotensin, support the contention for the existence of an NTR1 receptor subtype that is sensitive to SR 142948A but insensitive to SR 48692 (resembling NTR1 $1_{\mathrm{C}}$ in Table 1).

It is important to note that in this study no facilitatory effect of a low dose of neurotensin ( $30 \mathrm{pmol}$ ) injected into the RVM could be demonstrated in the tail flick test alone. While injection of this dose of neurotensin has been demonstrated previously to 
produce a decrease in tail flick latency (Urban and Smith, 1993), other researchers have demonstrated more recently that the ability to resolve this effect using the tail flick test is highly variable (Smith et al., 1997). One reason for this has been proposed to be due to the limits of this test paradigm to show drug-induced decreases in the threshold of the tail flick reaction (Hammond, 1989; Ness and Gebhart, 1986; Smith et. al., 1997).

Furthermore, it had been speculated that raising the threshold for responding in this test, by stressing the rats, might allow for the consistent expression of neurotensin's pain facilitatory response (Smith et. al., 1997). The current set of experiments confirmed this hypothesis, as a dose-response curve to neurotensin, that was generated using the tail flick test in stressed rats, showed that both RVM and i.c.v. administration of neurotensin had biphasic effects on nociception, with low doses resolving a significant anti-analgesic effect of neurotensin and higher doses producing a significant antinociception.

Further discrimination between the two antagonists, SR 142948A and SR 48692, was shown in experiments evaluating their ability to block this neurotensin-mediated anti-analgesia within the RVM of the stressed rat. SR 48692 was effective in reversing this effect of neurotensin, but SR 142948A was not. Interestingly, controls from these experiments revealed that these antagonists differ in their ability to inhibit the induction of stress-induced analgesia. SR 48692 appears to be effective in reducing the magnitude of stress-induced analgesia while SR 142948A appears to lack the ability to have this effect. This observation is important as it demonstrates for the first time that neurotensinergic mechanisms within the RVM may be involved in the production of stress-induced analgesia. Furthermore, these data support the possibility of a neurotensin receptor subtype that is sensitive to SR 48692 and insensitive to SR 142948A 
(corresponding to $\mathrm{NTR} 1_{\mathrm{D}}$ in Table 1 ).

With respect to the mechanism underlying the ability of systemic SR 142948A to potentiate morphine analgesia, it appears that SR 142948A's sole mechanism of action does not rely on its ability to inhibit neurotensin-dependent mechanisms subserving painfacilitatory functions within the RVM. In the current set of experiments no significant effect of SR 142948A was demonstrable in any experiment on neurotensin-mediated pain facilitation or anti-analgesia induced by exogenous administration of neurotensin, stress or merely injection of the antagonist alone. However, a modest effect was demonstrated in the experiment examining the ability of this antagonist administered directly into the RVM to alter systemic morphine analgesia. In this experiment, SR 142948A resulted in a dose-selective potentiation of morphine analgesia, with only the 30 pmol dose of SR 142948A being significantly different, and doses 10 fold higher and lower being without effect. Since SR 142948A is a selective and competitive antagonist of neurotensin receptors (Gully et al., 1997), this ability to potentiate morphine analgesia must be related to neurotensin receptor-dependent mechanisms within the RVM. However, results from other experiments in the present study, showing that the antagonist does not interact with neurotensin-dependent pain facilitatory systems in this same region, suggest that the antagonist may exert its effects through some indirect actions. Regardless of how SR 142948A administration into the RVM results in a potentiation of morphine analgesia, this effect (only at one dose and not nearly as robust as SR 48692) does not logically account for the ability of the antagonist, when administered systemically (all doses $\geq$ $0.001 \mathrm{mg} / \mathrm{kg}$ ), to potentiate systemic morphine analgesia (manuscript in preparation). Therefore, it appears that the ability of systemically administered SR 142948A to 
enhance the action of morphine may be related to the antagonism of neurotensin receptors located in other areas in the CNS (e.g. supraspinally within the PAG or at the level of the spinal cord). In support of this contention, neurotensin has been demonstrated to be involved in modulating nociception at additional sites within the CNS, such as within PAG (Behbehani and Fields, 1979; Behbehani and Pert, 1984; Sullivan and Pert, 1981; VanPraag and Frenk, 1990) and at the level of the spinal cord (see reviews by Coderre et al., 1993; Yaksh and Malmberg, 1993). Furthermore, site selective differences in the action of SR 142948 A and SR 48692 is only one possibility. It is also reasonable to propose that the two compounds undergo metabolism following systemic administration that does not occur following supraspinal administration. Therefore, an active metabolite of SR 142948A (i.e. following CYP3A4 mediated ndealkylation in the liver) may be responsible for the effects of the compound following systemic administration. In this regard the researcher can only make a speculation as all metabolic data were considered to be proprietary information and not available for analysis.

The issue of diffusion away from the site of injection raises other important pharmacokinetic and pharmacodynamic questions that have the potential to influence the interpretation of the data collected in this study. These questions, which are associated with not only the effects of neurotensin, but also with the ability of the two antagonists to alter the response to neurotensin, can be centered on the delay in onset and apparent extension in duration of action of both neurotensin and the two antagonists. First, in several studies now (Smith et al., 1997, Urban and Smith 1993; 1994; Urban et al., 1996b) including the present experiment the time required for neurotensin's to produce 
its peak antinociceptive effect has been on the order of 30 minutes, which far exceeds the time required (i.e. pharmacodynamics) for peptide to interact with its receptors and produce a response. Likewise, the response to neurotensin has duration of approximately 110 minutes, which far exceeds the time that one would expect the peptide to be present at the site of injection in an effective concentration, as the peptide is rapidly metabolized by brain peptidases (Checler et al., 1983; Mcdermott et al., 1982; 1983; Skidgel et al., 1984). The reason for this delay in the onset and prolonged action of neurotensin's is not understood, however diffusion of the peptide away from the site of injection is a definite possibility. In these experiments the target site for microinjection has been the $\mathrm{RMg}$, however microinjection of neurotensin into various nuclei surrounding the $\mathrm{RMg}$ has been demonstrated to result in significant antinociception (Urban and Smith, 1994). Therefore it is likely that both the delay in onset and prolonged effects of neurotensin following its administration into this region represents the action of neurotensin not only at the site of administration, but also at additional sites in the near proximity of the injection.

The issues of delay in onset and apparent extension of duration of action were also apparent in experiments examining the two antagonists. Staggering the time of administration of both SR 48692 and SR 142948A into the RVM relative to neurotensin administration revealed that the two antagonist have a similar onset and duration of action. These studies (data not shown) resolved that both antagonists have an onset within ten minutes and duration of action of 60 minutes. However, responses to the administration of SR 142948A and SR 48692 within the RVM in the current study as well as results examining SR 48692 within the RVM in the past (Smith et al., 1997) has demonstrated that these antagonists can produce effects that far exceed their duration of 
action. Similarly, the results could be explained by diffusion of the antagonist to surrounding sites where they modulate neurotensin's response. It should be noted however that diffusion is only one possible explanation for these enduring responses. Alternatively, the response to both neurotensin and the antagonists could be prolonged due to their ability to promote or prevent protein synthesis and/or signal transduction cascades. Additionally, the antagonists could be inhibitng neurotensin-mediated neuronal systems that have a different time frame for activation (i.e. neurotensin is released from neurons at a later period of time as the result of some cascade of events). These explanations are merely speculation however, and further investigations need to be conducted in order to elucidate the specific mechanisms that are involved in mediating these delayed and prolonged responses.

In conclusion, these results confirm that neurotensin dose-dependently activates opposing pain-inhibitory and pain-facilitatory neuronal processes through receptorselective mechanisms. Furthermore, SR 142948 A and SR 48692 have the ability to discriminate between these neurotensin receptor-selective mechanisms and neurotensin's multiple effects on pain modulation within the RVM. Moreover, these two antagonists appear to potentiate systemic morphine analgesia either through different mechanisms or sites of action. Although the mechanism of SR 48692 appears to involve neurotensinergic processes within the RVM, the direct mechanism of action of SR 142948A still needs to be resolved through further investigation. 


\section{REFERENCE LIST}

Abols IA and Basbaum AI (1981) Afferent connections of the rostral medulla of the cat: a neural substrate for midbrain-medullary interactions in the modulation of pain. J. Comp. Neurol. 201:285-297.

Adams JE (1976) Naloxone reversal of analgesia produced by brain stimulation in the human. Pain 2:161-166.

Aimone LD and Gebhart GF (1986) Stimulation-produced spinal inhibition from the midbrain in the rat is mediated by an excitatory amino acid neurotransmitter in the medial medulla. J. Neurosci. 6:1803-1813.

Airaksinen MS, Flugge G, Fuchs E, and Panula P (1989) Histaminergic system in the tree shrew brain. J. Comp. Neurol. 286:289-310.

Akil $\mathrm{H}$ and Liebeskind JC (1975) Monoaminergic mechanisms of stimulation-produced analgesia. Brain Res. 94:279-296.

Akil H and Mayer DJ (1976) Antagonism of stimulation-produced analgesia by naloxone, a narcotic antagonist. Science 191:961-962.

Araki T, Yamano M, Murakami T, Wanaka A, Betz H, and Tohyama M (1988) Localization of glycine receptors in the rat central nervous system: an immunocytochemical analysis using monoclonal antibody. Neurosci. 25:613624.

Arvidsson U, Cullheim S, Ulfhake B, Bennett GW, Fone KC, Cuello AC, Verhofstad AA, Visser TJ, and Hokfelt T (1990) 5-Hydroxytryptamine, substance P, and thyrotropin-releasing hormone in the adult cat spinal cord segment L7: immunohistochemical and chemical studies. Synapse 6:237-270.

Azami J, Llewelyn MB, and Roberts MHT (1982) The contribution of nucleus reticularis paragigantocellularis and nucleus raphe magnus to the analgesia produced by systemically administered morphine, investigated with the microinjection technique. Pain 12:229-246. 
Bandler, R, Carrive, P, and Depaulis, A (1991) Introduction: Emerging principles of organization of the midbrain periaqueductal gray matter, in The Midbrain Periaqueductal Gray Matter: Functional, Anatomical, and Neurochemical Organization, (Depaulis A and Bandler R eds) pp 1-8, Plenum Publishing Corp., New York.

Barbaresi P and Manfrini E (1988) Glutamate decarboxylase-immunoreactive neurons and terminals in the periaqueductal gray of the rat. Neurosci. 27:183-191.

Barbaro NM, Heinricher MM, and Fields HL (1986) Putative pain modulating neurons in the rostral ventral medulla: reflex-related activity predicts effects of morphine. Brain Res. 366 :203-210.

Barke KE and Hough LB (1992) Morphine-induced increases of extracellular histamine levels in the periaqueductal grey in vivo: a microdialysis study. Brain Res. 572:146-153.

Basbaum AI, Clanton CH, and Fields HL (1976) Opiate and stimulus-produced analgesia: functional anatomy of a medullospinal pathway. Proc. Natl. Acad. Sci. U. S. A. 73:4685-4688.

Basbaum AI, Clanton CH, and Fields HL (1978) Three bulbospinal pathways from the rostral medulla of the cat: an autoradiographic study of pain modulating systems. J. Comp. Neurol. 178:209-224.

Basbaum AI and Fields HL (1978) Endogenous pain control mechanisms: review and hypothesis. Annals of Neurology 4:451-462.

Basbaum AI and Fields HL (1979) The origin of descending pathways in the dorsolateral funiculus of the spinal cord of the cat and rat: further studies on the anatomy of pain modulation. J. Comp. Neurol. 187:513-531.

Basbaum AI and Fields HL (1984) Endogenous pain control systems: brainstem spinal pathways and endorphin circuitry. Annual Reviews of Neuroscience 7:309-338.

Basbaum AI, Marley N, O'Keefe J, and Clanton CH (1977) Reversal of morphine and stimulus produced analgesia by subtotal spinal cord lesions. Pain 3:43-56. 
Basbaum AI, Ralston DD, and Ralston HJ (1986) Bulbospinal projections in the primate: a light and electron microscopic study of a pain modulating system. J. Comp. Neurol. 250:311-323.

Beall JE, Martin RF, Applebaum AE, and Willis WD (1976) Inhibition of primate spinothalamic tract neurons by stimulation in the region of the nucleus raphe magnus. Brain Res. 114:328-333.

Beart PM, Summers RJ, Stephenson JA, Cook CJ, and Christie MJ (1990) Excitatory amino acid projections to the periaqueductal gray in the rat: a retrograde transport study utilizing D[3H] aspartate and [3H]GABA. Neurosci. 34:163-176.

Bederson JB, Fields HL, and Barbaro NM (1990) Hyperalgesia during naloxoneprecipitated withdrawal from morphine is associated with increased on-cell activity in the rostral ventromedial medulla. Somatosens. Mot. Res. 7:185-203.

Behbehani MM (1992) Physiological mechanisms of the analgesic effect of neurotensin. Ann. N. Y. Acad. Sci. 668:253-265.

Behbehani MM and Fields HL (1979) Evidence that an excitatory connection between the periaqueductal gray and nucleus raphe magnus mediates stimulation produced analgesia. Brain Res. 170:85-93.

Behbehani MM, Jiang MR, Chandler SD, and Ennis M (1990) The effect of GABA and its antagonists on midbrain periaqueductal gray neurons in the rat. Pain 40:195204.

Behbehani MM and Pert A (1984) A mechanism for the analgesic effect of neurotensin as revealed by behavioral and electrophysiological techniques. Brain Res. 324:3542.

Behbehani MM and Pomeroy SL (1978) Effect of morphine injected in periadueductal gray on the activity of single units in nucleus raphe magnus of the rat. Brain Res. 149:266-269.

Behbehani MM, Pomeroy SL, and Mack CE (1981) Interaction between central gray and nucleus raphe magnus: role of norepinephrine. Brain Res. Bull. 6:361-364. 
Beitz AJ (1982c) The nuclei of origin of brain stem enkephalin and substance P projections to the rodent nucleus raphe magnus. Neurosci. 7:2753-2768.

Beitz AJ (1982b) The organization of afferent projections to the midbrain periaqueductal grey of the rat. Neurosci. 7:133-159.

Beitz AJ (1982a) The sites of origin of brain stem neurotensin and serotonin projections to the rodent nucleus raphe magnus. J. Neurosci. 2:829-842.

Beitz, AJ, Mullett, MA, and Brandt, N (1988) The relationship of periaqueductal gray projections to bulbospinal neurons: a combined fluorogold-PHA-L analysis. Neurosci. Abstr. 14, 856 (Abstract).

Beitz AJ, Mullett MA, and Weiner LL (1983) The periaqueductal gray projections to the rat spinal trigeminal, raphe magnus, gigantocellular pars alpha and paragigantocellular nuclei arise from separate neurons. Brain Res. 288:307-314.

Bennett GJ and Mayer DJ (1979) Inhibition of spinal cord interneurons by narcotic microinjection and focal electrical stimulation in the periaqueductal central gray matter. Brain Res. 172:243-257.

Berge O-G, Cabrera IG, and Hole K (1988) Response latencies in the tail flick test depend on the tail skin temperature. Neurosci. Lett. 86:284-288.

Besson J-M, Guilbaud G, and Le Bars D (1975) Descending inhibitory influences exerted by the brainstem upon the activities of dorsal horn laminae $\mathrm{V}$ cells induced by intra-arterial injection of bradykinin into the limbs. J. Physiol. (Lond. ) 248:725739.

Betancur C, Canton M, Burgos A, Labeeuw B, Gully D, Rostene W, and Pelaprat D (1998) Characterization of binding sites of a new neurotensin receptor antagonist, [3H]SR 142948A, in the rat brain. Eur. J. Pharmacol. 343:67-77.

Bouthenet ML, Martres MP, Sales N, and Schwartz JC (1987) A detailed mapping of dopamine D-2 receptors in rat central nervous system by autoradiography with [125I]iodosulpride. Neurosci. 20:117-155. 
Bouthenet ML, Ruat M, Sales N, Garbarg M, and Schwartz JC (1988) A detailed mapping of histamine H1-receptors in guinea-pig central nervous system established by autoradiography with $\left[{ }^{125}\right.$ I]iodobolpyramine. Neurosci. 26:553600 .

Bowker RM, Steinbusch HWM, and Coulter JD (1981a) Serotonergic and peptidergic projections to the spinal cord demonstrated by a combined retrograde HRP histochemical and immunocytochemical staining method. Brain Res. 211:412417.

Bowker RM, Westlund KN, and Coulter JD (1981b) Origins of serotonergic projections to the spinal cord in rat: an immunocytochemical-retrograde transport study. Brain Res. 226:187-199.

Bowker RM, Westlund KN, Sullivan MC, and Coulter JD (1982b) Organization of descending serotonergic projections to the spinal cord. Prog. Brain Res. 57:239265.

Bowker RM, Westlund KN, Sullivan MC, Wilber JF, and Coulter JD (1982a) Transmitters of the raphe-spinal complex: immunocytochemical studies. Peptides 3:291-298.

Bowker RM, Westlund KN, Sullivan MC, Wilber JF, and Coulter JD (1983) Descending serotonergic, peptidergic and cholinergic pathways from the raphe nuclei: a multiple transmitter complex. Brain Res. 288:33-48.

Brodie MS and Proudfit HK (1986) Antinociception induced by local injections of carbachol into the nucleus raphe magnus in rats: alteration by intrathecal injection of monoaminergic antagonists. Brain Res. 371:70-79.

Carlton SM, Honda CN, Willcockson WS, Lacrampe M, Zhang D, Denoroy L, Chung JM, and Willis WD (1991) Descending adrenergic input to the primate spinal cord and its possible role in modulation of spinothalamic cells. Brain Res. 543:77-90.

Carraway R, Kitabgi P, and Leeman SE (1978) The amino acid sequence of radioimmunoassayable neurotensin from bovine intestine. J. Biol. Chem. 253:7996-7998.

Carraway R and Leeman SE (1973a) The isolation of a new hypotensive peptide, neurotensin, from bovine hypothalami. J. Biol. Chem. 248:6854-6861. 
Carraway R and Leeman SE (1975b) The amino acid sequence of a hypothalamic peptide, neurotensin. J. Biol. Chem. 250:1907-1911.

Carraway R and Leeman SE (1976) Characterization of radioimmunoassayable neurotensin in the rat. Its differential distribution in the central nervous system, small intestine, and stomach. J. Biol. Chem. 251:7045-7052.

Carstens E (1982) Inhibition of spinal dorsal horn neuronal responses to noxious skin heating by medial hypothalamic stimulation in the cat. J. Neurophysiol. 48:808822.

Carstens E, Bihl H, Irvine F, and Zimmerman M (1981) Descending inhibition from medial and lateral midbrain of spinal dorsal horn neuronal responses to noxious and non-noxious cutaneous stimuli in the cat. J. Neurophysiol. 45:1029-1042.

Carstens E, MacKinnon JD, and Guinan MJ (1982) Inhibition of spinal dorsal horn neuronal responses to noxious skin heating by medial preoptic and septal stimulation in the cat. J. Neurophysiol. 48:981-991.

Cervero F and Iggo A (1980) The substantia gelatinosa of the spinal cord: a critical review. Brain 103 :717-772.

Chalon P, Vita N, Kaghad M, Guillemot M, Bonnin J, Delpech B, Le Fur G, Ferrara P, and Caput D (1996) Molecular cloning of a levocabastine-sensitive neurotensin binding site. FEBS Lett. 386:91-94.

Checler F, Vincent JP, and Kitabgi P (1983) Degradation of neurotensin by rat brain synaptic membranes: involvement of a thermolysin-like metalloendopeptidase (enkephalinase), angiotensin-converting enzyme, and other unidentified peptidases. J. Neurochem. 41:375-384.

Cheng ZF, Fields HL, and Heinricher MM (1986) Morphine microinjected into the periaqueductal gray has differential effects on 3 classes of medullary neurons. Brain Res. 375:57-65.

Chung RY, Mason P, Strassman A, and Maciewicz R (1987) Suppression of the jawopening reflex by periaqueductal gray stimulation is decreased by paramedian brainstem lesions. Brain Res. 403:172-176. 
Clements JR, Beitz AJ, Fletcher TF, and Mullett MA (1985) Immunocytochemical localization of serotonin in the rat periaqueductal gray: a quantitative light and electron microscopic study. J. Comp. Neurol. 236:60-70.

Clements JR, Madl JE, Johnson RL, Larson AA, and Beitz AJ (1987) Localization of glutamate, glutaminase, aspartate and aspartate aminotransferase in the rat midbrain periaqueductal gray. Exp. Brain Res. 67:594-602.

Clineschmidt BV and Mcguffin JC (1977) Neurotensin administered intracisternally inhibits responsiveness of mice to noxious stimuli. Eur. J. Pharmacol. 46:395396.

Clineschmidt BV, Mcguffin JC, and Bunting PB (1979) Neurotensin: antinocisponsive action in rodents. Eur. J. Pharmacol. 54:129-139.

Coderre TJ, Katz J, Vaccarino AL, and Melzack R (1993) Contribution of central neuroplasticity to pathological pain: review of clinical and experimental evidence. Pain 52:259-285.

Cooper PE, Fernstrom MH, Rorstad OP, Leeman SE, and Martin JB (1981) The regional distribution of somatostatin, substance $\mathrm{P}$ and neurotensin in human brain. Brain Res. 218:219-232.

Cowie RJ and Holstege G (1992) Dorsal mesencephalic projections to pons, medulla, and spinal cord in the cat: limbic and non-limbic components. J. Comp. Neurol. 319:536-559.

Cruz L and Basbaum AI (1985) Multiple opioid peptides and the modulation of pain: immunohistochemical analysis of dynorphin and enkephalin in the trigeminal nucleus caudalis and spinal cord of the cat. J. Comp. Neurol. 240:331-348.

D'Amour FE and Smith DL (1941) A method for determining loss of pain sensation. $J$. Pharmacol. Exp. Ther. 72:74-80.

Dahlstrom A and Fuxe K (1964) Evidence for the existence of monoamine-containing neurons in the central nervous system. I. Demonstration of monoamines in the cell bodies of the brain stem neurons. Acta Physiol. Scand. 62:1-55. 
Dahlstrom A and Fuxe K (1965) Evidence for the existance of monoamine neurons in the central nervous system. II. Experimentally induced changes in the intraneuronal amine levels of the bulbospinal neuron systems. Acta Physiol. Scand. 64:1-36.

Dickenson AH, Oliveras JL, and Besson JM (1979) Role of the nucleus raphe magnus in opiate analgesia as studied by the microinjection technique in the rat. Brain Res. 170:95-111.

Dostrovsky JO, Shah Y, and Gray BG (1983) Descending inhibitory influences from the periaqueductal gray, nucleus raphe magnus, and adjacent recticular formation.II.Effects on medullary dorsal horn nociceptive and non-nociceptive neurons. J. Neurophysiol. 49:948-960.

Drower EJ and Hammond DL (1988) GABAergic modulation of nociceptive threshold: effects of THIP and bicuculline microinjected in the ventral medulla of the rat. Brain Res. 450:316-324.

Dubner R and Bennett GJ (1983) Spinal and trigeminal mechansims of nociception. Annual Reviews of Neuroscience 6:381-418.

Dubuc I, Costentin J, Terranova JP, Barnouin MC, Soubrie P, Le Fur G, Rostene W, and Kitabgi P (1994) The nonpeptide neurotensin antagonist, SR 48692, used as a tool to reveal putative neurotensin receptor subtypes. Br. J. Pharmacol. 112:352-354.

Dubuc I, Sarret P, Labbe-Jullie C, Botto JM, Honore E, Bourdel E, Martinez J, Costentin J, Vincent JP, Kitabgi P, and Mazella J (1999) Identification of the receptor subtype involved in the analgesic effect of neurotensin. J. Neurosci. 19:503-510.

Duggan AW, Hall JG, Headley PM, and Griersmith BT (1977) The effect of naloxone on the excitation of dorsal horn neurons of the cat by noxious and non-noxious cutaneous stimuli. Brain Res. 138:185-189.

Duggan AW, Hope PJ, and Lang CW (1991) Microinjection of neuropeptide Y into the superficial dorsal horn reduces stimulus-evoked release of immunoreactive substance P in the anaesthetized cat. Neurosci. 44:733-740.

Eide K and Hole K (1992) Interactions between substance P and norepinephrine in the regulation of nociception in mouse spinal cord. Pharmacol. Toxicol. 70:397-401. 
Eide PK and Hole K (1991) Interactions between serotonin and substance P in the spinal regulation of nociception. Brain Res. 550:225-230.

Fang FG, Moreau JL, and Fields HL (1987) Dose-dependent antinociceptive action of neurotensin microinjected into the rostroventromedial medulla of the rat. Brain Res. 420:171-174.

Faris PL, Komisaruk BR, Watkins LR, and Mayer DJ (1983) Evidence for the neuropeptide cholecystokinin as an antagonist of opiate analgesia. Science 219:310-312.

Fernstrom, MH, Carraway, R, and Leeman, SE (1980) Neurotensin, in Frontiers in Neuroendocrinology, (Martini L and Ganong WF eds) vol 6. Raven, New York.

Fields HL and Anderson SD (1978) Evidence that raphe-spinal neurons mediate opiate and midbrain stimulation-produced analgesias. Pain 5:333-349.

Fields HL, Barbaro NM, and Heinricher MM (1988) Brain stem neuronal circuitry underlying the antinociceptive action of opiates. Prog. Brain Res. 77:24557:245-257.

Fields HL, Basbaum AI, Clanton CH, and Anderson SD (1977) Nucleus raphe magnus inhibition of spinal cord dorsal horn neurons. Brain Res. 126:441-453.

Fields HL, Bry J, Hentall I, and Zorman G (1983a) The activity of neurons in the rostral medulla of the rat during withdrawal from noxious heat. J. Neurosci. 3:25452552.

Fields HL, Heinricher MM, and Mason P (1991) Neurotransmitters in nociceptive modulatory circuits. Annual Reviews of Neuroscience 14:219-245.

Fields HL, Malick A, and Burstein R (1995) Dorsal horn projection targets of ON and OFF cells in the rostral ventromedial medulla. J. Neurophysiol. 74:1742-1759.

Fields HL, Vanegas H, Hentall ID, and Zorman G (1983b) Evidence that disinhibition of brain stem neurones contributes to morphine analgesia. Nature 306:684-686. 
Frederickson RCA, Burgis V, Harrell CE, and Edwards JD (1978) Dual actions of Substance P on nociception: Possible role of endogenous opioids. Science 199:1359-1362.

Fujimoto JM, Arts KS, Rady JJ, and Tseng LF (1990) Spinal dynorphin A (1-17): possible mediator of antianalgesic action. Neuropharmacol. 29:609-617.

Gao K, Chen DO, Genzen JR, and Mason P (1998) Activation of serotonergic neurons in the raphe magnus is not necessary for morphine analgesia. J. Neurosci. 18:18601868.

Gebhart, GF (1986) Modulatory effects of descending systems on spinal dorsal horn neurons, in Spinal Afferent Processing, (Yaksh TL ed) pp 391-416, Plenum Press, New York.

Gebhart GF, Sandkuhler J, Thalhammer JG, and Zimmermann M (1983) Inhibition of spinal nociceptive information by stimulation in midbrain of the cat is blocked by lidocaine microinjected in nucleus raphe magnus and medullary reticular formation. J. Neurophysiol. 50:1446-1459.

Gerhart KD, Yezierski RP, Wilcox TK, Grossman AE, and Willis WD (1981) Inhibition of primate spinothalamic tract neurons by stimulation in ipsilateral or contralateral ventral posterior lateral (VPL) thalamic nucleus. Brain Res. 229:514-519.

Ghatei MA, Bloom SR, Langevin H, McGregor GP, Lee YC, Adrian TE, O'Shaughnessy DJ, Blank MA, and Uttenthal LO (1984) Regional distribution of bombesin and seven other regulatory peptides in the human brain. Brain Res. 293:101-109.

Gibson SJ, Polak JM, Allen JM, Adrian TE, Kelly JS, and Bloom SR (1984) The distribution and origin of a novel brain peptide, neuropeptide $\mathrm{Y}$, in the spinal cord of several mammals. J. Comp. Neurol. 227:78-91.

Glick SD and Crane LA (1978) Opiate-like and abstinence-like effects of intracerebral histamine administration in rats. Nature 273:547-549.

Gogas KR, Hough LB, Eberle NB, Lyon RA, Glick SD, Ward SJ, Yound RC, and Parsons ME (1989) A role for histamine and $\mathrm{H}_{2}$-receptors in opioid antinociception ${ }^{1}$. J. Pharmacol. Exp. Ther. 250:476-484. 
Gol A (1967) Relief of pain by electrical stimulation of the septal area. J. Neurol. Sci. 5:115-120.

Goldstein A (1976) Opioid peptides (endorphins) in pituitary and brain. Science 193:1081-1086.

Goodman, CB, Elmer, GI, Yang, H-YT, Lee, CH, and Rothman, RB (1995) Modulation of opioid receptors by anti-opioid peptides, in Pharmacology of Opioid Peptides, (Tseng LF ed) pp 303-319, Harwood Acad. Publ., Amsterdam.

Goodman SJ and Holcombe V (1976) Selective and prolonged analgesia in monkey resulting from brain stimulation. Pain Res. Ther. 1:495-502.

Greenamyre JT, Young AB, and Penney JB (1984) Quantitative autoradiographic distribution of $\mathrm{L}-[3 \mathrm{H}]$ glutamate-binding sites in rat central nervous system. $J$. Neurosci. 4:2133-2144.

Gully D, Canton M, Boigegrain R, Jeanjean F, Molimard JC, Poncelet M, Gueudet C, Heaulme M, Leyris R, Brouard A, Pelaprat D, Labbe-Jullie C, Mazella J, Soubrie P, Maffrand JP, Rostene W, Kitabgi P, and Le Fur G (1993) Biochemical and pharmacological profile of a potent and selective nonpeptide antagonist of the neurotensin receptor. Proc. Natl. Acad. Sci. USA 90:65-69.

Gully D, Labeeuw B, Boigegrain R, Oury-Donat F, Bachy A, Poncelet M, Steinberg R, Suaud-Chagny MF, Santucci V, Vita N, Pecceu F, Labbe-Jullie C, Kitabgi P, Soubrie P, Le Fur G, and Maffrand JP (1997) Biochemical and pharmacological activities of SR 142948A, a new potent neurotensin receptor antagonist. $J$. Pharmacol. Exp. Ther. 280:802-812.

Haber LH, Martin RF, Chatt AB, and Willis WD (1978) Effects of stimulation in nucleus reticularis gigantocellularis on the activity of spinothalamic tract neurons in the monkey. Brain Res. 153:163-168.

Hammond, DL (1986) Control systems for nociceptive processing: The descending inhibitory pathways, in Spinal Afferent Processing, (Yaksh TL ed) pp 363-390, Plenum Press, New York.

Hammond, DL (1989) Inference of pain and its modulation from simple behaviors, in Issues in Pain Measurement, (Chapman CR and Loeser JD eds) pp 69-91, Raven Press, New York. 
Hammond DL, Tyce GM, and Yaksh TL (1985) Efflux of 5-hydroxytryptamine and noradrenaline into spinal cord superfusates during stimulation of the rat medulla. J. Physiol. (Lond. ) 359:151-62:151-162.

Hammond DL and Yaksh TL (1984) Antagonism of stimulation-produced antinociception by intrathecal administration of methysergide or phentolamine. Brain Res. 298:329-337.

Handwerker HO, Iggo A, and Zimmerman M (1975) Segmental and supraspinal actions on dorsal horn neurons responding to noxious and non-noxious skin stimuli. Pain 1:147-165.

Hawranko AA, Monroe PJ, and Smith DJ (1994) Repetitive exposure to the hot-plate test produces stress induced analgesia and alters $\beta$-endorphin neuronal transmission within the periaqueductal gray of the rat. Brain Res. 667:283-286.

Hawranko AA, Monroe PJ, and Smith DJ (1996a) Paradoxical opioid-induced pain facilitation in rats and its enhancement by stress. Anesth Analg 82:S165

Hawranko AA and Smith DJ (1997) A pain facilitory action of $\beta$-endorphin is revealed in stressed rats. Analgesia 3:101-110.

Hawranko, A.A., Smith, D.L., Monroe, P.J., and Smith, D.J. (1996b) Opioid receptor mediated pain facilitation evoked by PAG $\beta$-endorphin is modulated by stress and spinal cholecystokinin. Neurosci. Abstr. 22, 1364 (Abstract).

Hayes RL, Price DD, Ruda M, and Dubner R (1979) Suppression of nociceptive responses in the primate by electrical stimulation of the brain or morphine administration: Behavioral and electrophysiological comparisions. Brain Res. 167:417-421.

Heaulme M, Leyris R, Le Fur G, and Soubrie P (1997) Involvement of potentially distinct neurotensin receptors in neurotensin-induced stimulation of striatal $[3 \mathrm{H}]$ dopamine release evoked by $\mathrm{KCl}$ versus electrical depolarization. Neuropharmacol. 36:1447-1454.

Heinricher, M.M., Haws, C.M., and Fields, H.L. (1987) Iontophoresis of the GABA antagonist bicuculline blocks off-cell pause: Evidence for GABA-mediated control of putative pain modulating neurons in the rostral ventromedial medulla. Neurosci. Abstr. 13, 299 (Abstract). 
Heinricher, MM, Haws, CM, and Fields, HL (1988) Opposing actions of norepinephrine and clonidine on single pain-modulating neurons in rostral ventromedial medulla, in Proc. 5th World Congr. on Pain, (Dubner R, Gebhart GF, and Bond MR eds) pp 590-594, Elsevier, Amsterdam.

Heinricher MM, McGaraughty S, and Grandy DK (1997) Circuitry underlying antiopioid actions of orphanin FQ in the rostral ventromedial medulla. J. Neurophysiol. 78:3351-3358.

Heinricher MM, Morgan MM, and Fields HL (1992) Direct and indirect actions of morphine on medullary neurons that modulate nociception. Neurosci. 48:533543.

Heinricher MM, Morgan MM, Tortorici V, and Fields HL (1994) Disinhibition of offcells and antinociception produced by an opioid action within the rostral ventromedial medulla. Neurosci. 63:279-288.

Heinricher MM and Tortorici V (1994) Interference with GABA transmission in the rostral ventromedial medulla: disinhibition of off-cells as a central mechanism in nociceptive modulation. Neurosci. 63:533-546.

Helmstetter FJ, Tershner SA, Poore LH, and Bellgowan PS (1998) Antinociception following opioid stimulation of the basolateral amygdala is expressed through the periaqueductal gray and rostral ventromedial medulla. Brain Res. 779:104-118.

Herkenham M, Lynn AB, Johnson MR, Melvin LS, De Costa BR, and Rice KC (1991) Characterization and localization of cannabinoid receptors in rat brain: a quantitative in vitro autoradiographic study. J. Neurosci. 11:563-583.

Hohmann AG, Martin WJ, Tsou K, and Walker JM (1995) Inhibition of noxious stimulus-evoked activity of spinal cord dorsal horn neurons by the cannabinoid WIN 55,212-2. Life Sci. 56:2111-2118.

Hokfelt T, Ljungdahl A, Terenius L, Elde R, and Nilsson G (1977) Immunohistochemical analysis of peptide pathways possibly related to pain and analgesia: Enkephalin and substance P. Proc. Natl. Acad. Sci. USA 74:3081-3085.

Hokfelt T, Phillipson O, and Goldstein M (1979a) Evidence for a dopaminergic pathway in the rat descending from the A11 cell group to the spinal cord. Acta Physiol. Scand. 107:393-395. 
Hokfelt T, Terenius L, Kuypers HG, and Dann O (1979b) Evidence for enkephalin immunoreactive neurons in the medulla oblongata projecting to the spinal cord. Neurosci. Lett. 14:55-60.

Holets VR, Hokfelt T, Rokaeus A, Terenius L, and Goldstein M (1988) Locus coeruleus neurons in the rat containing neuropeptide $\mathrm{Y}$, tyrosine hydroxylase or galanin and their efferent projections to the spinal cord, cerebral cortex and hypothalamus. Neurosci. 24:893-906.

Holstege G (1987) Some anatomical observations on the projections from the hypothalamus to brainstem and spinal cord: an HRP and autoradiographic tracing study in the cat. J. Comp. Neurol. 260:98-126.

Holstege G (1988) Direct and indirect pathways to lamina I in the medulla oblongata and spinal cord of the cat. Prog. Brain Res. 77:47-94.

Holstege G (1991a) Descending motor pathways and the spinal motor system: limbic and non-limbic components. Prog. Brain Res. 87:307-421.

Holstege, G (1991b) Descending pathways from the periaqueductal gray and adjacent areas, in The Midbrain Periaqueductal Gray Matter: Functional, Anatomical, and Neurochemical Organization, (Depaulis A and Bandler R eds) pp 239-265, Plenum Publishing Corp., New York.

Holstege G and Kuypers HG (1982) The anatomy of brain stem pathways to the spinal cord in cat. A labeled amino acid tracing study. Prog. Brain Res. 57:145-175.

Hosobuchi Y, Adams JE, and Linchitz R (1977) Pain relief by electrical stimulation of the central gray matter in humans and its reversal by naloxone. Science 197:183186.

Hua X-Y, Boublik JH, Spicer MA, Rivier JE, Brown MR, and Yaksh TL (1991) The antinociceptive effects of spinally administered neuropeptide $\mathrm{Y}$ in the rat: systematic studies on structure- activity relationship. J. Pharmacol. Exp. Ther. 258:243-243.

Hughes J (1975) Isolation of an endogenous compound from the brain with pharmacological properties similar to morphine. Brain Res. 88:295-308. 
Hughes J, Smith TW, and Kosterlitz HW (1975) Identification of two related pentapeptides from the brain with potent opiate agonist activity. Nature 258:577579.

Inagaki N, Yamatodani A, Ando-Yamamoto M, Tohyama M, Watanabe T, and Wada H (1988) Organization of histaminergic fibers in the rat brain. J. Comp. Neurol. 273:283-300.

Inase M, Nakahama H, Otsuki T, and Fang J (1987) Analgesic effects of serotonin microinjection into nucleus raphe magnus and nucleus raphe dorsalis evaluated by the monosodium urate (MSU) tonic pain model in the rat. Brain Res. 426:205211.

Jensen TS and Yaksh TL (1984) Spinal monoamine and opiate systems partly mediate the antinociceptive effects produced by glutamate at brainstem sites. Brain Res. 321:287-297.

Jensen TS and Yaksh TL (1986) Comparison of antinociceptive action of morphine in the periaqueductal gray, medial and paramedial medulla in rat. Brain Res. 363:99113.

Johansson O, Hokfelt T, Pernow B, Jeffcoate SL, White N, Steinbusch HW, Verhofstad AA, Emson PC, and Spindel E (1981) Immunohistochemical support for three putative transmitters in one neuron: coexistence of 5-hydroxytryptamine, substance P- and thyrotropin releasing hormone-like immunoreactivity in medullary neurons projecting to the spinal cord. Neurosci. 6:1857-1881.

Kalivas PW, Jennes L, Nemeroff CB, and Prange AJJ (1982) Neurotensin: topographical distribution of brain sites involved in hypothermia and antinociception. J. Comp. Neurol. 210:225-238.

Kalyuzhny AE and Wessendorf MW (1998) Relationship of mu- and delta-opioid receptors to GABAergic neurons in the central nervous system, including antinociceptive brainstem circuits. J. Comp. Neurol. 392:528-547.

Kaplan HJ and Fields HL (1990) Reversal of naloxone-precipitated hyperalgesia by lidocaine microinjection in the rostral ventromedial medulla of the lightly anesthetized rat. Pain Suppl. 5:445. 
Kavaliers M and Yang H-YT (1989) IgG from antiserum against endogenous mammalian FMRF-NH $\mathrm{N}_{2}$-related peptides augments morphine- and stress-induced analgesia in mice. Peptides 10:741-745.

Kellstein DE, Price DD, Hayes RL, and Mayer DJ (1990) Evidence that substance P selectively modulates C-fiber-evoked discharges of dorsal horn nociceptive neurons. Brain Res. 526:291-298.

Kiefel JM, Cooper ML, and Bodnar RJ (1991) Inhibition of mesencephalic morphine analgesia by methysergide in the medial ventral medulla of rats. Physiology \& Behavior 51:1-5.

Kiefel JM, Cooper ML, and Bodnar RJ (1992) Serotonin receptor subtype antagonists in the medial ventral medulla inhibit mesencephalic opiate analgesia. Brain Res. 597:331-338.

Kitabgi P, Carraway R, and Leeman SE (1976) Isolation of a tridecapeptide from bovine intestinal tissue and its partial characterization as neurotensin. J. Biol. Chem. 251:7053-7058.

Kitabgi P, Rostene W, Dussaillant M, Schotte A, Laduron PM, and Vincent JP (1987) Two populations of neurotensin binding sites in murine brain: discrimination by the antihistamine levocabastine reveals markedly different radioautographic distribution. Eur. J. Pharmacol. 140:285-293.

Kitabgi P (1989) Neurotensin modulates dopamine neurotransmission at several levels along the brain dopaminergic pathways. Neurochem. Int. 14:111-119.

Kivipelto L and Panula P (1991) Origin and distribution of neuropeptide-FF-like immunoreactivity in the spinal cord of rats. J. Comp. Neurol. 307:107-119.

Kneisley LW, Biber MP, and LaVail JH (1978) A study of the origin of brain stem projections to monkey spinal cord using the retrograde transport method. Exp. Neurol. 60:116-139.

Kuypers HGJM and Maisky VA (1975) Retrograde axonal transport of horseradish peroxidase from spinal cord to brain stem cell groups in the cat. Neurosci. Lett. 1:9-14. 
Kuypers HGJM (1967) The descending pathways to the spinal cord. Prog. Brain Res. 11:178-202.

Labbe-Jullie C, Dubuc I, Brouard A, Doulut S, Bourdel E, Pelaprat D, Mazella J, Martinez J, Rostene W, and Costentin J (1994) In vivo and in vitro structureactivity studies with peptide and pseudopeptide neurotensin analogs suggest the existence of distinct central neurotensin receptor subtypes. J. Pharmacol. Exp. Ther. 268:328-336.

Lake JR, Hammond MV, Shaddox RC, Hunsicker LM, Yang HY, and Malin DH (1991) $\mathrm{IgG}$ from neuropeptide FF antiserum reverses morphine tolerance in the rat. Neurosci. Lett. 132:29-32.

Le F, Cusack B, and Richelson E (1996) The neurotensin receptor: is there more than one subtype? Trends. Pharmacol. Sci. 17:1-3.

Leichnetz GR, Watkins LR, Griffin G, Martin RF, and Mayer DJ (1978) The projection from the nucleus raphe magnus and other brainstem nuclei to the spinal cord in the rat: A study using HRP blue reaction. Neurosci. Lett. 8:119-124.

Levant B and Nemeroff CB (1988) The psychobiology of neurotensin. Current Topics in Neuroendocrinology. 8:231-262.

Levy RA and Proudfit HK (1979) Analgesia produced by microinjection of baclofen and morphine at brain stem sites. Eur. J. Pharmacol. 57:43-55.

Lewis VA and Gebhart GF (1977) Evaluation of the periaqueductal central gray (PAG) as a morphine-specific locus of action and examination of morphine- induced and stimulation-produced analgesia at coincident PAG loci. Brain Res. 124:283-303.

Liebeskind JC, Guilbaud G, Besson JM, and Oliveras JL (1973) Analgesia from electrical stimulation of the periaqueductal gray matter in the cat: Behavioral observations and inhibitory effects on spinal cord interneurons. Brain Res. 50:441-446.

Light AR, Casale EJ, and Menetrey DM (1986) The effects of focal stimulation in nucleus raphe magnus and periaqueductal gray on intracellularly recorded neurons in spinal laminae I and II. Neurophysiol. 56:555-571. 
Light AR and Perl ER (1979a) Reexamination of the dorsal root projection to the spinal dorsal horn including observations on the differential termination of coarse and fine fibers. J. Comp. Neurol. 186:117-131.

Light AR and Perl ER (1979b) Spinal termination of functionally identified primary afferent neurons with slowly conducting myelinated fibers. J. Comp. Neurol. 186:133-150.

Lipton, MA, Bissett, G, Nemeroff, CB, Loosen, PT, and Prange, AJJ (1977) Neurotensin: A possible mediator of thermoregulation in the mouse, in Third Symposium On The Pharmacology Of Thermoregulation, (Lomax P, Schombaum E, and Cox B eds) Karger, Basel.

Liu RH, Fung SJ, Reddy VK, and Barnes CD (1995) Localization of glutamatergic neurons in the dorsolateral pontine tegmentum projecting to the spinal cord of the cat with a proposed role of glutamate on lumbar motoneuron activity. Neurosci. 64:193-208.

Llewelyn MB, Azami J, and Roberts MHT (1983) Effects of 5-hydroxytryptamine applied into nucleus raphe magnus on nociceptive thresholds and neuronal firing rate. Brain Res. 258:59-68.

Long JB, Kalivas PW, Youngblood WW, Prange AJJ, and Kizer JS (1984) Possible involvement of serotonergic neurotransmission in neurotensin but not morphine analgesia. Brain Res. 310:35-41.

Lovick TA (1992) Inhibitory modulation of the cardiovascular defence response by the ventrolateral periaqueductal grey matter in rats. Brain Res. 89:133-139.

Lovick TA (1993) Integrated activity of cardiovascular and pain regulatory systems: role in adaptive behavioural responses. Progress in Neurobiology 40:631-644.

Maier SF, Wiertelak EP, and Watkins LR (1992) Endogenous pain facilitory systems. APS Journal 1:191-198.

Malick JB and Goldstein JM (1978) Analgesic activity of substance P following intracerebral administration in rats. Life Sci. 23:835-844. 
Manberg PJ, Youngblood WW, Nemeroff CB, Rossor MN, Iversen LL, Prange AJJ, and Kizer JS (1982) Regional distribution of neurotensin in human brain. $J$. Neurochem. 38:1777-1780.

Mantyh PW (1983) Connections of the midbrain periaqueductal gray in the monkey. II. Descending efferent projections. J. Neurophysiol. 49:582-594.

Mantyh PW and Peschanski M (1982) Spinal projections from the periaqueductal grey and dorsal raphe in the rat, cat and monkey. Neurosci. 7:2769-2776.

Marchand JE and Hagino N (1983) Afferents to the periaqueductal gray in the rat. A horseradish peroxidase study. Neurosci. 9:95-106.

Martin GF, Cabana T, and Humbertson AOJ (1981) Evidence for collateral innervation of the cervical and lumbar enlargements of the spinal cord by single reticular and raphe neurons. Studies using fluorescent markers in double-labeling experiments on the North American opossum. Neurosci. Lett. 24:1-6.

Martin RF, Jordan LM, and Willis WD (1978) Differential projections of cat medullary raphe neurons demonstrated by retrograde labelling following spinal cord lesions. J. Comp. Neurol. 182:77-88.

Martin WJ, Tsou K, and Walker JM (1998) Cannabinoid receptor-mediated inhibition of the rat tail-flick reflex after microinjection into the rostral ventromedial medulla. Neurosci. Lett. 242:33-36.

Mash DC and Potter LT (1986) Autoradiographic localization of M1 and M2 muscarine receptors in the rat brain. Neurosci. 19:551-564.

Mason, P, Skinner, K, Cho, HJ, Basbaum, AI, and Fields, HL (1990) Anatomical evidence for gabaergic control of physiologically identified off-cells in the rostral ventromedial medulla, in Proc. VIth Int. Congr. IASP, (Bond MR ed) Elsevier, Amsterdam.

Mason P, Strassman A, and Maciewicz R (1986) Intracellular responses of raphe magnus neurons during the jaw-opening reflex evoked by tooth pulp stimulation. Brain Res. 379:232-241. 
Mayer DJ and Hayes R (1975) Stimulation-produced analgesia: development of tolerance and cross-tolerance to morphine. Science 188:941-943.

Mayer DJ and Liebeskind JC (1974) Pain reduction by focal electrical stimulation of the brain: an anatomical and behavioral analysis. Brain Res. 68:73-93.

Mayer DJ and Price DD (1976) Central nervous system mechanisms of analgesia. Pain 2:379-404.

Mayer DJ, Wolfe TL, Akil H, Carder B, and Liebeskind JC (1971) Analgesia from electrical stimulation in the brain stem of the rat. Science 174:1351-1354.

McCreery DB, Bloedel JR, and Hames EG (1975) Reduction of the response of cat spinothalamic neurons to graded mechanical stimuli by electrical stimulation of the lower brain stem. Brain Res. 97:151-156.

McCreery DB, Bloedel JR, and Hames EG (1979) Effects of stimulating in raphe nuclei and in recticular formation on response of spinothalamic neurons to mechanical stimuli. Neurophysiol. 42:166-182.

McDermott JR, Smith AI, Edwardson JA, and Griffiths EC (1982) Mechanism of neurotensin degradation by rat brain peptidases. Regul. Pept. 3:397-404.

McDermott JR, Smith AI, Dodd PR, Hardy JA and Edwardson JA (1983) Mechanism of degradation of LH-RH and neurotensin by synaptosomal peptidases. Peptides 4:25-30.

McLennan H (1983) Receptors for the excitatory amino acids in the mammalian central nervous system. Prog. Neurobiol. 20:251-271.

Mehler, WR (1962) The anatomy of the so-called "pain tract" in man: An analysis of the course and distribution of the ascending fibers of the fasciculus anterolateralis., in Basic Research in Paraplegia, (French JD and Porter RW eds) pp 22-65, Springfield, III: Thomas,

Meng XW, Budra B, Skinner K, Ohara PT, and Fields HL (1997) Noradrenergic input to nociceptive modulatory neurons in the rat rostral ventromedial medulla. J. Comp. Neurol. 377:381-391. 
Millar J and Williams GV (1989) Effects of iontophoresis of noradrenaline and stimulation of the periaqueductal gray on single-unit activity in the rat superficial dorsal horn. J. Comp. Neurol. 287:119-133.

Minson JB, Llewellyn-Smith IJ, Pilowsky PM, and Chalmers JP (1994) Bulbospinal neuropeptide Y-immunoreactive neurons in the rat: comparison with adrenalinesynthesizing neurons. Journal of the Autonomic Nervous System 47:233-243.

Mohrland JS and Gebhart GF (1979) Substance P-induced analgesia in the rat. Brain Res. 171:556-559.

Monaghan DT and Cotman CW (1985) Distribution of N-methyl-D-aspartate-sensitive L[3H]glutamate-binding sites in rat brain. J. Neurosci. 5:2909-2919.

Moore RY and Bloom FE (1979) Central catecholamine neuron systems: anatomy and physiology of the norepinephrine and epinephrine systems. Annu. Rev. Neurosci. 2:113-168.

Morton CR, Duggan AW, and Zhao ZQ (1984) The effects of lesions of medullary midline and lateral reticular areas on inhibition in the dorsal horn produced by periaqueductal grey stimulation in the cat. Brain Res. 301:121-130.

Moss MS and Basbaum AI (1983b) The fine structure of the caudal periaqueductal gray of the cat: morphology and synaptic organization of normal and immunoreactive enkephalin-labeled profiles. Brain Res. 289:27-43.

Moss MS and Basbaum AI (1983a) The peptidergic organization of the cat periaqueductal gray. II. The distribution of immunoreactive substance $\mathrm{P}$ and vasoactive intestinal polypeptide. J. Neurosci. 3:1437-1449.

Moss MS, Glazer EJ, and Basbaum AI (1981) Enkephalin-immunoreactive perikarya in the cat raphe dorsalis. Neurosci. Lett. 21:33-37.

Moss MS, Glazer EJ, and Basbaum AI (1983) The peptidergic organization of the cat periaqueductal gray. I. The distribution of immunoreactive enkephalin-containing neurons and terminals. J. Neurosci. 3:603-616. 
Murfin R, Bennett J, and Mayer DJ (1976) The effect of dorsolateral spinal cord (DLF) lesions on analgesia from morphine microinjected into the periaqueductal gray matter (PAG) of the rat. Neurosci. Abstr. 2:946

Naranjo JR, Sanchez-Franco F, and Del Rio J (1982a) Blockade by met-enkephalin antiserum of analgesia induced by substance P in mice. Neuropharmacol. 21:1295-1299.

Naranjo JR, Sanchez-Franco F, Garzon J, and Del Rio J (1982b) Analgesic activity of substance $\mathrm{P}$ in rats: apparent mediation by met-enkephalin release. Life Sci. 30:441-446.

Nemeroff CB, Bissette G, Prange AJJ, Loosen PT, Barlow TS, and Lipton MA (1977) Neurotensin: central nervous system effects of a hypothalamic peptide. Brain Res. 128:485-496.

Nemeroff CB, Osbahr AJ3, Manberg PJ, Ervin GN, and Prange AJ, Jr. (1979) Alterations in nociception and body temperature after intracisternal administration of neurotensin, beta-endorphin, other endogenous peptides, and morphine. Proc. Natl. Acad. Sci. U. S. A. 76:5368-5371.

Ness TJ and Gebhart GF (1986) Centrifugal modulation of the rat tail flick reflex evoked by graded noxious heating of the tail. Brain Res. 386:41-52.

Nygren LG and Olson L (1977) A new major projection from locus coeruleus: the main source of noradrenergic nerve terminals in the ventral and dorsal columns of the spinal cord. Brain Res. 132:85-93.

Ogawa, S, Kow, L-M, McCarthy, MM, Pfaff, DW, and Schwartz-Giblin, S (1991) Midbrain PAG control of female reproductive behavior: In Vitro electrophysiological characterization of actions of lordosis-relevant substances, in The Midbrain Periaqueductal Gray Matter: Functional, Anatomical, and Neurochemical Organization, (Depaulis A and Bandler R eds) pp 211-235, Plenum Publishing Corp., New York.

Oliveras J-L, Redjemi F, Guilbaud G, and Besson J-M (1975) Analgesia induced by electrical stimulation of the inferior centralis nucleus of the raphe in the cat. Pain 1:139-145. 
Osborne PB, Vaughan CW, Wilson HI, and Christie MJ (1996) Opioid inhibition of rat periaqueductal grey neurones with identified projections to rostral ventromedial medulla in vitro. J. Physiol. (Lond. ) 490:383-389.

Oury-Donat F, Thurneyssen O, Gonalons N, Forgez P, Gully D, Le Fur G, and Soubrie P (1995) Characterization of the effect of SR48692 on inositol monophosphate, cyclic GMP and cyclic AMP responses linked to neurotensin receptor activation in neuronal and non-neuronal cells. Br. J. Pharmacol. 116:1899-1905.

Pang IH and Vasko MR (1986) Effect of depletion of spinal cord norepinephrine on morphine-induced antinociception. Brain Res. 371:171-176.

Pasternak GW, Goodman R, and Snyder SH (1975) An endogenous morphine-like factor in mammalian brain. Life Sci. 16:1765-1769.

Paxinos, G and Watson, C (1986) The Rat Brain in Stereotaxic Coordinates. 2nd Ed., Academic Press, Inc.,San Diego.

Pert A and Snyder SH (1973) Opiate receptor: Demonstration in nervous tissue. Science 179:1011-1014.

Pert A and Yaksh T (1974) Site of morphine induced analgesia in the primate brain: relation to pain pathways. Brain Res. 80:135-140.

Pert CB, Kuhar MJ, and Snyder SH (1976) Opiate receptor: autoradiographic localization in the rat brain. Proc. Natl. Acad. Sci. U. S. A. 73:3729-3733.

Pertovaara A (1998) A neuronal correlate of secondary hyperalgesia in the rat spinal dorsal horn is submodality selective and facilitated by supraspinal influence. Exp. Neurol. 149:193-202.

Pertovaara A, Wei H, and Hamalainen MM (1996) Lidocaine in the rostroventromedial medulla and the periaqueductal gray attenuates allodynia in neuropathic rats. Neurosci. Lett. 218:127-130.

Phillips S, Cantrill R, Ford D, and Mitchel D (1986) Microinjection of dopamine agonists into the nucleus raphe magnus affects nociception in rat. Pain 26:259-266. 
Poncelet M, Gueudet C, Gully D, Soubrie P, and Le Fur G (1994) Turning behavior induced by intrastriatal injection of neurotensin in mice: sensitivity to non-peptide neurotensin antagonists. Naunyn Schmiedebergs Arch. Pharmacol. 349:57-60.

Prange AJJ, Nemeroff CB, Bissette G, Manberg PJ, Osbahr AJ, Burnett GB, Loosen PT, and Kraemer GW (1979) Neurotensin: distribution of hypothermic response in mammalian and submammalian vertebrates. Pharmacol. Biochem. Behav. 11:473-477.

Prieto GJ, Cannon JT, and Liebeskind JC (1983) N. raphe magnus lesions disrupt stimulation-produced analgesia from ventral but not dorsal midbrain areas in the rat. Brain Res. 261:53-57.

Proudfit HK and Anderson EG (1975) Morphine analgesia: blockade by raphe magnus lesions. Brain Res. 98 :612-618.

Proudfit HK and Hammond DL (1981) Alterations in nociceptive threshold and morphine-induced analgesia produced by intrathecally administered amine antagonists. Brain Res. 218:393-399.

Pugsley TA, Akunne HC, Whetzel SZ, Demattos S, Corbin AE, Wiley JN, Wustrow DJ, Wise LD, and Heffner TG (1995) Differential effects of the nonpeptide neurotensin antagonist, SR 48692, on the pharmacological effects of neurotensin agonists. Peptides 16:37-44.

Radhakrishnan V and Henry JL (1991) Novel substance P antagonist, CP-96,345, blocks responses of cat spinal dorsal horn neurons to noxious cutaneous stimulation and to substance P. Neurosci. Lett. 132:39-43.

Redgrave P, Dean P, Michell IJ, Odekunle A, and Clarke A (1986) The projection from the superior colliculus to cuneiform area in the rat.I. Anatomical studies. Exp. Brain Res. 72:611-625.

Reichling, DB (1991) GABAergic neuronal circuitry in the periaqueductal gray matter, in The Midbrain Periaqueductal Gray Matter: Functional, Anatomical, and Neurochemical Organization, (Depaulis A and Bandler R eds) pp 329-344, Plenum Publishing Corp., New York. 
Reigle TG (1985) Increased brain norepinephrine metabolism correlated with analgesia produced by the periaqueductal gray injection of opiates. Brain Res. 338:155159.

Renno WM, Mullett MA, and Beitz AJ (1992) Systemic morphine reduces GABA release in the lateral but not the medial portion of the midbrain periaqueductal gray of the rat. Brain Res. 594:221-232.

Reynolds DV (1969) Surgery in the rat during electrical analgesia induced by focal brain stimulation. Science 164:444-445.

Rhoades RW, Mooney RD, Rohrer WH, Nikoletseas MM, and Fish SE (1989) Organization of the projection from the superficial to the deep layers of the hamster's superior colliculus as demonstrated by the anterograde transport of Phaseolus vulgaris leucoagglutinin. J. Comp. Neurol. 283:54-70.

Rhodes DL and Liebeskind JC (1978) Analgesia from the rostral brain stem stimulation in the rat. Brain Res. 143:521-532.

Richardson JD, Aanonsen L, and Hargreaves KM (1998) Hypoactivity of the spinal cannabinoid system results in NMDA-dependent hyperalgesia. J. Neurosci. 18:451-457.

Rivot JP, Chaouch A, and Besson JM (1980) Nucleus raphe magnus modulation of response of rat dorsal horn neurons to unmyelinated fiber inputs: partial involvement of serotonergic pathways. J. Neurophysiol. 44:1039-1057.

Rodriguez RE and Sacristan MP (1989) In vivo release of CCK-8 from the dorsal horn of the rat: inhibition by DAGOL. FEBS Lett. 250:215-217.

Ross CA, Armstrong DM, Ruggiero DA, Pickel VM, Joh TH, and Reis DJ (1981) Adrenaline neurons in the rostral ventrolateral medulla innervate thoracic spinal cord: a combined immunocytochemical and retrograde transport demonstration. Neurosci. Lett. 25:257-262.

Rothman RB (1992) A review of the role of anti-opioid peptides in morphine tolerance and dependence. Synapse 12:129-138. 
Roychowdhury SM and Heinricher MM (1997) Effects of iontophoretically applied serotonin on three classes of physiologically characterized putative pain modulating neurons in the rostral ventromedial medulla of lightly anesthetized rats. Neurosci. Lett. 226:136-138.

Sagen J and Proudfit HK (1985) Evidence for pain modulation by pre- and postsynaptic noradrenergic receptors in the medulla oblongata. Brain Res. 331:285-293.

Sandkuhler J and Gebhart GF (1984) Relative contributions of the nucleus raphe magnus and adjacent medullary reticular formation to the inhibition by stimulation in the periaqueductal gray of a spinal nociceptive reflex in the pentobarbitalanesthetized rat. Brain Res. 305:77-87.

Sandkuhler, J., Thalhammer, J.G., Gebhart, G.F., and Zimmerman, M. (1982) Lidocaine microinjected in the NRM does not block the inhibition by stimulation in the PAG of noxious-evoked responses of dorsal horn neurons in cat. Neurosci. Abstr. 8 , 768 (Abstract).

Satoh M, Oku P, and Akaike A (1983) Analgesia produced by microinjection of 1glutamate into the rostral ventromedial bulbar nuclei of the rat and its inhibition by intrathecal alpha-adrenergic blocking agents. Brain Res. 261:361-364.

Schaeffer P, Laplace MC, Bernat A, Prabonnaud V, Gully D, Lespy L, and Herbert JM (1998) SR142948A is a potent antagonist of the cardiovascular effects of neurotensin. J. Cardiovasc. Pharmacol. 31:545-550.

Schiff JM (1858) Lehrbuch der Physiologie des Menschen I. Muskel and Nervenphysiologie 234,253-255.

Schmauss C and Herz A (1987) Intrathecally administered dynorphin-(1-17) modulates morphine-induced antinociception differently in morphine-naive and morphinetolerant rats. Eur. J. Pharmacol. 135:429-431.

Schotte A, Leysen JE, and Laduron PM (1986) Evidence for a displaceable non-specific $[3 \mathrm{H}]$ neurotensin binding site in rat brain. Naunyn Schmiedebergs Arch.

Pharmacol. 333:400-405. 
Schultzberg M, Hokfelt T, Nilsson G, Terenius L, Rehfeld JF, Brown M, Elde R, Goldstein M, and Said S (1980) Distribution of peptide- and catecholaminecontaining neurons in the gastro-intestinal tract of rat and guinea-pig: immunohistochemical studies with antisera to substance $\mathrm{P}$, vasoactive intestinal polypeptide, enkephalins, somatostatin, gastrin/cholecystokinin, neurotensin and dopamine beta-hydroxylase. Neurosci. 5:689-744.

Semenenko FM and Lumb BM (1992) Projections of anterior hypothalamic neurons to the dorsal and ventral periaqueductal grey in the rat. Brain Res. 582:237-245.

Sherman AD and Gebhart GF (1975) Pain-induced alteration of glutamate in periaqueductal central gray and its reversal by morphine. Life Sci. 15:1781-1789.

Sherrington CS and Sowton SCM (1915) Observations on reflex responses to single break shocks. J. Physiol. (Lond. ) 49:331-348.

Singer HS, Coyle JT, Frangia J, and Price DL (1981) Effects of spinal transection on presynaptic markers for glutamatergic neurons in the rat. Neurochem. Res. 6:485496.

Skagerberg G, Bjorklund A, Lindvall O, and Schmidt RH (1982) Origin and termination of the diencephalo-spinal dopamine system in the rat. Brain Res. Bull. 9:237-244.

Skidgel RA, Engelbrecht S, Johnson AR, and Erdos EG (1984) Hydrolysis of substance p and neurotensin by converting enzyme and neutral endopeptidase. Peptides 5:769-776.

Skirboll L, Hokfelt T, Dockray G, Rehfeld J, Brownstein M, and Cuello AC (1983) Evidence for periaqueductal cholecystokinin-substance $\mathrm{P}$ neurons projecting to the spinal cord. J. Neurosci. 3:1151-1157.

Smith DJ, Hawranko AA, Monroe PJ, Gully D, Urban MO, Craig CR, Smith JP, and Smith DL (1997) Dose-dependent pain-facilitatory and -inhibitory actions of neurotensin are revealed by SR 48692, a nonpeptide neurotensin antagonist: influence on the antinociceptive effect of morphine. J. Pharmacol. Exp. Ther. 282:899-908.

Soja PJ and Sinclair JG (1983) Tonic descending influences on cat spinal cord dorsal horn neurons. Somatosens. Res. 1:83-93. 
Soper WY and Melzack R (1982) Stimulation-produced analgesia: evidence for somatotopic organization in the midbrain. Brain Res. 251:301-311.

Spencer DG Jr, Horvath E, and Traber J (1986) Direct autoradiographic determination of M1 and M2 muscarinic acetylcholine receptor distribution in the rat brain: relation to cholinergic nuclei and projections. Brain Res. 380:59-68.

Spinella M, Cooper ML, and Bodnar RJ (1996) Excitatory amino acid antagonists in the rostral ventromedial medulla inhibit mesencephalic morphine analgesia in rats. Pain 64:545-552.

Steinberg R, Brun P, Fournier M, Souilhac J, Rodier D, Mons G, Terranova JP, Le Fur G, and Soubrie P (1994) SR 48692, a non-peptide neurotensin receptor antagonist differentially affects neurotensin-induced behaviour and changes in dopaminergic transmission. Neurosci. 59:921-929.

Stiller CO, Gustafsson H, Fried K, and Brodin E (1997) Opioid-induced release of neurotensin in the periaqueductal gray matter of freely moving rats. Brain Res. 774:149-158.

Suberg SN and Watkins LR (1987) Interaction of cholecystokinin and opioids in pain modulation. Pain Headache. 9:247-65:247-265.

Suh HH, Collins KA, and Tseng LF (1992) Intrathecal cholecystokinin octapeptide attenuates the antinociception and release of immunoreactive Met-enkephalin induced by intraventricular beta-endorphin in the rat. Neuropeptides 21:131-137.

Suh HH and Tseng LF (1990) Differential effects of sulfated cholecystokinin octapeptide and proglumide injected intrathecally on antinociception induced by betaendorphin and morphine administered intracerebroventricularly in mice. Eur. $J$. Pharmacol. 179:329-338.

Sullivan, T.L. and Pert, A. (1981) Analgesic activity of non-opiate neuropeptides following injection into the rat periaqueductal gray matter. Neurosci. Abstr. 7 , 504 (Abstract).

Sundler F, Akanson R, Hammer RA, Alumets J, Carraway R, Leeman SE, and Zimmerman EA (1977) Immunohistochemical localization of neurotensin in endocrine cells of the gut. Cell Tissue Res. 178:313-321. 
Tallarida, RJ and Murray, RB (1987) Manual of Pharmacological Calculations with Computer Programs. 2nd Ed., Springer-Verlag,New York.

Tanaka K, Masu M, and Nakanishi S (1990) Structure and functional expression of the cloned rat neurotensin receptor. Neuron 4:847-854.

Tanaka M, Matsumoto Y, Murakami T, Hisa Y, and Ibata Y (1996) The origins of catecholaminergic innervation in the rostral ventromedial medulla oblongata of the rat. Neurosci. Lett. 207:53-56.

Tang J, Chou J, Iadarola M, Yang HY, and Costa E (1984) Proglumide prevents and curtails acute tolerance to morphine in rats. Neuropharmacol. 23:715-718.

Tortorici V and Vanegas H (1995) Anti-nociception induced by systemic or PAGmicroinjected lysine-acetylsalicylate in rats. Effects on tail-flick related activity of medullary off- and on-cells. Eur. J. Neurosci. 7:1857-1865.

Tseng LF and Collins KA (1992) Cholecystokinin administered intrathecally selectively antagonizes intracerebroventricular $\beta$-endorphin-induced tail-flick inhibition in the mouse. J. Pharmacol. Exp. Ther. 260:1086-1092.

Uhl GR, Goodman RR, and Snyder SH (1979) Neurotensin-containing cell bodies, fibers and nerve terminals in the brain stem of the rat: immunohistochemical mapping. Brain Res. 167:77-91.

Uhl GR and Snyder SH (1977a) Neurotensin receptor binding, regional and subcellular distributions favor transmitter role. Eur. J. Pharmacol. 41:89-91.

Uhl GR and Snyder SH (1977b) Regional and subcellular distribution of brain neurotensin. Life Sci. 19:1827-1832.

Urban, M.O., Coutinho, S.V., and Gebhart, G.F. (1996c) Modulation of viseromotor response to noxious visceral stimulation by neurotensin in the rostral ventromedial medulla. 8th World Cong. on Pain 251 (Abstract).

Urban, M.O. and Gebhart, G.F. (1994) Dose dependent inhibition and facilitation of spinal unit responses to noxious heat by neurotensin in the nucleus raphe magnus. Neurosci. Abstr. 20, 756 (Abstract). 
Urban MO and Gebhart GF (1997) Characterization of biphasic modulation of spinal nociceptive transmission by neurotensin in the rat rostral ventromedial medulla. J. Neurophysiol. 78:1550-1562.

Urban MO, Jiang MC, and Gebhart GF (1996a) Participation of central descending nociceptive facilitatory systems in secondary hyperalgesia produced by mustard oil. Brain Res. 737:83-91.

Urban MO and Smith DJ (1993) Role of neurotensin in the nucleus raphe magnus in opioid induced antinociception from the periaqueductal gray. J. Pharmacol. Exp. Ther. 265:580-586.

Urban MO and Smith DJ (1994) Localization of the antinociceptive and antianalgesic effects of neurotensin within the rostral ventromedial medulla. Neurosci. Lett. 174:21-25.

Urban MO, Smith DJ, and Gebhart GF (1996b) Involvement of spinal cholecystokinin B receptors in mediating neurotensin hyperalgesia from the medullary nucleus raphe magnus in the rat. J. Pharmacol. Exp. Ther. 278:90-96.

Valverde O, Maldonado R, Fournie-Zaluski M-C, and Roques BP (1994) Cholecystokinin B antagonists strongly potentiate antinociception mediated by endogenous enkephalins. J. Pharmacol. Exp. Ther. 270:77-88.

van Wimersma G, van Praag MC, Kalmann R, Rinkel GJ, Croiset G, Hoeke EC, van Egmond MA, and Fekete M (1982) Behavioral effects of neurotensin. Ann. N. Y. Acad. Sci. 400:319-329.

Vanegas H, Barbaro NM, and Fields HL (1984b) Midbrain stimulation inhibits tail-flick only at currents sufficient to excite rostral medullary neurons. Brain Res. 321:127-133.

Vanegas H, Barbaro NM, and Fields HL (1984a) Tail-flick related activity in medullospinal neurons. Brain Res. 321:135-141.

VanPraag H and Frenk H (1990) The role of glutamate in opiate descending inhibition of nociceptive spinal reflexes. Brain Res. 524:101-105. 
Vaughan CW and Christie MJ (1997) Presynaptic inhibitory action of opioids on synaptic transmission in the rat periaqueductal grey in vitro. J. Physiol. (Lond. ) 498:463472.

Vincent JP (1995) Neurotensin receptors: Binding properties, transduction pathways, and structure. Cell. Mol. Neurobiol. 15:501-512.

Vita N, Laurent P, Lefort S, Chalon P, Dumont X, Kaghad M, Gully D, Le Fur G, Ferrara $\mathrm{P}$, and Caput D (1993) Cloning and expression of a complementary DNA encoding a high affinity human neurotensin receptor. FEBS Lett. 317:139-142.

Wall PD (1967) The laminar organization of dorsal horn and effects of descending impulses. Journal of Physiology 188:403-423.

Watkins LR, Cobelli DA, Faris P, Aceto MD, and Mayer DJ (1982) Opiate vs non-opiate footshock-induced analgesia (FSIA): The body region shocked is a critical factor. Brain Res. 242:299-308.

Watkins LR, Kinscheck IB, Kaufman EF, Miller J, Frenk H, and Mayer DJ (1985b) Cholecystokinin antagonists selectively potentiate analgesia induced by endogenous opiates. Brain Res. 327:181-190.

Watkins LR, Kinscheck IB, and Mayer DJ (1985a) Potentiation of morphine analgesia by the cholecystokinin antagonist proglumide. Brain Res. 327:169-180.

Watkins LR, Suberg SN, Thurston CL, and Culhane ES (1986) Role of spinal cord neuropeptides in pain sensitivity and analgesia: thyrotropin releasing hormone and vasopressin. Brain Res. 362:308-317.

Westlund KN, Bowker RM, Ziegler MG, and Coulter JD (1982) Descending noradrenergic projections and their spinal terminations. Prog. Brain Res. 57:219238.

Westlund KN and Coulter JD (1980) Descending projections of the locus coeruleus and subcoeruleus/medial parabrachial nuclei in monkey: axonal transport studies and dopamine- beta-hydroxylase immunocytochemistry. Brain Res. 2:235-264. 
Wiesenfeld-Hallin Z and Duranti R (1987) Intrathecal cholecystokinin interacts with morphine but not substance $\mathrm{P}$ in modulating the nociceptive flexion reflex in the rat. Peptides 8:153-158.

Wiesenfeld-Hallin Z, Xu XJ, Hughes J, Horwell DC, and Hokfelt T (1990) PD134308, a selective antagonist of cholecystokinin type $\mathrm{B}$ receptor, enhances the analgesic effect of morphine and synergistically interacts with intrathecal galanin to depress spinal nociceptive reflexes. Proc. Natl. Acad. Sci. U. S. A. 87:7105-7109.

Wiklund L, Behzadi G, kalen P, Headley PM, Nicolopoulos LS, Parsons CG, and West DC (1988) Autoradiographic and electrophysiological evidence for excitatory amino acid transmission in the periaqueductal gray projection to nucleus raphe magnus in the rat. Neurosci. Lett. 93:158-163.

Willcockson WS, Gerhart KD, Cargill CL, and Willis WD (1983) Effects of biogenic amines on raphe-spinal tract cells. J. Pharmacol. Exp. Ther. 225:637-645.

Willcockson WS, Kim J, Shin HK, Chung JM, and Willis WD (1986) Actions of opioids on primate spinothalamic tract neurons. J. Neurosci. 6:2509-2520.

Williams FG and Beitz AJ (1989) A quantitative ultrastructural analysis of neurotensinlike immunoreactive terminals in the midbrain periaqueductal gray: analysis of their possible relationship to periaqueductal gray-raphe magnus projection neurons. Neurosci. 29 :121-134.

Willis WD, Haber LH, and Martin RF (1977) Inhibition of spinothalamic tract cells and interneurons by brainstem stimulation in the monkey. J. Neurophysiol. 40:968981.

Woolfe $\mathrm{G}$ and Macdonald AD (1944) The evaluation of the analgesic action of pethidine hydrochloride (demerol). J. Pharmacol. Exp. Ther. 80:300-307.

Xu X-J, Hao JX, Hokfelt T, and Weisenfeld-Hallin Z (1994) The effects of intrathecal neuropeptide $\mathrm{Y}$ on the spinal nociceptive flexor reflex in rats with intact sciatic nerves and after peripheral axotomy. Neurosci. 63:817-826.

Yaksh TL (1979) Direct evidence that spinal serotonin and noradrenaline terminals mediate the spinal antinociceptive effects of morphine in the periaqueductal gray. Brain Res. 160:180-185. 
Yaksh TL, Jessell TM, Gamse R, Mudge AW, and Leeman SE (1980) Intrathecal morphine inhibits substance $P$ release from mammalian spinal cord in vivo. Nature 286:155-156.

Yaksh, TL and Malmberg, AB (1993) The Pharmacology of Pain Transmission, in Textbook of Pain, 3rd Ed., (Wall PD and Melzack R eds) Churchill Livingstone,

Yaksh TL, Plant RL, and Rudy TA (1977) Studies on the antagonism by raphe lesions of the antinociceptive action of systemic morphine. Europ. J. Pharmacol. 41:399408.

Yaksh TL and Tyce GM (1979) Microinjection of morphine into the periaqueductal gray evokes the release of serotonin from spinal cord. Brain Res. 171:176-181.

Yaksh TL and Wilson PR (1979) Spinal serotonin terminal system mediates antinociception. J. Pharmacol. Exp. Ther. 208:446-453.

Yaksh TL, Yeung JC, and Rudy TA (1976) Systematic examination of the rat of brain sites sensitive to the direct application of morphine: observation of differential effects within the periaqueductal gray. Brain Res. 114:83-103.

Yunger LM, Harvey JA, and Lorens SA (1973) Dissociation of the analgesic and rewarding effects of brain stimulation in the rat. Physiol. Behav. 10:909-913.

Zambotti F, Zonta N, Parenti M, Tommasi R, Vicentini L, Conci F, and Mantegazza P (1982) Periaqueductal gray matter involvement in the muscimol-induced decrease of morphine antinociception. Naunyn Schmiedebergs Arch. Pharmacol. 318:368369.

Zhuo M and Gebhart GF (1990a) Characterization of descending inhibition and facilitation from the nuclei reticularis gigantocellularis and gigantocellularis pars alpha in the rat. Pain 42:337-350.

Zhuo M and Gebhart GF (1990b) Spinal cholinergic and monoaminergic receptors mediate descending inhibition from the nuclei reticularis gigantocellularis (NGC) and gigantocellularis pars alpha (NGC) in the rat. Brain Res. 535:67-78. 
Zhuo M and Gebhart GF (1991) Spinal serotonin receptors mediate descending facilitation of a nociceptive reflex from the nuclei reticularis gigantocellularis and gigantocellularis pars alpha in the rat. Brain Res. 550:35-48.

Zhuo M and Gebhart GF (1992) Characterization of descending facilitation and inhibition of spinal nociceptive transmission from the nuclei reticularis gigantocellularis and gigantocellularis pars alpha in the rat. J. Neurophysiol. 67:1599-1614.

Zhuo M and Gebhart GF (1997) Biphasic modulation of spinal nociceptive transmission from the medullary raphe nuclei in the rat. J. Neurophysiol. 78:746-758.

Zhuo Y, Sun Y-H, Zhang Z-W, and Han J-S (1993) Increased release of immunoreactive cholecystokinin octapeptide by morphine and potentiation of $\mu$-opioid analgesia by $\mathrm{CCK}_{\mathrm{B}}$ receptor antagonist L-365260 in rat spinal cord. Eur. J. Pharmacol. 234:147-154.

Zorman G, Belcher G, Adams JE, and Fields HL (1982) Lumbar intrathecal naloxone blocks analgesia produced by microstimulation of the ventromedial medulla in the rat. Brain Res. 236:77-84.

Zorman G, Hentall ID, Adams JE, and Fields HL (1981) Naloxone-reversible analgesia produced by microstimulation in the rat medulla. Brain Res. 219:137-148. 


\section{CURRICULUM VITAE}

\section{Jeffrey P. Smith}

Department of Pharmacology and Toxicology

Robert C. Byrd Health Sciences Center

West Virginia University School of Medicine

Morgantown, West Virginia 26506

Voice 304-293-3561

Facsimile 304-293-6854

email: jsmith2@wvu.edu

\section{PERSONAL DATA}

Place of Birth: Wheeling, West Virginia

Date of Birth: $\quad$ October 4, 1971

Citizenship: USA

Marital Status: $\quad$ Married

Children: None

Social Security: 232-33-0799

\section{EDUCATION}

Undergraduate: West Virginia University Morgantown, West Virginia

BA, Chemistry

May, 1994

Graduate: $\quad$ West Virginia University

Morgantown, West Virginia

Ph.D., Pharmacology and Toxicology

Anticipated August, 1999

Technical Training: GC, FTIR Spectrometer (IR), Proton NMR, and SPEC-20.

Small mammal stereotaxic surgery, microinjection techniques, analgesiometric testing (tail-flick, hot plate, and formalin models), stress paradigms (repetitive exposure to a noxious heat source, exposure to a natural predator, restraint), small mammal intrathecal surgery, intrathecal injection techniques, and some histological techniques. 
Teaching Experience:Co-leader of a Medical Pharmacology discussion group (POPS), Group facilitator for Medical Pharmacology, lecturer for nursing pharmacology class, responsible for training new personnel in laboratory methodology and techniques described above.

\section{PROFESSIONAL SOCIETIES}

Student member of the American Chemical Society 1992-1994

Society for Neuroscience - National and West Virginia Chapters 1996-present American Society for Pharmacology and Experimental Therapeutics 1998-present Society for Experimental Biology and Medicine 1998-present

\section{AWARDS AND HONORS}

Recipient of National Management Association-Ohio Valley Chapter Scholarship 1990

Secretary- American Chemical Society Student Affiliates, West Virginia

University

Chapter 1993-1994

West Virginia University Training Grant $1994-98$

NIH Training Grant 1998-present

Who's Who Among American College Students

Graduate Student Representative Dept. of Pharmacology and Toxicology, West Virginia University School of Medicine 1998-present

Awarded Best Presentation by a student University of Pittsburgh School of Medicine, Department of Pharmacology Research Day 1998

\section{CURRENT RESEARCH ACTIVITY}

Neurotensin activated descending pain facilitatory and inhibitory neuronal pathways and their relationship to narcotic analgesia. Of particular interest is the pharmacological manipulation of pain facilitatory pathways to enhance opioid action.

\section{WORKS IN PROGRESS}

Smith, J.P., Hawranko, A.A., Gully, D., Smith, D.L., Sarkar, M.A. and Smith, D.J. (1999) Comparison of the ability of neurotensin receptor antagonists, SR 48692 and SR $142948 \mathrm{~A}$, to enhance morphine antinociception in rats following systemic administration. (Eur. J. Pharmacol. in preparation). 
Smith, J.P., Hawranko, A.A. and Smith, D.J. (1999) Differential mechanisms of action for two non-peptide neurotensin receptor anatgonists, SR 48692 and SR 142948A, with respect to their ability to enhance morphine antinociception. (J. Pharmacol. Exp. Ther. in preparation)

Smith, J.P., Hawranko, A.A., Smith, D.L. and Smith, D.J. (1999) Physiological and pharmacological conditions that allow the discrimination of neurotensin antianalgesia. (Brain Res. in preparation)

\section{PUBLICATIONS}

Smith, D.J., Hawranko, A.A., Smith, J.P. and Patterson, K.E. (1999) Neurotensin neurons reduce $\beta$-endorphin antinociception. Abst. International Narcotics Research Conference.

Smith, J.P., Hawranko, A.A., Smith, D.L., Patterson, K.E. and Smith, D.J. (1998) Neurotensin is anti-analgesic following physiological or pharmacological manipulations that produce antinociception. Abst. Soc. Neurosci. 24: 1624.

Smith, D.J., Hawranko A.A., Monroe, P.J., Gully, D., Urban, M.O., Craig, C.R., Smith, J.P., and Smith D. L. (1997) Dose -dependent pain facilitatory and inhibitory actions of neurotensin are revealed by SR48692, a non-peptide neurotensin antagonist: Influence on morphine's antinociceptive effect. J. Pharmacol. Exp. Ther. 282: 899-908.

Smith, J.P., Hawranko, A.A. and Smith, D.J. (1997) Neurotensin receptor antagonists, SR 48692 and SR 142948A, block neurotensin-mediated pain facilitation to potentiate the antinociceptive effect of morphine. Abst. Soc. Neurosci. 23: 1536. 